Aus der Klinik für Anästhesiologie

(Prof. Dr. med. M. Quintel)

der Medizinischen Fakultät der Universität Göttingen

\title{
Untersuchung der Effektivität eines neuen Wärmesystems zur Prävention perioperativer Hypothermie
}

\author{
INAUGURAL-DISSERTATION \\ zur Erlangung des Doktorgrades \\ der Medizinischen Fakultät der \\ Georg-August-Universität zu Göttingen \\ vorgelegt von \\ Hannah Lena Peichl \\ aus \\ Göttingen
}

Göttingen 2015 
Dekan:

Prof. Dr. rer. nat. H. K. Kroemer

I. Berichterstatter: $\quad$ PD Dr. Thorsten Perl

II. Berichterstatter/in: PD Dr. Martin Wachowski

III. Berichterstatter/in: Prof. Dr. Margarete Schön 


\section{Abkürzungsverzeichnis}

\begin{tabular}{|c|c|}
\hline$A$ & Oberfläche $\left[\mathrm{m}^{2}\right]$ \\
\hline ASA & American Society of Anesthesiologists \\
\hline ATP & Adenosintriphosphat \\
\hline Abb. & Abbildung \\
\hline BMI & Body-Mass-Index \\
\hline bzw. & Beziehungsweise \\
\hline C & Wärmekapazität Coulomb \\
\hline${ }^{\circ} \mathrm{C}$ & Grad Celsius \\
\hline EKG & Elektrokardiogramm \\
\hline$\epsilon$ & Emissivität \\
\hline GKW & Gesamtkörperwärmemenge \\
\hline $\mathrm{H}_{\mathrm{K}}$ & Wärmeaustauschkoeffizient für Konduktion $\left[\mathrm{W} \mathrm{m}^{-2}{ }^{\circ} \mathrm{C}^{-1}\right]$ \\
\hline HME & Heat and Moisture Exchanger \\
\hline IR & Infrarot \\
\hline ITN & Intubationsnarkose \\
\hline i.v. & intravenös \\
\hline $\mathrm{K}$ & Kelvin \\
\hline $\mathrm{Kg}$ & Kilogramm \\
\hline MW & Mittelwert \\
\hline Min. & Minute/n \\
\hline$m^{2}$ & Quadratmeter \\
\hline PD & proportional/differential \\
\hline PTT & partielle Thromboplastinzeit \\
\hline Q & Wärmefluss \\
\hline $\mathrm{Q} / \mathrm{A}$ & Wärmefluss pro Fläche \\
\hline$Q_{C}$ & Wärmefluss durch Konvektion [W] \\
\hline $\mathrm{Q}_{\mathrm{K}}$ & Wärmefluss durch Konduktion / Fläche [W] \\
\hline$Q_{R}$ & Wärmefluss durch Radiation [W] \\
\hline SD & Standardabweichung \\
\hline $\mathrm{SpO}_{2}$ & Sauerstoffpartialdruck \\
\hline$S$ & Sekunde \\
\hline $\mathrm{T}$ & Temperatur \\
\hline $\mathrm{T}_{\mathrm{A}}$ & Temperatur der Auflagefläche $\left[{ }^{\circ} \mathrm{C}\right]$ \\
\hline $\mathrm{T}_{\mathrm{H}}$ & Hauttemperatur $\left[{ }^{\circ} \mathrm{C}\right]$ \\
\hline
\end{tabular}


$\mathrm{T}_{\mathrm{L}} \quad$ Temperatur des strömenden Mediums [ $\left[{ }^{\circ} \mathrm{C}\right]$

$\mathrm{T}_{\mathrm{W}} \quad$ Temperatur des körpernächsten Festkörpers [ $\left.{ }^{\circ} \mathrm{C}\right]$

TEP Totalendoprothese

Tab. Tabelle

T Zeit [Min]

VAS Visuelle Analogskala

v Strömungsgeschwindigkeit $\left[\mathrm{m} \mathrm{s}^{-1}\right]$

W Watt

z.B. zum Beispiel

$\sigma \quad$ Stefan-Boltzmann-Konstante $\left(5,67^{*} 10^{-8} \mathrm{~W} / \mathrm{m}^{2 *} \mathrm{~K}^{4}\right)\left[\mathrm{W} \mathrm{m}^{-2} \mathrm{~K}^{4}\right]$ 


\section{Inhaltsverzeichnis}

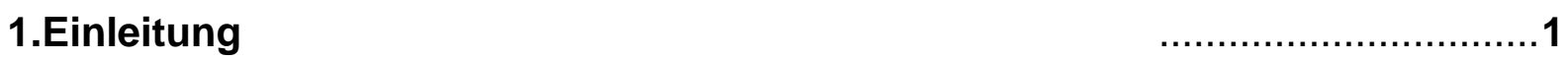

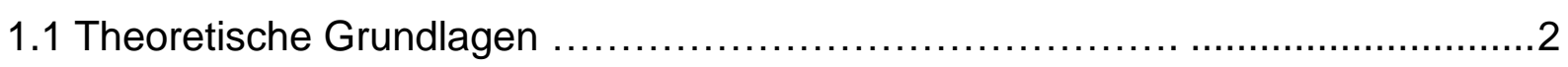

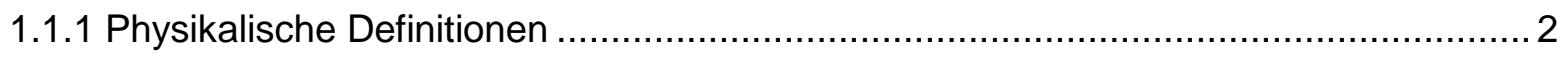

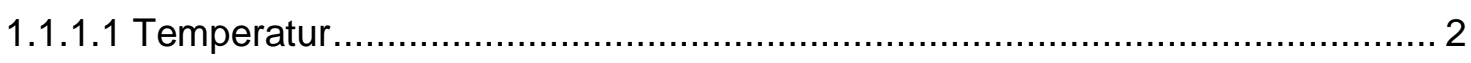

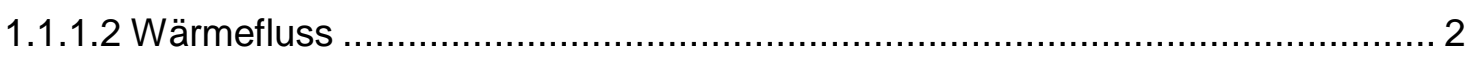

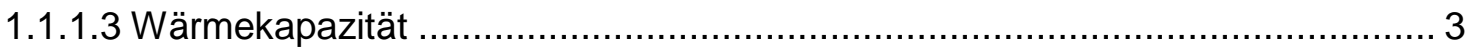

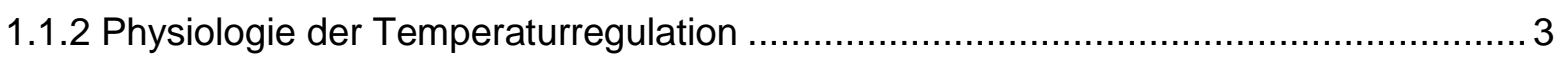

1.1.2.1 Das Temperaturfeld des Körpers.......................................................... 4

1.1.3 Regelkreis der Temperaturregulation ......................................................... 5

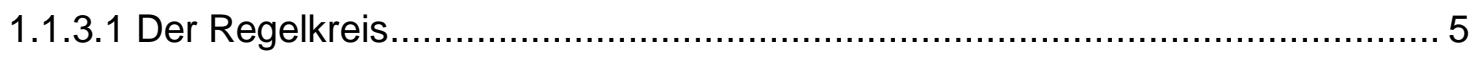

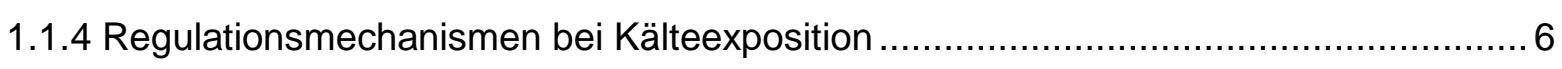

1.1.4.1 Thermoregulatorische Vasokonstriktion............................................... 7

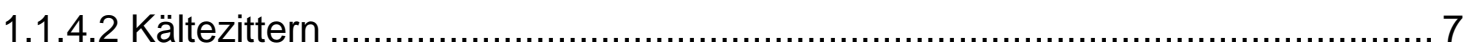

1.1.4.3 Thermogenese des braunen Fettgewebes ......................................... 8

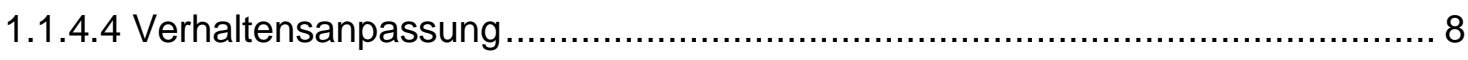

1.1.5 Mechanismen der Wärmebildung und des Wärmeaustausches mit der Umwelt .........9

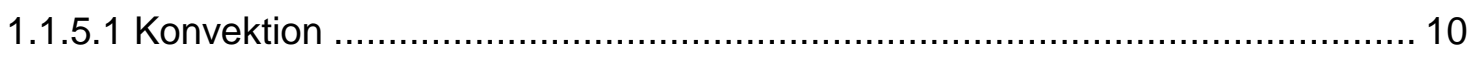

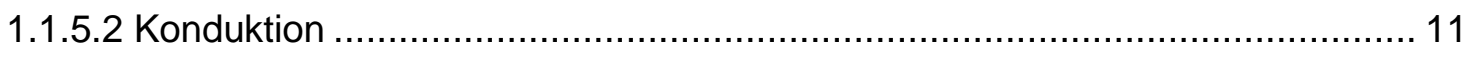

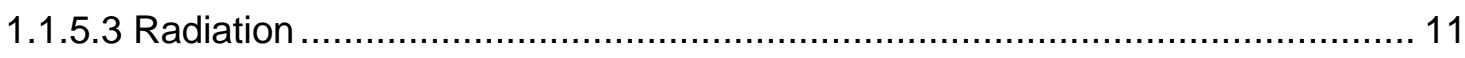

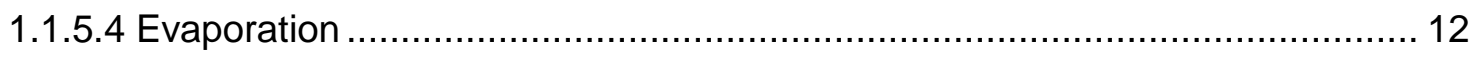

1.1.5.5 Die Verteilung der verschiedenen Mechanismen beim Wärmetransfer im

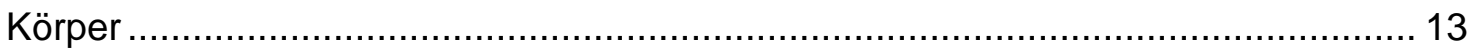

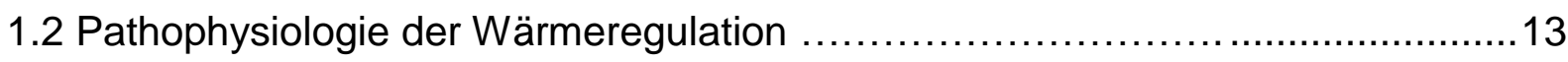

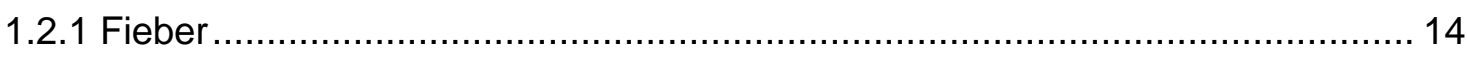

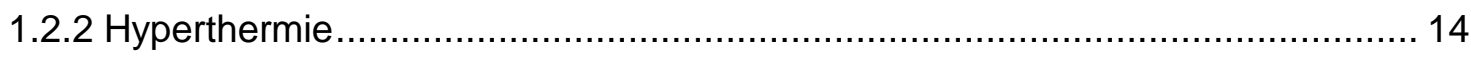

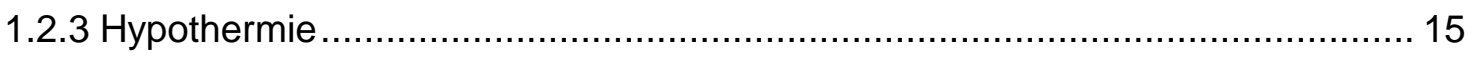

1.3 Pathophysiologie der perioperativen Hypothermie ...............................16

1.3.1 Entstehung von perioperativer Hypothermie .................................................. 16

1.3.1.1 Präoperative Körperkerntemperatur ................................................. 16

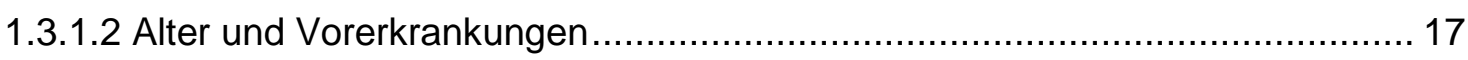

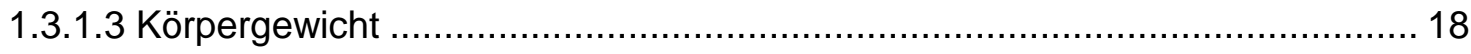


1.3.1.4 Vormedikation 18

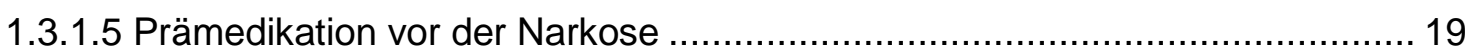

1.3.2 Thermoregulation unter Allgemeinanästhesie ................................................ 20

1.3.2.1 Wärmeumverteilung während der Narkose............................................. 21

1.3.2.2 Phasen der Wärmeumverteilung bei der Allgemeinanästhesie ..................... 21

1.3.2.3 Einfluss verschiedener Anästhetika auf die Thermoregulationsschwellen...... 22

1.3.3 Risiken und klinische Bedeutung der perioperativen Hypothermie .......................... 23

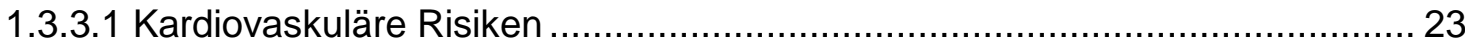

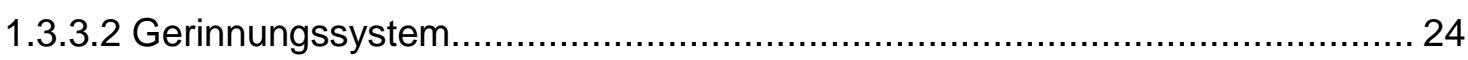

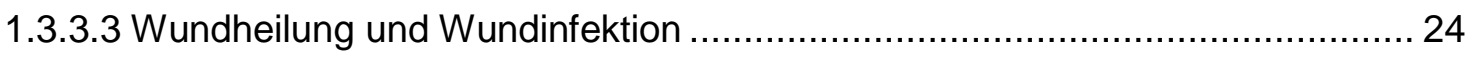

1.3.3.4 Einfluss auf die Pharmakokinetik und Pharmakodynamik ............................ 25

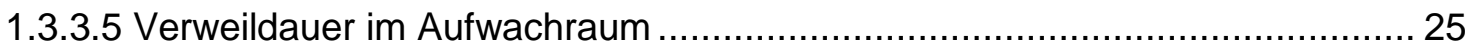

1.3.3.6 Kosten und ökonomische Überlegungen .......................................... 26

1.4 Wärmeprotektion und Vermeidung perioperativer Hypothermie......................26

1.4.1 Möglichkeiten des Wärmemanagements .................................................. 27

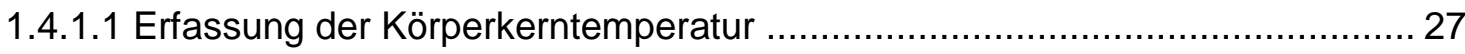

1.4.1.2 Möglichkeiten der Wärmeprotektion .................................................... 28

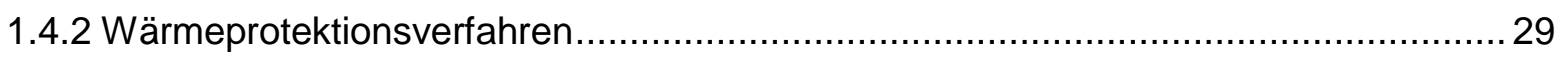

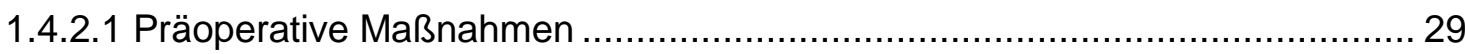

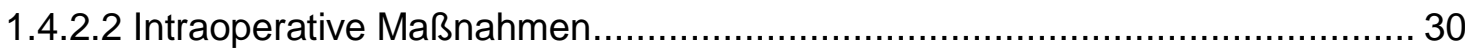

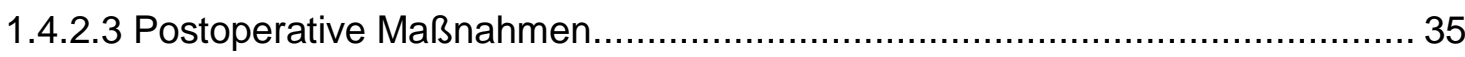

1.4.3 Risiken perioperativer Wärmeprotektion und Wärmezufuhr ................................ 36

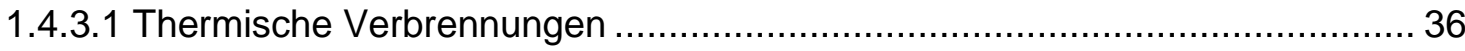

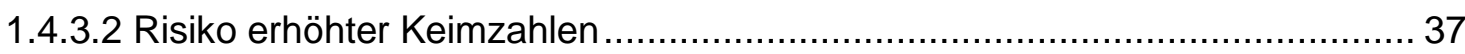

1.4.3.3 Luftblasenbildung bei Infusionswärmern ............................................ 37

2. Material und Methoden $\quad$............................38

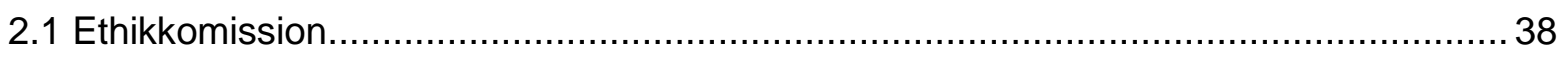

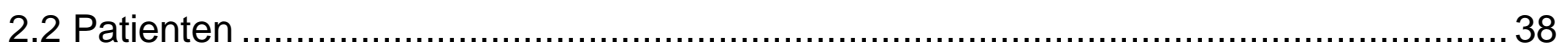

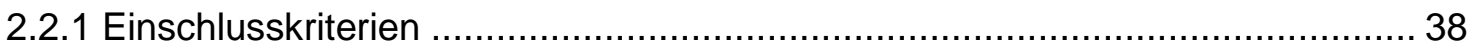

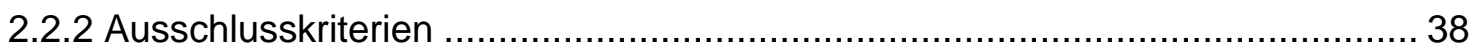

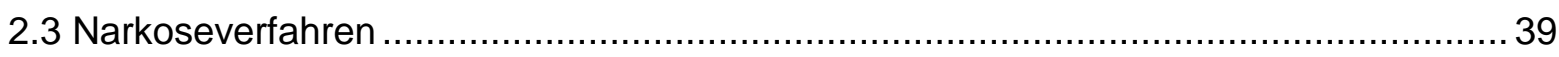

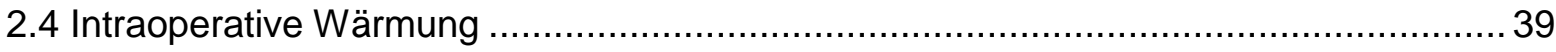




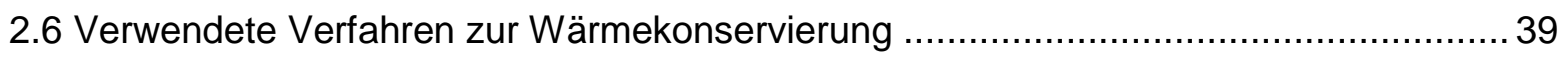

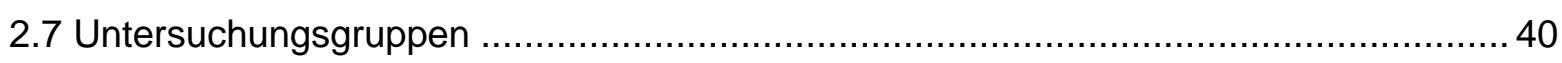

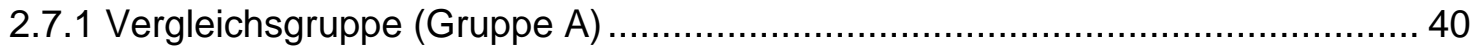

2.7.2 Passive Vorwärmung/ Isolationsgruppe (Gruppe B) .................................. 40

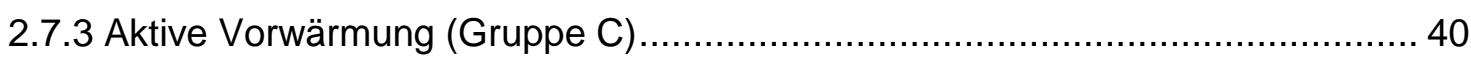

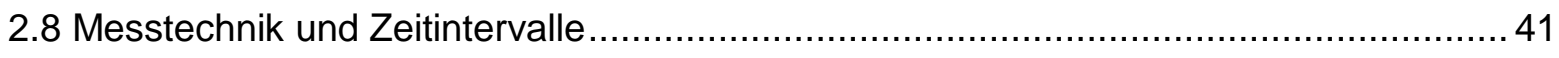

2.8.1 Prä-und postoperative Temperaturmessung ................................................. 41

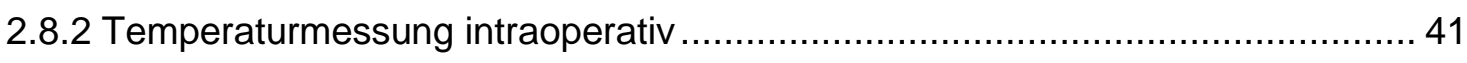

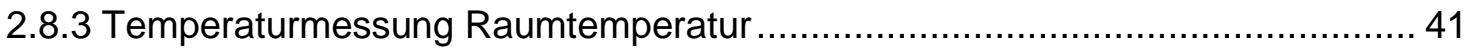

2.8.4 Erfassung des subjektiven Wärmeempfindens und Aldrete Skala ................... 41

2.8.5 Erfassung der Dauer einzelner Maßnahmen ........................................... 42

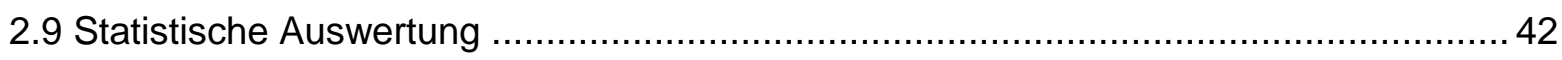

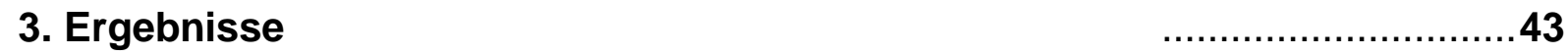

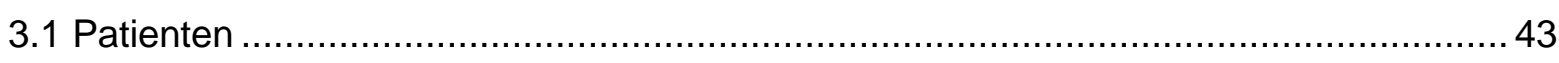

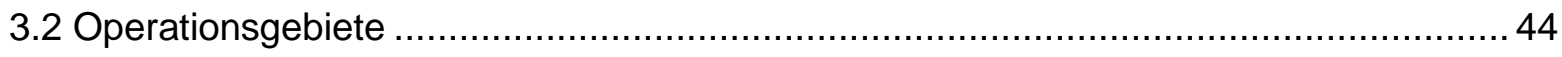

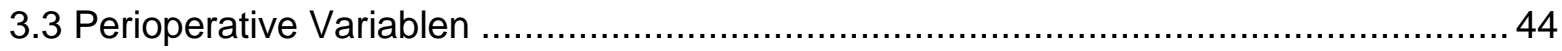

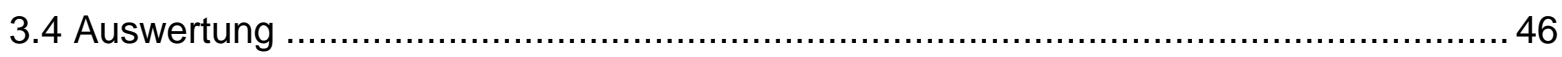

3.4.1 Verlauf der präoperativen Körperkerntemperaturen vor Narkoseeinleitung....... 46

3.4.2 Subjektives Wärmeempfinden ............................................................. 50

3.4.3 Verlauf der intraoperativen Körperkerntemperaturen nach Narkoseeinleitung .. 51

3.4.4 Entwicklung der Körperkerntemperatur zum Operationsende ......................... 52

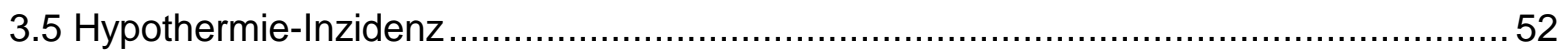

3.6 Verlauf der postoperativen Körperkerntemperaturen im Aufwachraum .......................54

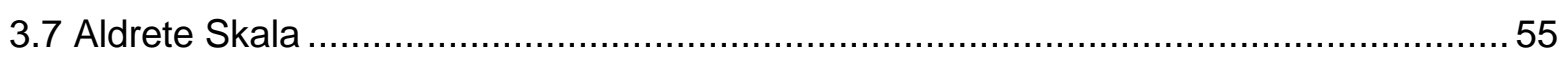

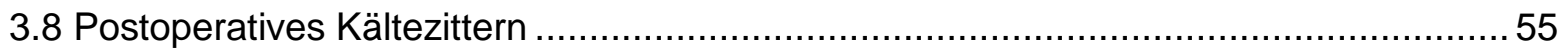

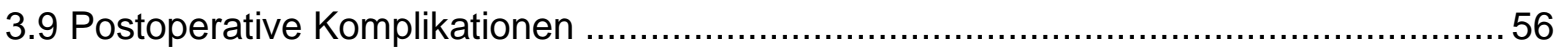

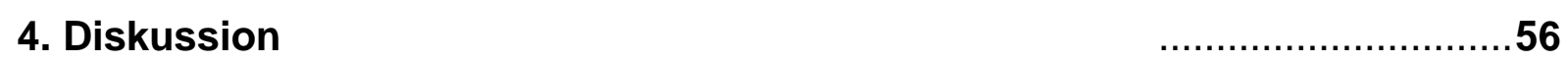

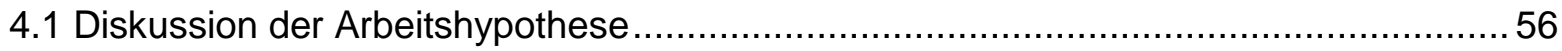

4.2 Diskussion der wärmeprotektiven Verfahren in den Studiengruppen ..........................57

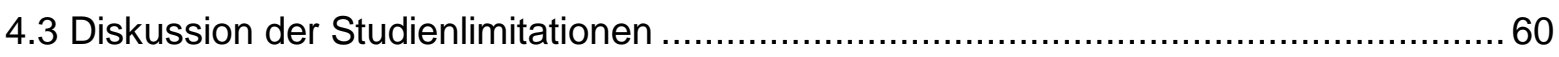

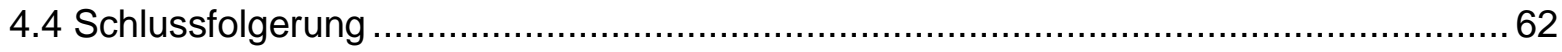


5. Zusammenfassung

6. Tabellen- und Abbildungsverzeichniss

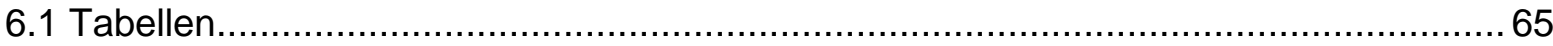

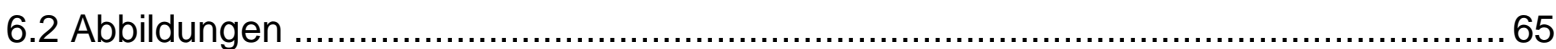

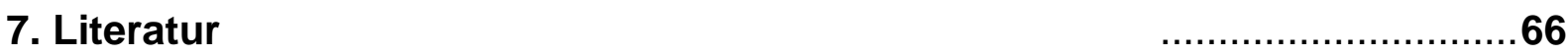




\section{Einleitung}

\section{Einführung in die allgemeine Problematik}

Die perioperative Hypothermie stellt eine der häufigsten unerwünschten Nebenwirkungen der Narkose im klinischen Alltag dar (Vaughan et al. 1981).

Die Inzidenz der im Aufwachraum registrierten postoperativen Hypothermie wird im Schnitt mit ca. $70 \%$ angegeben (National Collaborating Centre for Nursing and Supportive Care 2008).

Randomisierte Studien zu diesem Themenschwerpunkt zeigen selbst bei nur milder Hypothermie deutliche negative Einflüsse auf das operative Gesamtergebnis. Speziell bei ausgedehnten chirurgischen Eingriffen in Allgemeinanästhesie werden die körpereigenen Mechanismen der Thermoregulation erheblich gestört. Eine konstante Körperkerntemperatur ist ohne eine aktive Wärmezufuhr nicht möglich. Neben einem verlangsamten Metabolismus von Medikamenten durch eine veränderte Pharmakokinetik sind kardiozirkulatorische Komplikationen, Störungen des Immunsystems und des Proteinstoffwechsels, ein erhöhtes Blutungs- und Transfusionsrisiko sowie vermehrte Wundinfektionen und Wundheilungsstörungen eine direkte Folge der perioperativen Hypothermie. Kältezittern sowie Temperaturunbehagen beim Patienten deuten zusätzlich auf eine eingeschränkte intraoperative Thermoregulation mit postoperativer kompensatorischer Gegenregulation hin. Insbesondere Komplikationen in Hinsicht auf die postoperative Wundheilung erhöhen die Hospitalisationsdauer und folglich die Kosten einer medizinischen Behandlung um ein Vielfaches. Durch den gezielten Einsatz von effizienten Wärmesystemen sollte vor allem bei chirurgischen Risikopatienten eine perioperative Hypothermie verhindert werden (Leslie und Sessler 2003). Die Annahme, dass perioperative Hypothermie durch alleinige intraoperative Wärmemaßnahmen effizient verhindert werden kann (Scott und Buckland 2006), zeigt sich als nicht zutreffend. Selbst bei kleinen Eingriffen ist die standardmäßig applizierte Wärmetherapie ohne vorwärmende Maßnahmen meist nicht ausreichend (Andrzejowski et al. 2008, Fanelli et al. 2009). Präoperative Maßnahmen wie die Vorwärmung des Patienten in der Wartezone durch konduktive Verfahren, Infrarotstrahler oder konvektive Luftwärmer zielen dabei auf eine Erhöhung der Wärmemenge in der Körperperipherie. Die Wärmeumverteilung nach Narkoseeinleitung zeigt eine deutlich geringere Ausprägung.

Die Einführung eines effizienten Vorwärmprogramms in die tägliche Klinikroutine unter Einbezug aller beteiligten Fachrichtungen ist auch in einem Haus der Maximalversorgung möglich (Bräuer et al. 2010). Auf diesem Hintergrund sollte der Nutzen der präoperativen 
Vorwärmung deutlich im klinischen Alltag hervorgehoben werden und vermehrt in das Bewusstsein aller beteiligten Disziplinen rücken.

\section{Fragestellung}

Ziel der Untersuchung ist es, die Effektivität eines neuen Vorwärmsystems zur Prävention der intra- und postoperativen Hypothermie im klinischen Gebrauch zu testen. Dabei soll die rein intraoperative Anwendung eines konvektiven Wärmesystems mit einem präoperativen Vorwärmmodell in Form einer konvektiven Anwendung oder einer reinen Isolation verglichen werden. Daraus folgt die Fragestellung, ob es deutliche Unterschiede in der Körperkerntemperatur zwischen den drei Behandlungsgruppen gibt und ob durch die oben genannten Maßnahmen das Risiko einer intraoperativen Hypothermie verringert werden kann.

\subsection{Theoretische Grundlagen}

\subsubsection{Physikalische Definitionen}

\subsubsection{Temperatur}

Die Temperatur $(T)$ beschreibt die mittlere kinetische Energie pro Teilchen eines Volumens und stellt dadurch eine physikalische sowie thermodynamische Zustandsgröße dar, die in der SI-Einheit Kelvin $(\mathrm{K})$ angegeben wird. $0 \mathrm{~K}$ geben dabei als absoluten Nullpunkt die tiefst mögliche Temperatur an. In der Medizin ist die von der Kelvin-Skala abgeleitete Celsius-Skala mit der Einheit Grad Celsius $\left({ }^{\circ} \mathrm{C}\right.$ ) üblich (The Commission for Thermal Physiology of the International Union of Physiological Sciences 2001).

\subsubsection{Wärmefluss}

Der Wärmefluss (Q/A) stellt als physikalische Größe eine quantitative Beschreibung von Wärmeaustauschvorgängen dar. Die Berechnung erfolgt aus der Änderung der Gesamtkörperwärmemenge und der körpereigenen Energieproduktion über ein gewähltes Zeitintervall. Dadurch bietet der Wärmefluss ein physikalisches Maß für die Höhe des Wärmetransfers zwischen Körper und Umgebung mit unterschiedlichen Temperaturen pro Zeit (The Commission for Thermal Physiology of the International Union of Physiological Sciences 2001). 


\subsubsection{Wärmekapazität}

Die Wärmekapazität (c) beschreibt die Fähigkeit eines Körpers, die aufgenommene Energie in Form von thermischer Energie zu speichern. Sie gibt an, wie viel Energie benötigt wird um einen Temperaturanstieg in einem Körper zu erreichen bzw. zeigt den gegenteiligen Energieverlust bei Temperaturabfall eines Objektes. Die Wärmekapazität wird in Coulomb angegeben [ $\mathrm{c}=\mathrm{J} \mathrm{kg}^{-1} \mathrm{~K}^{-1}$ ].

Zusätzlich definiert man durch die unterschiedlichen physikalischen Eigenschaften der Stoffe die spezifische Wärmekapazität. Diese auf die Masse eines Stoffes bezogene Wärmekapazität gibt die benötigte zugeführte Energie an, um die Temperatur um ein $\mathrm{K}$ bzw. ${ }^{\circ} \mathrm{C}$ zu erhöhen (The Commission for Thermal Physiology of the International Union of Physiological Sciences 2001, Harms 2000). Beim Menschen beträgt die spezifische Wärmekapazität durchschnittlich $3,475 \mathrm{~kJ}^{\circ} \mathrm{C}^{-1} \mathrm{~kg}^{-1}$ (Burton 1935).

\subsubsection{Physiologie der Temperaturregulation}

\section{Allgemeine Einführung}

Als gleichwarmes oder homoiothermes Lebewesen wird die Körperkerntemperatur des Menschen trotz wechselnder Umgebungstemperatur präzise kontrolliert. Rückkopplungsmechanismen zwischen verschiedenen Stellgliedern im System stehen dabei im Vordergrund der Regulation. Faktoren wie Alter, körperliche Belastung, Hormone (Schilddrüse), Drogen/Medikamente (Alkohol, Sedativa) und Anästhesie beeinflussen ebenfalls individuell die Temperaturregulation (Morley-Forster 1986).

Meist wird die durchschnittliche Körpertemperatur in der Literatur mit $37^{\circ} \mathrm{C}$ angegeben, doch zeigen 95\% der Bevölkerung durch physiologische Schwankungen morgendliche, oral gemessene Temperaturen zwischen $36,3-37,1^{\circ} \mathrm{C}$ (Gekle et al. 2005). Studienergebnisse zur präoperativen Körperkerntemperatur an 446 Patienten vor einem chirurgischen Eingriff ergaben noch größere interindividuelle Schwankungen in der Körperkerntemperatur mit einem Median bei $36,4^{\circ} \mathrm{C}$. Folglich zeigten $50 \%$ der Patienten Körperkerntemperaturen unter $36,4^{\circ} \mathrm{C}$. Am häufigsten wurden Werte von $36,1^{\circ} \mathrm{C}$ gemessen (Mitchell und Kennedy 2001).

Zusätzlich schwankt die Körperkerntemperatur im Rahmen der zirkadianen Rhythmik um ca. $0,5-0,7^{\circ} \mathrm{C}$ mit einem morgendlichen Tief- und abendlichen Höchstwert.

Frauen weisen im Zusammenhang mit dem monatlichen Menstruationszyklus nach dem Eisprung bis zur nächsten Menstruation einen Anstieg der Basaltemperatur um ca. $0,5^{\circ} \mathrm{C}$ auf (Lee 1988). 


\subsubsection{Das Temperaturfeld des Körpers}

Im menschlichen Körper trennt man zwei thermische Kompartimente voneinander. Den Körperkern mit Körperstamm und Kopf sowie die Körperschale mit Haut und Extremitäten (Gekle et al. 2005, Burton 1935). Der Körperkern besteht aus gut durchbluteten, inneren Gewebestrukturen mit nahezu konstanten Temperaturen. Das Temperaturverhältnis zueinander wird durch Anpassung des Kreislaufs oder durch einen Wärmeverlust an die Umwelt beeinflusst, wobei der Körperkern eine konstante Temperatur hat und die Temperatur der Peripherie variieren kann (The Commission for Thermal Physiology of the International Union of Physiological Sciences (2001).

Insgesamt repräsentiert der Körperkern 50-60\% der Gesamtkörpermasse des menschlichen Körpers (Matsukawa et al. 1995b).

Dem Körperkern wird die Körperschale in der Peripherie gegenübergestellt. Die Gewebetemperaturen sind hier inhomogen und können variable Werte annehmen, die durchschnittlich $2^{\circ}-4^{\circ} \mathrm{C}$ unterhalb der gemessenen Körperkerntemperatur liegen. Bei einer Umgebungstemperatur von $25^{\circ} \mathrm{C}$ und leichter Körperbekleidung findet sich eine durchschnittliche Körperschalentemperatur von $33^{\circ} \mathrm{C}$ (Burton 1935). Bei extremen, von außen einwirkenden Temperaturbelastungen oder physiologischen Gegebenheiten kann diese Temperaturdifferenz jedoch eine vielfach größere Spanne mit stärkeren Temperaturgradienten zwischen Körperkern und der Peripherie einnehmen.

Ein kleiner Temperaturgradient zwischen Schale und den kernnahen Schichten resultiert zum einen aus einer warmen Umgebung, zum anderen durch Vasodilatation der Blutgefäße. Beide Mechanismen enden in einen Wärmefluss vom Körperkern in Richtung Peripherie. Dieser Effekt kann soweit ausgeprägt sein, dass die peripheren Gewebetemperaturen sich der Körperkerntemperatur annähern und dessen Werte über einen begrenzten Zeitraum annehmen (Gekle et al. 2005).

Wird der Organismus wiederum in eine kühlere Umgebung überführt, weichen Körperkern und Körperschalentemperatur wieder um die beschriebenen Werte voneinander ab. Vasokonstriktion bewirkt gegenteilig einen verminderten Wärmefluss in die Peripherie, hält metabolische Wärme in den Körperkerngebieten zurück und steigert dadurch den Temperaturgradienten. Arme und Beine werden durch die dickere Schale thermisch vom Körperkern abgekoppelt (Gekle et al. 2005).

Durch diesen beschriebenen Mechanismus ist es möglich, die Körperkerntemperatur ohne energieverbrauchende Mechanismen wie Schwitzen oder Kältezittern aufrechtzuerhalten. In dieser als Zwischenschwellenbereich (interthreshold range) bezeichneten Spanne findet keine Thermoregulation statt. 


\subsubsection{Regelkreis der Temperaturregulation}

\section{Allgemeine Einführung}

Als oberstes, dominantes Zentrum der Thermoregulation fungiert im Säugetier der Hypothalamus. Aufgabe dieses Regulationszentrums ist der durchgängige Abgleich der Solltemperatur mit der Ist- Temperatur. Eine konstante Körperkerntemperatur wird erreicht, wenn sich ein Fließgleichgewicht zwischen Wärmebildung und Wärmeabgabe einstellt. Es handelt sich um ein hierarchisch geordnetes Temperaturkontrollsystem, das sich vom rostralen Hypothalamus über den Hirnstamm bis zum Rückenmark erstreckt. Dies bestätigt sich unter anderem darin, dass bei Verletzung oder komplettem Ausfall des Hypothalamus die Thermoregulation des menschlichen Körpers merklich eingeschränkt bzw. entkoppelt wird. Patienten mit hoher Querschnittsverletzung zeigen ebenfalls eine gestörte Temperaturregulation, jedoch keine vollständige Poikilothermie. Es lässt sich keine isolierte Region im Gehirn des Säugetiers ausmachen, die allein für die Thermoregulation zuständig ist (Boulant 1980, Boulant 1996).

\subsubsection{Der Regelkreis}

Das Temperaturregulationssystem endothermer Organismen entspricht einem Regelkreis aus verschiedenen Stellgliedern mit Rückkopplung (Gunga 2008). Die Körperkerntemperatur als zentrale Regelgröße ergibt sich als integrativer Wert verschiedener lokaler Temperaturen aus peripheren Geweben. Thermorezeptoren aus unterschiedlichen Gewebearten und Körperstrukturen können thermale Informationen aus der Peripherie aufnehmen (Istwert der Regelgröße), verarbeiten und zum Hypothalamus leiten (Satinoff 1978). Der Prozess der thermoregulatorischen Informationsverarbeitung lässt sich dabei in drei Phasen unterteilen: Afferente Temperaturerfassung, zentrale Verarbeitung und efferente Antwort.

Auf molekularer Ebene der Temperaturerfassung handelt es sich um eine direkte Aktivierung unselektiver Kationenkanäle der TRP- (transient receptor potential channels) Superfamilie, die als Hauptsensoren der Temperaturwahrnehmung gelten. Kältesensoren vom Typ TRP Melastin 8- (TRPM8) oder CMR1 (cold and menthol receptor 1) werden bei Umgebungstemperaturen $<27^{\circ} \mathrm{C}$ sowie durch chemische Kühlmittel wie Menthol aktiviert. Hierdurch lässt sich die kühlende Wirkung der Pfefferminze erklären. TRPA1 reagieren bei Umgebungstemperaturen $<17^{\circ} \mathrm{C}$ (McKemy et al. 2002, Peier et al. 2002).

Wärmesensoren der TRP-Familie besitzen Aktivierungsschwellen bei $33-39^{\circ} \mathrm{C}$ (TRPV3) sowie $25-34^{\circ} \mathrm{C}$ (TRPV4). Für schmerzhafte Hitzereize $\geq 42^{\circ} \mathrm{C}$ dient TRPV1 als Sensor, der zugleich durch Capsaicin, den aktiven Bestandteil der Chili-Schoten, sowie Protonen 
$(\mathrm{pH} \leq 5,8)$ aktiviert wird (Caterina et al. 1997, Tominaga et al. 1998). Exprimiert werden diese Ionenkanäle in Zellkörpern, Axonen sowie an peripheren freien Nervenendigungen somatosensorischer Neurone. Die Zellkörper dieser neuronalen Subpopulation liegen in den Spinalganglien sowie im Ganglion Trigeminale, ihre Synapsen im Hinterhorn des Rückenmarks.

Thermorezeptoren zeichnen sich durch eine hohe Sensitivität aus. Periphere Sensoren gehören zu der Gruppe der PD-(Proportional/Differenzial) Rezeptoren mit tonischen und phasischen Antwortverhalten. Dadurch liefern sie nicht nur Informationen über die Hauttemperatur, sondern erfassen zusätzlich die Geschwindigkeit der Temperaturänderung (Gekle et al. 2005). So kann beispielsweise ein Temperaturanstieg der Hautoberfläche von nur $0,003^{\circ} \mathrm{C}$ erfasst und eine thermoregulatorische Antwort hervorgerufen werden. Die Fähigkeit der Körperoberfläche, durch Signale von Thermorezeptoren an das zentrale Nervensystem die Körpertemperatur zu beeinflussen, ist dabei jedoch nicht einheitlich. Die Gesichtshaut stellt beispielsweise eine fünfmal sensiblere Körperregion als andere Körperstellen des Menschen dar. Ebenfalls zeigt sich eine erhöhte Sensitivität gegenüber rasch eintretenden thermalen Störungen im Gegensatz zu langsamen (Gekle et al. 2005). In der präoptischen Region des vorderen Hypothalamus (Regler) laufen afferente Impulse von Wärme- und Kälterezeporen ein. Kältesignale werden primär über $A \delta$ - Fasern geleitet, Wärmeafferenzen über unmyelinisierte C-Fasern (Poulus 1981). Gekreuzt und ungekreuzt durchziehen sie den Vorderseitenstrang zum Hypothalamus. Dabei stammen $20 \%$ der Afferenzen von eigenen, temperaturempfindlichen Wärme- und Kälteneuronen der Area preoptica (zentrale Thermosensoren), 20\% aus anderen Gehirnregionen, 20\% aus dem Rückenmark, 25\% aus dem Abdomen und 15\% von peripheren Thermosensoren der Haut (Sessler 1990).

Zusätzlich kommt es zu einer Gewichtung der eintreffenden Afferenzen. Um eine gleich große Antwort auszulösen, muss die erfasste Temperaturänderung an peripheren Thermosensoren 10-mal größer sein als an zentralen Thermosensoren (Gekle et al. 2005).

\subsubsection{Regulationsmechanismen bei Kälteexposition}

Besteht eine Differenz zwischen Soll- und Istwert oder werden Schwellenwerte eines Temperaturbereiches überschritten, greifen thermoregulatorische Kontrollmechanismen in Form positiver bzw. negativer Rückkopplung. Hier kommt es unter Führung des Hypothalamus als zentrale Kontrollinstanz zu einem Zusammenwirken mehrerer thermoregulatorischer Mechanismen. Das hierarchisch aufgebaute System gewährleistet dabei maximale Effizienz bei der Aufrechterhaltung der Körperkerntemperatur. 
Es können folgende Stellglieder im Regelkreis im Sinne eines Effektormechanismus verändert werden (Gekle et al. 2005):

- Anpassung der Hautdurchblutung

- Thermogenese durch Muskelkontraktion („Kältezittern“)

- Non-shivering thermogenesis im braunen Fettgewebe

- Erhöhter Grundumsatz

\subsubsection{Thermoregulatorische Vasokonstriktion}

Noradrenalinfreisetzung aus sympathischen Nervenfasern führt zu einer a1-Rezeptorvermittelten Vasokonstriktion an kutanen arteriovenösen Shunts. Hierdurch kommt es zu einer Drosselung der peripheren Hautdurchblutung, die Haut kühlt ab. Hieraus ergibt sich ein verringerter Temperaturgradient zwischen Umgebung und Körper. Die Wärmeabgabe über die Haut sinkt. Zusätzlich spielt das Gegenstromprinzip eine zentrale Rolle bei der Umverteilung des venösen Rückstroms. Das über die Arterien in die Extremitäten strömende Blut fließt nun weniger durch die oberflächlichen Venen zurück, sondern wird über tiefe, den Arterien benachbarten Begleitvenen zurück zum Körperkern geleitet. Durch diesen Kurzschluss wird ein zu hoher Wärmeverlust aus dem arteriellen Blut über die Körperperipherie verhindert. Es resultiert eine funktionelle Abkopplung von Körperkern und Körperschale, welches den zentralen Wirkmechanismus der thermoregulatorischen Vasokonstriktion darstellt (Sessler 1990, Sessler 1997).

\subsubsection{Kältezittern}

Sinkt die Körperkerntemperatur trotz der thermoregulatorischen Vasokonstriktion weiter ab, kommt es beim Erwachsenen zum Kältezittern (Shivering). Diese Form der Wärmebildung bildet sich in einer unwillkürlichen Muskeltätigkeit ab, in der zunächst tonische und erst im folgenden Verlauf bei bestehender Kälteeinwirkung phasische motorische Einheiten aktiviert werden. Meist wird der Beginn durch eine Erhöhung des Muskeltonus am Musculus Masseter („eingefrorener Unterkiefer“) beobachtet. Es folgt eine Aktivierung der Schultermuskulatur bis hin zum Zittern des gesamten Körpers. Die Wärmeproduktion kann hierdurch um den 4-5 fachen Wert des Grundumsatzes gesteigert werden, birgt jedoch durch den enormen Energieverbrauch der intensiven Muskelaktivität bei internistisch vorerkrankten Patienten deutliche Risiken (Gunga 2008, Schäfer 2002). Festzustellen ist ein $30-40 \%$ höherer $\mathrm{O}_{2}$-Verbrauch, eine vermehrte $\mathrm{CO}_{2}$ Produktion sowie eine erhöhte arterio- venöse $\mathrm{O}_{2}$ Differenz (Bay et al. 1968, Frank et al. 1993). 
Hinzu kommt, dass besonders das postoperative Kältezittern vom Patienten als extrem unangenehm empfunden wird und als bleibender, negativer Eindruck erhalten bleibt (Schäfer 2002).

\subsubsection{Thermogenese des braunen Fettgewebes}

Zwar verfügt das reife Neugeborene unmittelbar nach der Geburt über alle autonomen thermoregulatorischen Mechanismen, jedoch zeigen sie durch ein ungünstiges Oberflächen/Volumen-Verhältnis einen bedrohlichen Wärmeverlust. Beim Absinken der Umgebungstemperatur vermögen Neugeborene die Wärmebildung durch eine erhöhte chemische Thermogenese im brauen Fettgewebe zu steigern.

Das zwischen den Schulterblättern und Axilla eingebettete wärmeerzeugende Gewebe zeigt eine hohe Mitochondriendichte und ist reichlich vaskularisiert. An der inneren Mitochondrienmembran sorgen Entkopplungsproteine dafür, dass der durch die Atmungskette erzeugte Protonengradient nicht zur ATP-Bildung genutzt werden kann. Die Energie wird in Form von Wärme freigesetzt (Brück et al. 1990).

Der maximale thermoregulatorische Stoffwechselanstieg, der beim unbekleideten Erwachsenen bei Umgebungstemperaturen zwischen 5 und $0^{\circ} \mathrm{C}$ erreicht wird, liegt jedoch bei Neugeboren bereits bei $23^{\circ} \mathrm{C}$. Während Erwachsene mit heftigem Kältezittern auf die Umgebungstemperatur reagieren, sieht man dem Neugeborenen die zitterfreie Thermogenese nicht an. Folgen sind ein stark ansteigender Sauerstoffverbrauch mit der Gefahr einer metabolischen Entgleisung (Gekle et al. 2005).

\subsubsection{Verhaltensanpassung}

Bewusste thermische Empfindungen werden im sensorischen Kortex erzeugt. Sie führen neben den autonomen Regulationsmechanismen beispielsweise zu einer Verkleinerung effektiver Körperoberfläche durch Zusammenkauern, Auswahl wärmerer Kleidung oder Einsatz von Willkürmotorik (Gekle at al. 2005).

Eine thermoregulatorische Anpassung im Sinne einer Verhaltensänderung setzt eine bewusste Wahrnehmung der Temperaturveränderung voraus. Der menschliche Körper ist nur eingeschränkt in der Lage, Veränderungen der zentralen Körperkerntemperatur zu registrieren. Hingegen werden Temperaturschwankungen an der Körperoberfläche sofort erfasst. Verhaltensregelung erfolgt dadurch größtenteils über eine über die Haut vermittelte Temperaturwahrnehmung (Abb.1).Bei der autonomen Regulationsantwort hingegen spielt dieser Mechanismus nur in 10-20\% eine Rolle (Cheng et al. 1995). 


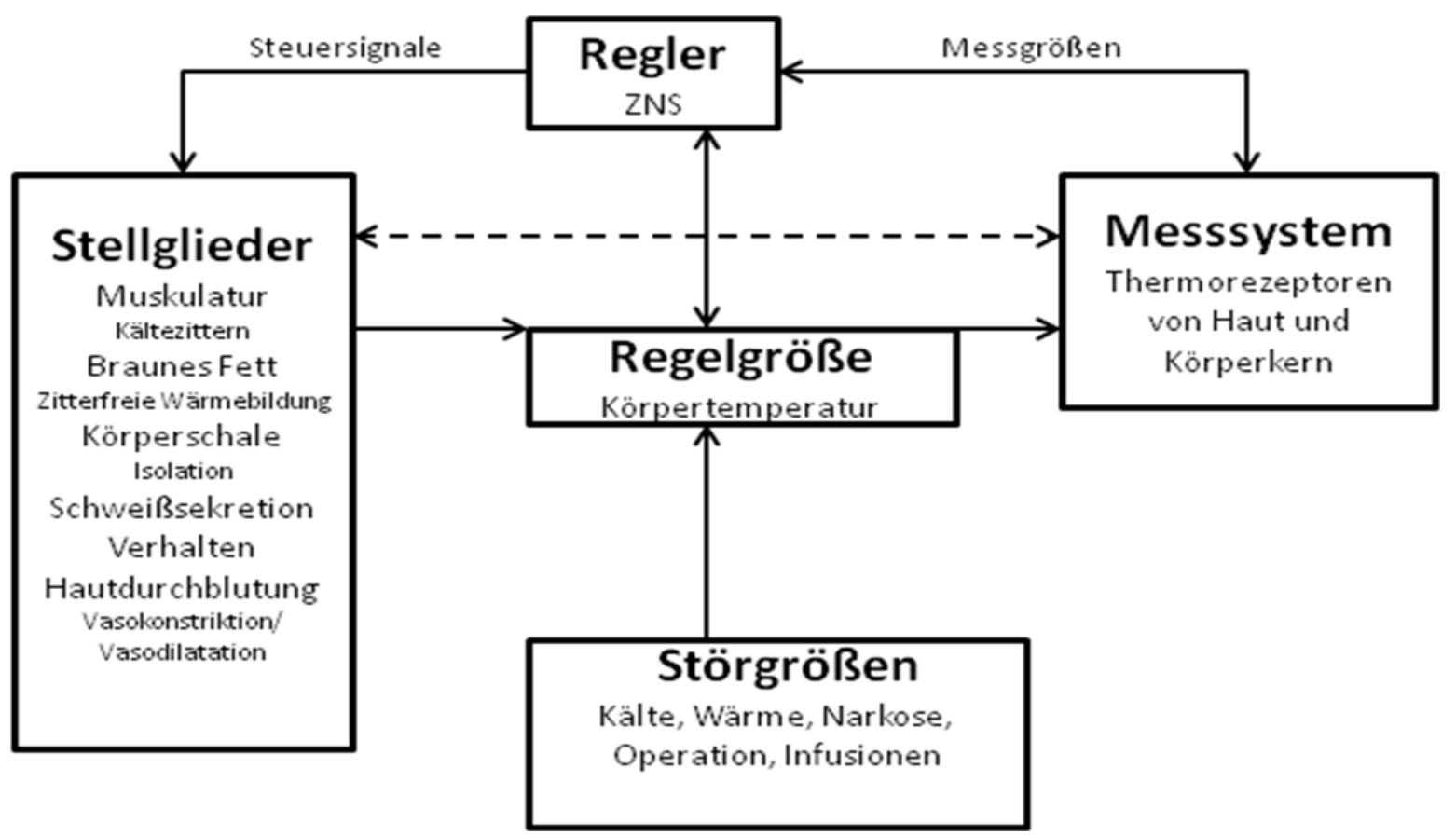

Abbildung 1: Regelkreis der Thermoregulation (Modell modifiziert nach Simon 1997, S. 649 )

\subsubsection{Mechanismen der Wärmebildung und des Wärmeaustausches mit der Umwelt}

\section{Allgemeine Einführung}

Eine konstante Körperkerntemperatur kann gewährleistet werden, wenn die Wärmeabgabe im Gleichgewicht mit der Wärmebildung steht. Dabei entspricht die Wärmebildung einer Funktion des Energieumsatzes (Gekle et al. 2005). Als Thermoneutralzone wird die Umgebungstemperatur bezeichnet, in dem die Gesamtwärmebilanz ohne zusätzlichen Energieaufwand aufrechterhalten wird und nur minimale Wärmeproduktion und Abgabe erforderlich sind. Bei einem unbekleideten Erwachsenen liegt dieser Bereich zwischen 28$30^{\circ} \mathrm{C}$ Umgebungstemperatur (Gekle et al. 2005).

Davon abzugrenzen ist der Bereich der Körperkerntemperatur, in dem die Temperatureinstellung weder über wärmeerhaltende, (Kältezittern) noch über wärmereduzierende (Schweißproduktion) Reaktionen erfolgt (Abb. 2). In der interthreshold range erfolgt die Thermoregulation allein durch Variation der Hautdurchblutung. Beim Menschen umfasst dieser Bereich lediglich $0,2^{\circ} \mathrm{C}-0,4^{\circ} \mathrm{C}$ (Lopez et al. 1994, Sessler 1991). 


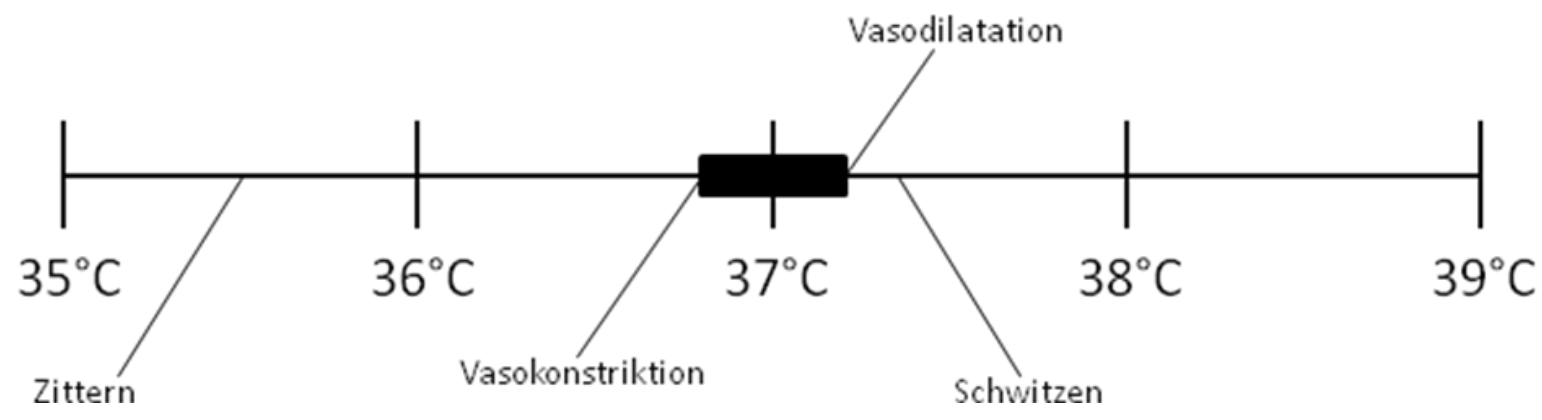

Abbildung 2: die Thermoregulationsschwellen modifiziert nach Sladen (1991), S. 166

Die Haut stellt den wichtigsten Ort des Wärmeaustausches mit der Umgebung dar. Über die Lunge und Atemwege kann zusätzlich Wärme abgegeben werden. Generell verläuft die Wärmeabgabe nach dem 2. Satz der Thermodynamik vom Ort der höheren Energie zum Ort der geringeren Energie. Wärme fließt über einen Gradienten vom warmen Körper hin zum kalten Körper. Die Wärmeabgabe erfolgt über vier verschiedene physikalische Mechanismen:

1.) Wärmeströmung (Konvektion)

2.) Wärmeleitung (Konduktion)

3.) Wärmestrahlung (Radiation)

4.) Verdunstung (Evaporation)

\subsubsection{Konvektion}

Konvektion beschreibt den Wärmetransport durch Strömung eines bewegten Mediums wie Flüssigkeit oder Gas. Unter Ruhebedingungen wird aus dem Körperkern über das Blut Wärme in die Peripherie übertragen. Die Abgabe von Wärme erfolgt ebenfalls über den konvektiven Transport, da durch Haut und Lunge zwei Organe mit großer Oberfläche im Kontakt zur Umwelt stehen.

Für die Konvektion gilt folgende Gesetzmäßigkeit:

$Q_{C} / A=h_{C} \sqrt{v}\left(T_{H}-T_{L}\right)$

$\mathrm{Q}_{\mathrm{C}}=$ Wärmefluß durch Konvektion $\quad[\mathrm{W}]$

$\mathrm{A}=$ Oberfläche $\left[\mathrm{m}^{2}\right]$

$\mathrm{h}_{\mathrm{C}}=$ Wärmeaustauschkoeffizient für Konvektion $\quad\left[\mathrm{W} \mathrm{m}^{-2}{ }^{\circ} \mathrm{C}^{-1}\right]$

$\mathrm{v}=$ Strömungsgeschwindigkeit $\left[\mathrm{m} \mathrm{s}^{-1}\right]$

$\begin{array}{llll}\mathrm{T}_{\mathrm{H}}=\text { Hauttemperatur } & {\left[{ }^{\circ} \mathrm{C}\right]}\end{array}$

$\begin{array}{llll}\mathrm{T}_{\mathrm{L}} & = & \text { Temperatur des strömenden Mediums } & {\left[{ }^{\circ} \mathrm{C}\right]}\end{array}$ 
Je schneller die Strömungsgeschwindigkeit über einen Körper und je höher der Temperaturgradient zwischen Haut und Umgebung, desto höher ist der resultierende Wärmefluss. Ebenso findet Konvektion statt, wenn erwärmte Luft von der Körperoberfläche nach oben steigt und durch nachströmende, kühle Umgebungsluft ersetzt wird (English 2001, Gekle et al. 2005).

\subsubsection{Konduktion}

Konduktion beschreibt den Transport von kinetischer Wärmeenergie innerhalb eines unbewegten Mediums auf ein anderes, beispielsweise zwischen einem Körper und dem Operationstisch. Der Wärmetransport verläuft hierbei von Molekül zu Molekül. Die dabei abgegebene Wärmemenge folgt dem Diffusionsgesetz und ist abhängig von der Größe der Kontaktfläche, dem Temperaturgradienten und der Austauschzeit. (English 2001, Gekle et al. 2005).

$Q_{K} / A=h_{K}(T a-T h)$

$\mathrm{Q}_{\mathrm{K}}=$ Wärmefluß durch Konduktion / Fläche [W]

$\mathrm{A}=$ Fläche $\left[\mathrm{m}^{2}\right]$

$\mathrm{H}_{\mathrm{K}}=$ Wärmeaustauschkoeffizient für Konduktion $\quad\left[\mathrm{W} \mathrm{m}^{-2}{ }^{\circ} \mathrm{C}^{-1}\right]$

$\begin{array}{llll}\mathrm{T}_{\mathrm{A}}= & \text { Temperatur der Auflagefläche } & {\left[{ }^{\circ} \mathrm{C}\right]}\end{array}$

$\begin{array}{lll}\mathrm{T}_{\mathrm{H}}=\text { Hauttemperatur } & {\left[{ }^{\circ} \mathrm{C}\right]}\end{array}$

\subsubsection{Radiation}

Radiation beschreibt die Übertragung von Wärme durch Strahlung zwischen zwei Objekten unterschiedlicher Temperatur. Der Körper kann Strahlung (z.B Infrarot) sowohl aufnehmen und in Wärme umwandeln als auch über Strahlung Wärmeenergie verlieren. Die Wärmeaufnahme durch Sonneneinstrahlung erfolgt z.B. über Radiation. Dies geschieht zum einen über große Entfernungen, zum anderen ohne Vermittlung von Materie und ist abhängig von der Temperaturdifferenz zwischen den Körpern (English 2001, Gekle et al. 2005). Für die Radiation gilt folgende Gesetzmäßigkeit:

$Q_{R} / A=\in \sigma\left(T_{H}^{4}-T_{W}^{4}\right)$

\begin{tabular}{|c|c|c|}
\hline$Q_{R}$ & Wärmefluß durch Radiation & {$[\mathrm{W}]$} \\
\hline$=$ & Oberfläche & {$\left[\mathrm{m}^{2}\right]$} \\
\hline$=$ & Emissivität (für Haut aus praktischen Gründen gleich 1) & [dimensionslos] \\
\hline$=$ & Stefan-Boltzmann-Konstante $\left(5,67^{*} 10^{-8} \mathrm{~W} / \mathrm{m}^{2}{ }^{*} \mathrm{~K}^{4}\right)$ & {$\left[\mathrm{W} \mathrm{m} \mathrm{m}^{-2} \mathrm{~K}^{4}\right]$} \\
\hline$=$ & Hauttemperatur & {$\left[{ }^{\circ} \mathrm{C}\right]$} \\
\hline$=$ & Temperatur des körpernächsten Festkörpers & {$\left[{ }^{\circ} \mathrm{C}\right]$} \\
\hline
\end{tabular}




\subsubsection{Evaporation}

Evaporation beschreibt die Abgabe wärmeenergiereicher Moleküle von einer Flüssigkeitsoberfläche an die Umgebung. Im Unterschied zu den vorherigen Mechanismen hängt die Verdunstung nicht von der Temperaturdifferenz zwischen zwei Körpern ab. Ausschlaggebend für das Ausmaß der abgegebenen Wärmemenge ist die Wasserdampfdruckdifferenz zwischen Haut und Umgebung. Über die Schweißdrüsen der Haut sowie die Alveolarwände der Lunge werden in Ruhe ca. 20-50 ml h-1 Wasser abgegeben (Perspiratio insensibilis). Dies entspricht einer Wärmemenge von 14-35 W. Über die Perspiratio insensibilis hinaus liegt ein erhöhter evaporativer Wärmeverlust intraoperativ bei großen Wundflächen oder der Eröffnung seröser Körperhöhlen vor.

Hier wird dem Körper zusätzlich Wärme in Form von Verdunstung entzogen (English 2001, Gekle et al. 2005).

Für die Evaporation gilt folgende Gesetzmäßigkeit:

$Q_{E V} / A=h_{e} *\left(\bar{p}_{s}-p_{a}\right)$

$\mathrm{Q}_{\mathrm{EV}}=$ Wärmefluß durch Evaporation [W]

$\mathrm{A}=$ Oberfläche $\left[\mathrm{m}^{2}\right]$

$\mathrm{h}_{\mathrm{e}}=$ Wärmeaustauschkoeffizient für Evaporation $\quad\left[\mathrm{W} \mathrm{m}^{-2} \mathrm{mmHg}^{-1}\right]$

$\mathrm{p}_{\mathrm{s}}=$ Wasserdampfpartialdruck der Umgebung [mmHg] 


\subsubsection{Die Verteilung der verschiedenen Mechanismen beim Wärmetransfer im}

Körper

Am leicht bekleideten und stehenden Menschen wurden die prozentualen Anteile der einzelnen Wärmeabgabemechanismen im Ruhezustand bestimmt (Abb. 3).

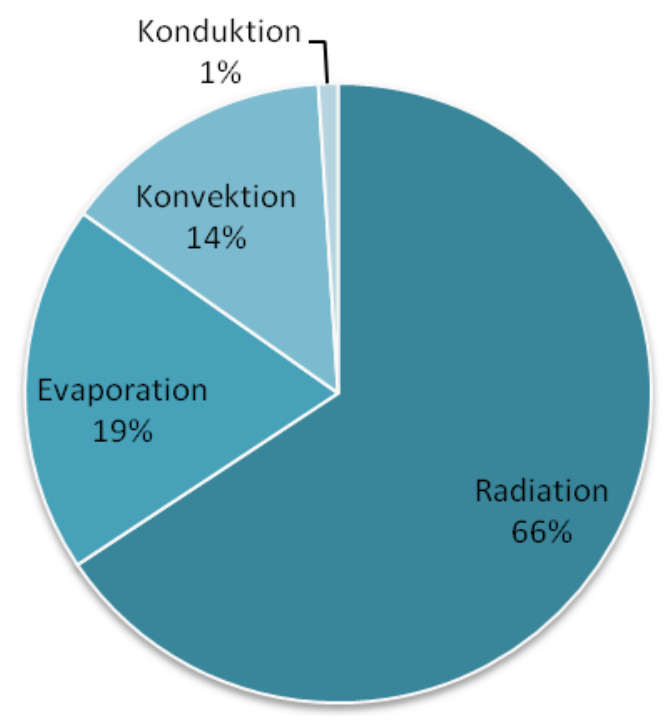

Abbildung 3: Verteilung der Wärmeabgabemechanismen beim stehenden bekleideten Menschen in Ruhe

Als wichtigster Mechanismus wird mit $65 \%$ Anteil an der Gesamtwärmeabgabe die Radiation gewertet. Die Evaporartion wird mit 19\% beziffert. Die Konvektion wird mit 15\% angegeben. Die Konduktion spielt beim stehenden Menschen durch die geringe Kontaktfläche mit $<1 \%$ nur eine geringe Rolle (Brück 1990).

\subsection{Pathophysiologie der Wärmeregulation}

\section{Allgemeine Einführung}

Zu den pathophysiologischen Zuständen der Wärmeregulation zählt man das Fieber, die Hyperthermie mit der Sonderform der malignen Hyperthermie sowie die Hypothermie. Historisch bedingt, jedoch ohne feste Definition werden Temperaturen $>38^{\circ} \mathrm{C}$ als Hyperthermie, Temperaturen $<36^{\circ} \mathrm{C}$ als Hypothermie beschrieben (National Collaborating Centre for Nursing and Supportive Care 2008, Sessler 2001). 


\subsubsection{Fieber}

Beim Fieber erfolgt im Körper eine Sollwertverstellung der Körperkerntemperatur. Pyrogene führen zu einer vermehrten Freisetzung von Zytokinen in Form von Interleukin-1 $\beta$, Interleukin-6 sowie Interferon- $\alpha$. Interleukin- $1 \beta$ bindet an Rezeptoren im Organum vasculorum laminae terminalis und setzt Prostaglandin $E_{2}$ frei. Über die Wirkung dieses Mediators am Hypothalamus kommt es zur Erhöhung des Temperatursollwertes. Es folgt eine periphere Vasokonstriktion, wodurch die Wärmeabgabe vermindert wird. Über einsetzendes Kältezittern (Schüttelfrost) wird die Wärmebildung gesteigert um den neuen Sollwert zu erreichen. Eine periphere Vasodilatation mit vermehrtem Schwitzen führt nach Abklingen der Entzündungsreaktion zur normalen Sollwerteinstellung (Brück 1990).

\subsubsection{Hyperthermie}

Im Gegensatz zum Fieber kommt es bei Hyperthermie nicht zu einer Veränderung des Sollwerts der Körperkerntemperatur. Durch erhöhte Wärmebildung (Arbeit in der Sonne) und geringe Wärmeabgabe bei hoher Luftfeuchtigkeit sind Mechanismen wie Konvektion, Strahlung und Verdunstung vermindert. Es folgt eine unphysiologische Zunahme der Körperkerntemperatur $>37^{\circ} \mathrm{C}$ mit starker peripheren Vasodilatation. Zusätzlicher Flüssigkeitsmangel verstärkt die Kreislaufdekompensation. Es kommt zur Minderdurchblutung des Zentralnervensystems mit Hitzekollaps.

Eine gefährliche Sonderform der Hyperthermie stellt die maligne Hyperthermie mit einer klinischen Inzidenz von 1: 30000 dar. Hier kommt es durch einen genetischen Defekt des Ryanodin-Rezeptors-1 der Skelettmuskultur speziell in der Narkose zu einer unkontrollierten $\mathrm{Ca}^{2+}$ Freisetzung aus dem sarkoplasmatischen Retikulum (Steinfath et al. 2002). Durch die Verwendung von depolarisierenden Muskelrelaxanzen wie Succinylcholin, volatiler Anästhetik -mit Ausnahme von Lachgas- sowie verschiedenen Neuroleptika kommt es bei genetischer Disposition zu einer akuten intrazellulären Kalziumstoffwechselstörung in der Skelettmuskulatur mit Anstieg der Körperkerntemperatur und dramatischer Zunahme des $\mathrm{O}_{2}$-Verbrauchs. Tachykardie, Rigor sowie eine metabolische Azidose sind frühe Zeichen der malignen Hyperthermie, der eigentliche namensgebende Temperaturanstieg gehört erst zu den Spätsymptomen. Die Anwendung von EKG-Monitoring und Kapnometrie ermöglicht eine frühzeitige Diagnose des hypermetabolen Zustands des Patienten (Urmwyler und Hartung 1994). 


\subsubsection{Hypothermie}

Die Hypothermie bezeichnet in der Fachliteratur das Absinken der Körperkerntemperatur $<36^{\circ} \mathrm{C}$ (Sessler 2001). Eingeteilt wird die Hypothermie dabei in drei Schweregrade. Eine milde Hypothermie liegt bei einer Körperkerntemperatur von $<36{ }^{\circ} \mathrm{C}$ bis $32{ }^{\circ} \mathrm{C}$ vor. Für Temperaturen zwischen $32{ }^{\circ} \mathrm{C}$ und $28^{\circ} \mathrm{C}$ wurde der Begriff der moderaten Hypothermie geprägt. Bei schwerer Hypothermie erreicht die Körperkerntemperatur Werte $<28^{\circ} \mathrm{C}$.

Man unterscheidet in der Praxis zwischen der akzidentellen oder induzierten Hypothermie. Mögliche Ursachen einer akzidentellen Hypothermie können zentrale Störungen der Kälteabwehr bzw. Aufhebung der Kälteabwehrmechanismen durch Alkohol oder Medikamentenmissbrauch darstellen. Ebenfalls bedeutet die Narkose im klinischen Alltag einen Eingriff in den Wärmehaushalt des Patienten. Durch die reduzierte Wärmeproduktion in Narkose und die Wärmeproduktion übersteigenden Wärmeverluste resultiert meist direkt die Hypothermie. Kommt es durch den fortlaufenden Wärmeverlust zu einer Körperkerntemperatur von $26^{\circ}-28^{\circ} \mathrm{C}$, kann es durch ein gestörtes Reizleitungssystem am Herzen zum Tod durch Kammerflimmern kommen (Brück 1990).

Der positive Effekt der induzierten Hypothermie zur Begrenzung und Vermeidung sekundärer Hirnschäden infolge hypoxischer oder ischämischer Ereignisse ist bereits seit längerem bekannt. Durch die herabgesetzte Körperkerntemperatur kommt es zu einer generellen Verlangsamung des Glukose- sowie Sauerstoffverbrauchs. Eine Körperkerntemperatur von $30^{\circ} \mathrm{C}$ senkt den Sauerstoffverbrauch um bis zu $50 \%$, weitere Abkühlung auf $25^{\circ} \mathrm{C}$ Körperkerntemperatur auf $25 \%$ des Ursprungswertes (Schirmer 2007). Die neuroprotektive Wirkung zeigt der Schutz vor schädlichen biochemischen Vorgängen durch freie Radikale und Mediatoren bei der Reperfusion nach Ischämie (Negovsky 1988). In der Kardiochirurgie findet die induzierte Hypothermie seit 1950 ihre Anwendung um die Folgen der perioperativen Ischämie so gering wie möglich zu halten und eine kardioprotektive Wirkung zu erzielen (Bigelow et al. 1950, Dae et al. 2002). In der Neurochirurgie wird durch die gezielt induzierte, milde Hypothermie die intraoperative Ischämietoleranz erhöht (Rosomoff 1965). 


\subsection{Pathophysiologie der perioperativen Hypothermie}

\section{Allgemeine Einführung}

Nahezu alle Patienten, die sich einer Narkose in Allgemeinanästhesie unterziehen, zeigen eine Reduktion der Körperkerntemperatur und erreichen dadurch einen hypothermen Zustand (Vaughan et al. 1981). Insbesondere nach langen und invasiven Operationen erreichen durchschnittlich 50-70\% aller Patienten den Aufwachraum mit einer Körperkerntemperatur unter $36^{\circ} \mathrm{C}$ (Frank et al. 1994). Maßgebliche Faktoren für das Ausmaß des Temperaturverlustes stellen dabei Anästhesieverfahren, verwendete Medikamentendosen, intraoperative Abdeckung des Patienten und Raumtemperatur dar (Morris und Wilkey 1970, Morris 1971 a und b). Schon Pickering deutete im Lancet durch den Satz "The best way to cool a man is to give him anesthetic" (Pickering 1958, S.59) auf einen direkten Zusammenhang zwischen Narkose und Körperkerntemperatur hin.

\subsubsection{Entstehung von perioperativer Hypothermie}

Bei der Entstehung der perioperativen Hypothermie spielen signifikante Schutz- wie auch Risikofaktoren eine wichtige Rolle, die in ihrer Bedeutung im klinischen Alltag jedoch häufig unterschätzt werden.

Nach einer Studie wurden vier unabhängige prä- und intraoperative Faktoren gefunden, die zur Entstehung von perioperativen Hypothermie beitragen (Abelha et al. 2005):

1.) Präoperative Körperkerntemperatur

2.) Intraoperativer Flüssigkeitsumsatz

3.) Ausmaß des operativen Eingriffs

4.) Postoperativer Krankheitsschweregrad, ermittelt mit dem SAPS-II-Score

Zusätzlich zu diesen genannten Faktoren sind Alter und Vorerkrankungen, Vormedikation sowie die Prämedikation zur Narkosevorbereitung zu beachtende Aspekte.

\subsubsection{Präoperative Körperkerntemperatur}

Eine hohe präoperative Körperkerntemperatur stellt einen protektiven Schutzfaktor vor perioperativer Hypothermie dar. Hingegen entwickeln Patienten mit einer niedrigen Ausgangstemperatur sowie präoperativen Kälteempfindungen häufiger eine intraoperative Hypothermie. Eine Studie an 446 Patienten zeigte, dass schon bei Ankunft des Patienten in den Operationsbereich der Median der gemessenen Körperkerntemperaturen bei nur $36,4^{\circ} \mathrm{C}$ lag. Bei der Hälfte aller Patienten ließ sich dementsprechend eine niedrigere Temperatur als $36,4^{\circ} \mathrm{C}$ als präoperativer Ausgangswert ermitteln. Die meisten Patienten 
erreichten eine präopertive Körperkerntemperatur von $36,1^{\circ} \mathrm{C}$ (Mitchell und Kennedy 2001). Wenn man bedenkt, dass es nach der Narkoseeinleitung grundsätzlich zu einer Wärmeumverteilung im Körper kommt und eine Körperkerntemperatur von nur $36,1^{\circ}$ als Ausgangswert angenommen wird, so ist ein hypothermer Temperaturverlauf umso wahrscheinlicher.

\subsubsection{Alter und Vorerkrankungen}

Durch Unterschiede in der körperlichen Konstitution weisen Kinder und besonders kranke, ältere Menschen eine besondere Hypothermiedisposition auf. Säuglinge und Kleinkinder kühlen aufgrund des ungünstigen Verhältnisses von großer Oberfläche zum Körpergewicht besonders rasch aus.

Ältere Menschen zeigen unter Kälteeinwirkung eine abgeschwächte thermoregulatorische Antwort in Form von Vasokonstriktion (Kenney und Munce 2003). Zusätzlich ist die metabolische Wärmeproduktion bei Kältestress deutlich eingeschränkt.

Hinzukommen bei Patienten verschiedene Vorerkrankungen, die nachweislich zur Hypothermiehäufigkeit beitragen.

Diese sind:

1.) Hypothyreose

2.) Polyneuropathien (z.B beim Diabetes mellitus)

3.) Querschnittslähmungen

4.) Zwischenhirnschädigungen

5.) Syringomyelie und Syringobulbi

Die Hypothyreose bedingt durch eine hormonelle Reduktion des Grundumsatzes eine signifikante Kälteintoleranz. Bei der Polyneuropathie kommt es hingegen durch eine verzögerte Vasokonstriktion der peripheren Blutgefäße zur gestörten Thermoregulation mit einem erhöhten Hypothermierisiko (Kitamura et al. 2000). Auch Patienten mit akuter Alkoholintoxikation (erhöhte periphere Vasodilatation), mit Querschnittslähmungen oder anderen neurologischen Erkrankungen zeigen eine veränderte Thermoregulation mit deutlicher Hypothermiedisposition (Sladen 1991).

Mögliche Vorerkrankungen, die einer perioperativen Hypothermie entgegenwirken und dadurch als mögliche Schutzfaktoren dienen sind die Hyperthyreose, Adipositas (Kurz et al. 1995b) sowie unbehandelte Hypertonie (Kasai et al. 2003a). 


\subsubsection{Körpergewicht}

Eine Studie von Kurz et al. (1995b) belegt die Korrelation zwischen der Patientenmorphologie in Bezug auf den Körperfettanteil sowie das Gewicht-Oberflächenverhältnis zum intraoperativen Körperkerntemperaturverlust. Es konnte bestätigt werden, dass sich der Temperaturverlust in der Einleitungsphase der Narkose zunächst in einem umgekehrten proportionalen Verhältnis zum Körperfettanteil und Gewicht-Oberflächenverhältnis darstellt. Aktive Wärmemaßnahmen bekommen dadurch besonders bei kurzen Eingriffen von adipösen Patienten einen nicht so hohen Stellenwert zugeschrieben wie bei vergleichsweise kachektischen Patienten. In der zweiten, linearen Phase der intraoperativen Temperatureinstellung zeigt sich ebenfalls eine umgekehrt proportionale Beziehung zwischen Körperkerntemperatur zum Gewicht-Oberflächenverhältnis. Auch hier liegen die Wärmeverluste von schlanken Patienten deutlich über den Wärmeverlusten von adipösen Patienten. In der sich anschließenden Plateauphase kommt es durch die einsetzende Thermoregulation zur peripheren Vasokonstriktion. Hier konnte keine Abhängigkeit von der Morphologie nachgewiesen werden, alle Patienten zeigten eine Reduktion der Abkühlungsgeschwindigkeit um ein Vierfaches (Kurz et al. 1995b).

\subsubsection{Vormedikation}

Bei der Abschätzung des Hypothermierisikos spielt die dauerhafte Medikamenteneinnahme des Patienten ebenfalls eine Rolle. Unerwünschte Arzneimittelinteraktionen wirken sich negativ auf die intraoperative Thermoregulation aus und begünstigen so die Hypothermie.

Einen besonders starken Effekt zeigt die Dauermedikation mit Psychopharmaka in einer Studie mit schizophrenen Patienten (Kudoh et al. 2003). Diese Studiengruppe zeigte nach Langzeiteinnahme von Neuroleptika schon vor der Narkose eine tendenziell niedrigere Körperkerntemperatur und neigte zum schnelleren intraoperativen Wärmeverlust.

Den gegenteiligen Effekt zeigen Patienten mit einer Dauermedikation in Form von Antidepressiva. Sie zeigen schon vor Narkoseeinleitung tendenziell eine höhere Körperkerntemperatur und eine dadurch bedingte niedrigere Hypothermierate (Kudoh et al. 2003).

Die chronische Einnahme des Calcium-Antagonisten Nifedipin zur Hypertoniebehandlung verringert das Ausmaß der intraoperativen Hypothermie signifikant.

Die orale Applikation von 20 mg lang wirksamen Nifedipin $12 \mathrm{~h}$ vor der geplanten Opera-

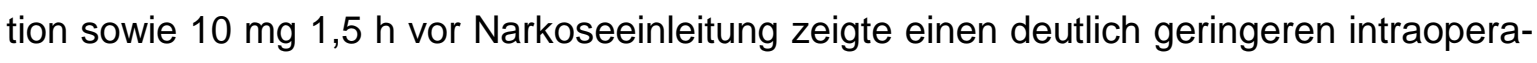
tiven Temperaturverlust gegenüber der Kontrollgruppe ohne Nifedipineinnahme $\left(0,8^{\circ} \mathrm{C}\right.$ gegenüber $1,7^{\circ} \mathrm{C}$ in der ersten Stunde). Grund hierfür ist die hämodynamische Wirkung 
dieser Substanzgruppe mit indirekter Beeinflussung der Thermoregulation. Durch die schon vor der Narkoseeinleitung induzierte Vasodilatation wird der zentrale Thermoregulationsmechanismus abgeschwächt, die intraoperative Wärmeumverteilung fällt deutlich geringer aus (Vassilieff 1994).

\subsubsection{Prämedikation vor der Narkose}

Bei der Wahl einer geeigneten Prämedikation vor einer geplanten Narkose fällt die Wahl heute meist auf einen Wirkstoff aus der Familie der Benzodiazepine. Midazolam beispielsweise ist allgemein gut verträglich, wirkt angstlösend und leicht sedierend mit einer kurzen Absorptionszeit (Hung et al. 1996). Eine Studie von Kurz et al. 1995a zeigt einen Zusammenhang zwischen der Prämedikation mit Midazolam und dem Abfall der Körperkerntemperatur vor Narkoseeinleitung.

Die kontinuierliche Applikation von $40 \mathrm{mg} / 4 \mathrm{~h}$ Midazolam zeigt jedoch eine Erniedrigung der Thermoregulationsschwelle für Vasokonstriktion von nur $0,7^{\circ} \mathrm{C}$. Dies entspricht einem deutlich geringeren Einfluss im Gegensatz zu anderen gebräuchlichen Anästhetika. Faktoren wie der erreichte Benzodiazepin-Plasmaspiegel sowie Sedierungstiefe des Patienten spielen in der Reduktion intraoperativen Körperkerntemperatur ebenfalls eine entscheidende Rolle (Matsukawa et al. 1997). Eine weiterführende Studie belegt, dass durch eine moderate Sedationstiefe in Form einer niedrig dosierten Prämedikation mit Midazolam das Ausmaß der perioperativen Hypothermie eingeschränkt werden kann.

Hier liegt die Empfehlung bei $0,04 \mathrm{mg} \mathrm{kg}^{-1}$ (Toyota et al. 2004). Durch die dadurch erreichte leichte präoperative Sedierung kommt es zu einer vorweggenommenen Wärmeumverteilung vom Körperkern in die Peripherie. Die Narkosetiefe ist durch eine moderate Sedierung ebenfalls besser steuerbar, das Ausmaß des Wärmeverlusts fällt deutlich geringer aus.

Atropin führt über eine gesteigerte Stoffwechselrate zu einer Erhöhung der präoperativen Körperkerntemperatur. Die Schwellenanhebung zur Schweißsekretion durch Atropin spielt dabei eine eher unterordnete Rolle. Bei geriatrischen Patienten konnte durch die Kombination von Midazolam und Atropin der negative Einfluss von Midazolam auf die präoperative Körperkerntemperatur aufgehoben werden. Ursächlich dafür ist eine Interaktion zwischen dem Benzodiazepin- Rezeptor und einer cholinergen Inhibition durch Atropin (Matsukawa et al. 2001). Dennoch ist der Einsatz von Atropin zur Hypothermieprophylaxe mit relevanten Risiken behaftet. Besonders bei Patienten mit koronaren Herzerkrankungen sowie Aortenklappenstenose stellt die durch Atropin induzierte Tachykardie ein erhöhtes Risikopotenzial da und erscheint dadurch nicht sinnvoll. $\alpha$-Agonisten wie Clonidin führen zu einem Absenken der thermoregulatorischen 
Schwellentemperatur und beeinflussen dadurch die Vasokonstriktion- und Zittergrenze (Delaunay et al. 1993).

Durch diese bestätigte Wirkung findet Clonidin häufig im Aufwachraum seine Anwendung zur Behandlung von postoperativem Kältzittern (Joris et al. 1993). Eine weitere Studie belegt, dass durch die prophylaktische Gabe von $2 \mu \mathrm{g} \mathrm{kg}{ }^{-1} \mathrm{KG}$ Clonidin vor der Narkoseeinleitung die Inzidenz von postoperativem Kältezittern von 55\% auf 5\% gesenkt werden kann. Trotz der sedierenden Eigenschaft von Clonidin wird dadurch die Extubationszeit nicht verlängert (Grundmann et al. 1997).

Histaminrezeptorblocker $\left(\mathrm{H}_{1}\right.$ und $\mathrm{H}_{2}$-Blocker), die bei der Aspirationsprophylaxe zur Anhebung des Magensaft-pH präoperativ Anwendung finden, führen signifikant durch eine Erniedrigung der Vasokonstriktionsschwelle zu einem verstärkten Risiko der perioperativen Hypothermie (Hirose et al. 1995).

\subsubsection{Thermoregulation unter Allgemeinanästhesie}

Durch das Einschleusen des Patienten in den OP-Bereich verliert dieser die Möglichkeit, durch autonome Verhaltensanpassungen wie beispielsweise das Anziehen von wärmender Bekleidung ein Gleichgewicht zwischen Wärmeproduktion und Wärmeabgabe herzustellen und aufrecht $\mathrm{zu}$ erhalten. Durch die zusätzliche Gabe von Narkosemedikamenten, die eine ausgeprägte vasodilatatorische Wirkung besitzen, verläuft die Wärmeumverteilung noch ausgeprägter und schneller. Hier beginnt die Verantwortung des Anästhesisten, den Patienten durch ein effektives Wärmemanagement perioperativ vor hohen Wärmeverlusten zu schützen und eine normotherme Körperkerntemperatur aufrechtzuerhalten. 


\subsubsection{Wärmeumverteilung während der Narkose}

Während die Thermoneutralzone beim wachen Menschen eine maximale Spannbreite von $0,2-0,4^{\circ} \mathrm{C}$ aufweist, verschiebt sich der Schwellenwert der Thermoregulation unter dem Einfluss der Allgemeinnarkose erheblich. Anästhetika wirken durch eine Verschiebung des Schwellenwertes im Bereich der Vasokonstriktionsschwelle. Die thermische Neutralzone verzehnfacht sich von $0,4^{\circ} \mathrm{C}$ auf $2^{\circ}-4^{\circ} \mathrm{C}$. Der Hypothalamus ist nicht mehr in der Lage, die Körperkerntemperatur zwischen $36^{\circ} \mathrm{C}-37^{\circ} \mathrm{C}$ adäquat zu regulieren (Imrie und Hall 1990).
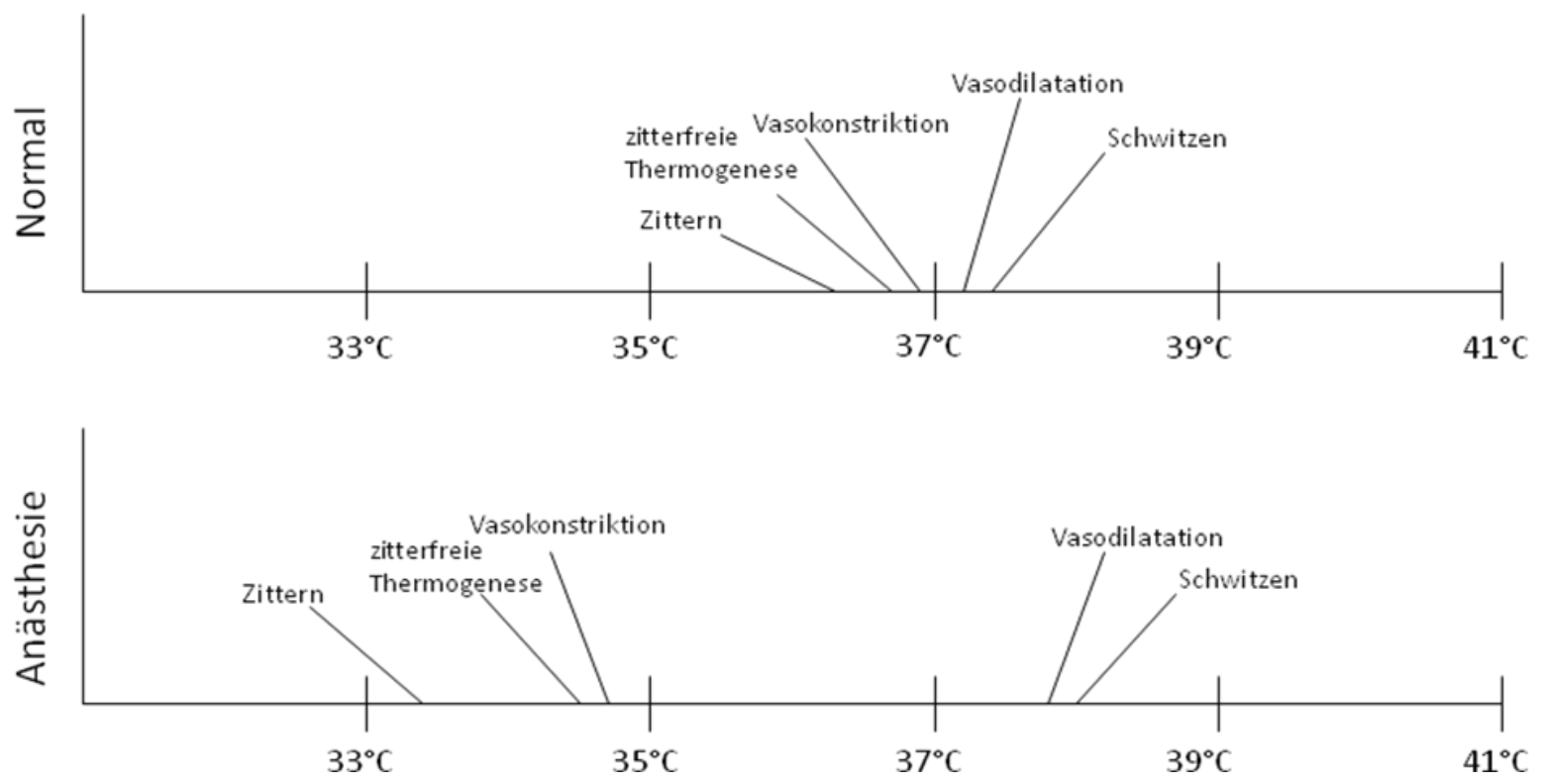

Abbildung 4: Schwellenwerte der Thermoregulation Normal / Anästhesie modifiziert nach Buggy und Crossley (2000), S.617

\subsubsection{Phasen der Wärmeumverteilung bei der Allgemeinanästhesie}

Die Wärmeumverteilung nach Narkoseeinleitung folgt immer einem charakteristischen Muster. In der ersten Stunde sinkt die Körperkerntemperatur rasch um $1-1,5^{\circ} \mathrm{C}$ vom Ausgangswert. Hieraus ergibt sich meist schon eine initiale Hypothermie (Cooper und Trezek 1971). Diese erste Phase des schnellen Abfalls der Körperkerntemperatur resultiert hauptsächlich aus einer Wärmeumverteilung zwischen dem wärmeren Körperkern und der kälteren Körperperipherie (Sessler et al. 1995). Durch die thermoregulatorische Vasokonstriktion von arteriovenösen Shunts stellen Körperkern und Körperperipherie zwei funktionell getrennte Kompartimente dar. Dabei wird die Temperatur im Körperkern durch die Thermoregulation konstant gehalten, die Temperaturen in der Körperperipherie verändern sich je nach Umgebungsbedingung. Durch den Einsatz von Pharmaka in der Narkoseeinleitung, die eine ausgeprägte systemische Vasodilatation bewirken, kommt es 
zur Aufgabe der thermoregulatorischen Vasokonstriktion. Zentrales, wärmeres Blut gelangt in die kalte Körperperipherie.

Es kommt zur Wärmeumverteilung. Dabei stellt der Temperaturgradient zwischen beiden Kompartimenten die treibende Kraft dar und bestimmt das Ausmaß der Wärmeumverteilung (Matsukawa et al. 1995b).

In der Erstbeschreibung nach der Studie von Matsukawa et al. 1995b wurde der Wärmeverlust in der ersten Stunde der Narkose mit $1,6^{\circ} \mathrm{C} \pm 0,3^{\circ} \mathrm{C}$ angegeben. Dabei fielen $81 \%$ des Wärmeverlustes auf die Wärmeumverteilung. Andere klinische Studien zeigen jedoch einen abgeschwächten Effekt nach Narkoseeinleitung mit weniger ausgeprägten Wärmeverlusten mit Abfällen zwischen $0,4-1,0^{\circ} \mathrm{C}$ (Sessler et al. 1988, Bräuer et al. 2000b). Diese unterschiedlichen Ergebnisse lassen sich soweit deuten, dass das Ausmaß der Wärmeumverteilung maßgeblich durch den Wärmegehalt der Körperperipherie bestimmt wird. Eine warme Körperperipherie (durch z.B. Vorwärmung des Patienten) besitzt einen geringeren Temperaturgradienten als eine sehr kalte. Die Wärmeumverteilung fällt deutlich geringer aus.

In der zweiten linearen Phase, die ca. zwei bis drei Stunden andauert, nimmt die Bedeutung der Wärmeumverteilung ab. Hier steht nun der Einfluss der negativen Wärmebilanz im Vordergrund des intraoperativen Temperaturverlaufes. Der Wärmeverlust übersteigt die metabolische Wärmeproduktion, welche zusätzlich durch die Allgemeinanästhesie um 15-40\% vermindert wird (Sessler 2000). Ursächlich dafür sind reduzierte Stoffwechselvorgänge im Gehirn sowie eine verminderte Muskeltätigkeit.

In der dritten Phase, der Plateauphase, kommt der Abfall der Körperkerntemperatur zum Erliegen. Durch das Wiedereinsetzen der thermoregulatorischen Vasokonstriktion stellt sich eine konstante Körperkerntemperatur ein.

\subsubsection{Einfluss verschiedener Anästhetika auf die Thermoregulationsschwellen}

Durch den Einsatz von Allgemeinanästhetika kommt es wie in Kapitel 4.3.1 beschrieben über zwei Mechanismen zur ausgeprägten Wärmeumverteilung mit deutlichen Wärmeverlusten. Zum einen führt der Einsatz von Hypnotika, Inhalationsanästhetika und Opiaten zu einer Verschiebung des Schwellenwertes für Vasokonstriktion unter die aktuelle Körperkerntemperatur. Durch diese Sollwertverstellung wird der Schutzmechanismus der Vasokonstriktion zur Vermeidung großer Wärmeverluste aufgehoben und greift erst bei wesentlich geringeren Körperkerntemperaturen (Xiong et al. 1996, Matsukawa et al. 1995b). Zusätzlich besitzen die meisten Anästhetika selbst einen vasodilatierenden Effekt (Weiskopf 1995, Matsukawa et al. 1995a). Dadurch kommt es zum Wärmeabstrom entlang 
des ausgebildeten Temperaturgradienten aus dem Körperkern durch die vermehrte Durchblutung kalter Hautareale in die Peripherie.

\subsubsection{Risiken und klinische Bedeutung der perioperativen Hypothermie}

Zahlreiche klinische Studien belegen einen signifikanten Zusammenhang zwischen perioperativer Hypothermie und relevanten Risiken für den Patienten. Dabei rücken nicht nur gesundheitliche Aspekte wie kardiovaskuläre Ereignisse, Veränderungen der Blutgerinnung und Verzögerung der Wundheilung in den Vordergrund. Auch erlangen ökonomische Überlegungen in diesem Zusammenhang einen immer höheren Stellenwert.

\subsubsection{Kardiovaskuläre Risiken}

Kardiale Ereignisse während und unmittelbar nach der Narkose zählen zu den führenden Todesursachen. Kardial vorbelastete Patienten, die im Operationssaal eine perioperative Hypothermie entwickeln, zeigen eine signifikant höhere Inzidenz für kritische kardiale Zwischenfälle. Eine Reduktion der Körpertemperatur unter $35^{\circ} \mathrm{C}$ in dieser Patientengruppe führt zu einem zwei- bis dreifach erhöhtem Risiko für frühe postoperative Myokardischämie (Frank et al. 1993). Eine nachfolgende, prospektiv randomisierte Studie an 300 kardialen Risikopatienten unterstreicht den direkten Zusammenhang zwischen milder Hypothermie und dem Auftreten von instabiler Angina Pectoris, Myokardinfarkt sowie akutem Herzstillstand (Frank et al. 1997). In der hypothermen Patientengruppe kam es signifikant zu mehr pathologische kardiale Ereignisse (6,3\%) als in der normothermen Kontrollgruppe (1,4\%). Ebenfalls zeigt sich eine Risikoreduktion von 5,5\% (2.4\% vs. $7.9 \%)$ für ventrikuläre Tachykardien bei Normothermie im Vergleich zur hypothermen Patientengruppe (Frank et al. 1997).

Auch zeigt sich ein Einfluss auf den menschlichen Katecholaminspiegel unter Hypothermie. Leicht bekleidetet, männliche Probanden, die eine Stunde einer Umgebungstemperatur von $6,5^{\circ} \mathrm{C}$ ausgesetzt waren, zeigten einen erhöhten Adrenalin- und Noradrenalinspiegel im Urin (Arnett und Watts 1960). Dabei konnte zum einen das Absinken der Herzfrequenz, zum anderen der Blutdruckanstieg unter Kälteeinwirkung beobachtet werden. Wilkerson et al. konnten bei Probanden, die unbekleidet einer Umgebungstemperatur unter $15^{\circ} \mathrm{C}$ ausgesetzt wurden, einen Anstieg von Adrenalin, Noradrenalin und Kortisol nachweisen (Wilkerson et al. 1974). 


\subsubsection{Gerinnungssystem}

Hypothermie mündet in einer Störung der Blutgerinnung auf zwei Ebenen. Betroffen ist dabei zum einen die Thrombozytenaggregation, zum anderen die plasmatische Gerinnungskaskade (Sessler 2001). Es kommt zur reversiblen Thrombozytenfunktionsstörung durch verminderte Thromboxan- $A_{2}$ Synthese sowie Expression von P-Selektin und Glykoprotein Ib (Faraday und Rosenfeld 1998).

Folglich führt die mangelnde Thrombozytenadhäsion sowie -Aggregation zu einer nachweisbar verlängerten Blutungszeit (Valerie et al. 1992).

Die plasmatische Gerinnungskaskade stellt sich ebenfalls temperaturabhängig dar. Dies zeigt sich in der Endstrecke durch eine signifikant verlängerte Prothrombinzeit sowie partielle Thromboplastinzeit. Wird bei $37^{\circ} \mathrm{C}$ die PTT mit $36 \mathrm{~s}$ bestimmt, so beträgt sie bei $34^{\circ} \mathrm{C}$ schon $39,4 \mathrm{~s}$. Maximal verlängerte Werte zeigen sich bei $31^{\circ} \mathrm{C}$ mit $46,1 \mathrm{~s}$ (Rohrer und Natale 1992). Der gestörten Blutgerinnung folgt ein vermehrter intraoperativer Blutverlust mit einem erhöhten Transfusionsbedarf.

Die klinisch signifikante Auswirkung der Gerinnungsinhibition unter Hypothermie wurde durch mehrere Studien im Bereich der Abdominalchirurgie (Bock et al. 1998) sowie bei Knie- und Hüftgelenksersatz belegt (Winkler et al. 2000). Zusätzlich wird die Bildung von Fibrin-Clots als provisorische Wundmatrix in der plasmatischen Gerinnungskaskade unter Hypothermie beeinträchtigt (Singer und Clark 1999).

\subsubsection{Wundheilung und Wundinfektion}

Schon eine milde perioperative Hypothermie führt zu einem erhöhten Risiko der Wundinfektion und Beeinträchtigung der frühen Wundheilungsphase. Durch thermoregulatorische Vasokonstriktion mit konsekutivem Abfall des subkutanen Sauerstoffpartialdrucks wird die Synthese von antibakteriell wirkenden Sauerstoffradikalen beeinträchtigt (Kurz et al. 1996). Eine verminderte Kollagensynthese um den Wundrandbereich durch hypotherme Einflüsse wurde ebenfalls belegt (Kurz et al. 1996). Durch eingeschränkte Mobilität der neutrophilen Granulozyten und Makrophagen fehlt zusätzlich die Fähigkeit der Phagozytose. Es kommt zur immunologischen Störung mit verminderter T-Zell-vermittelten Antikörperproduktion (Beilin et al. 1998).

Kurz et al. verglichen eine Patientengruppe, die keine Wärmetherapie nach der Einleitung erhielt und in der intraoperative Körperkerntemperaturen bis max. $34,5^{\circ} \mathrm{C}$ toleriert wurden mit einer normothermen Kontrollgruppe. Durch die Anwendung eines konvektiven Wärmesystems wurde in dieser Studiengruppe eine durchschnittliche Körperkerntemperatur von $36,5^{\circ} \mathrm{C}$ gehalten. 
In der chirurgischen Nachsorge wiesen hypotherme $\left(34,7+/-0,6{ }^{\circ} \mathrm{C}\right)$ Patienten im Vergleich mit normothermen Patienten $\left(36,6+/-0,5^{\circ} \mathrm{C}\right)$ eine signifikant geringere Inzidenz (19 \% vs. $6 \%$ ) von Wundinfektionen auf. Zusätzlich zeigte sich bei der hypothermen Patientengruppe ein durchschnittlich längerer Krankenhausaufenthalt von 2,6 Tagen (Kurz et al. 1996).

Melling et al. verglichen zwei verschiedene präoperative Wärmetherapieverfahren (lokale Wärme vs. konduktive Wärmezufuhr) mit einer Kontrollgruppe ohne präoperative Vorwärmung. Die Vorwärmzeit lag in beiden Wärmegruppen bei 30 min vor Operationsbeginn. 14\% aller Patienten mit akzidentieller intraoperativen Hypothermie zeigten in der Nachsorge postoperative Wundinfektion. In der normothermen Kontrollgruppe hingegen nur 5\%. Ein signifikanter Unterschied zwischen den beiden präoperativ angewendeten Wärmeverfahren konnte nicht gezeigt werden (Melling et al. 2001).

\subsubsection{Einfluss auf die Pharmakokinetik und Pharmakodynamik}

Auch der Medikamentenmetabolismus durch enzymatische Elimination wird temperaturabhängig beeinflusst. Die durch perioperative Hypothermie deutlich verlängerte Wirkdauer von Muskelrelaxanzien zeigt sich bei Vecuronium wie auch bei Atracurium.

Für Vecuronium lässt sich bei einer Körperkerntemperatur von $34,5^{\circ} \mathrm{C}$ eine Verdoppelung der Wirkdauer von $28 \pm 4$ min auf $62 \pm 8$ min nachweisen (Heier et al. 1991). Der dadurch erzeugte Überhang an Muskelrelaxanzien kann zu einer postoperativen Atemdepression führen. Die Wirkdauer von Atracurium wird bei einer Abnahme der Körperkerntemperatur von $3^{\circ} \mathrm{C}$ um $60 \%$ verlängert (Leslie et al. 1995).

Während der kontinuierlichen Gabe von Propofol zeigt sich bei hypothermen Patienten mit einer Körperkerntemperatur von $34^{\circ} \mathrm{C}$ ein im Vergleich zum normothermen Patienten $28 \%$ höherer Plasmaspiegel. Ursächlich hierfür ist der verringerte Abbaumetabolismus zwischen dem zentralen und peripheren Kompartiment bei Hypothermie (Leslie et al. 1995). Fentanyl zeigt bei hypothermen Körperkerntemperaturen um $25 \% \pm 11 \%$ höhere Plasmaspiegel als in der normothermen Kontrollgruppe. Dieser Effekt kann bis zu 6 Stunden auch nach Erwärmung nachgewiesen werden (Fritz et al. 2005). In Bezug auf Inhalationsanästhetika zeigt sich eine Erniedrigung der MAC um ca. $5 \%$ pro ${ }^{\circ} \mathrm{C}$ (Liu et al. 2001).

\subsubsection{Verweildauer im Aufwachraum}

Hypotherme Patienten zeigen eine signifikant längere Verweildauer im Aufwachraum. Dies gilt auch, wenn die postoperative Körperkerntemperatur nicht als Entlassungskriterium gewertet wird (Lenhardt et al. 1997). 
Durch das häufigere postoperative Zittern bei Hypothermie (Horn et al. 1998) kommt es zu einem kurzfristig erhöhten Atemminutenvolumen bis über 30l/min (Ciofolo et al. 1989), verlängertem Monitoringbedarf mit gestörter EKG- und Blutdruckerfassung (Schäfer und Kunitz 2002) sowie zum Abfall der peripheren Sauerstoffsättigung. Es konnten in einer Probandenuntersuchung Werte von unter $80 \% \quad \mathrm{SpO}_{2}$ bei pulmonal gesunden, hypothermen Probanden nachgewiesen werden (Jones und McLarren 1965). Extrem starkes Zittern kann zusätzlich Blutungen auslösen und zu Wundzerreißungen führen. Postoperative Schmerzen werden durch die gesteigerte Muskelaktivität verstärkt und das subjektive Kältegefühl vom Patienten als sehr unangenehm empfunden.

\subsubsection{Kosten und ökonomische Überlegungen}

Durch die oben genannten Risiken des unzureichenden Wärmemanagements im operativen Bereich können die Behandlungskosten pro Patient immens steigen. Nicht nur verlängerte Krankenhausliegezeiten durch Wundheilungsstörungen und Wundinfektionen sind die Folge (Kurz et al. 1996). Höhere Kosten entstehen ebenfalls durch einen vermehrten Transfusionsbedarf durch Hypothermie-assoziierte Gerinnungsstörungen. Zu erwähnen ist hier, dass nicht die Kosten für die Blutprodukte an sich, sondern vielmehr die mit der Transfusion verknüpften Folgekosten in Form von erhöhten Wundinfektions- und Pneumonieraten ins Gewicht fallen. Hier können sich die anfallenden Kosten auf 100014.000 US \$ pro Patient aufsummieren (Spöhr und Böttiger 2002).

Auf diesem Hintergrund wird deutlich, dass ein adäquates Wärmemanagement auch mit teureren und aufwändigeren Wärmeprotektionsverfahren bei gegebener Indikation am Ende kostengünstiger ist als erhöhte Behandlungskosten im Verlauf, die sich aus Komplikationen der perioperativen Hypothermie ergeben ( $\mathrm{Ng}$ et al. 2003).

\subsection{Wärmeprotektion und Vermeidung perioperativer Hypo- thermie}

\section{Allgemeine Einführung}

Die aufgeführten Risiken und Nebenwirkungen der akzidentiellen perioperativen Hypothermie und dadurch entstehende Folgen für den Patienten machen deutlich, dass das vorrangige Ziel in der vollständigen Vermeidung der Hypothermie liegen sollte. Jeder Patient, der sich einem Eingriff in Allgemein-, Spinal (Arkilic et al. 2000) oder Epiduralanästhesie (Sessler und Ponte 1990) unterzieht, sollte durchgehend eine Körperkerntemperatur von mindestens $36^{\circ} \mathrm{C}$ aufweisen. Grundlage dazu muss standardmäßig ein individuell auf den Patienten angepasstes, wärmeprotektives Gesamtkonzept sein. 
Diese Maßnahmen sollten idealerweise schon präoperativ auf der Station am Patienten beginnen und über die Einschleusung in den OP-Trakt bis zum Ende des Eingriffs kontinuierlich weitergeführt werden (Horn und Torossian 2010).

\subsubsection{Möglichkeiten des Wärmemanagements}

Grundsätzlich lassen sich im Gebiet des perioperativen Wärmemanagements zwei Säulen abgrenzen. Zum einen gehört zum Thermomanagement die valide Erfassung der Körperkerntemperatur am Patienten. Darüber hinaus wird über eine Isolation oder zusätzlich effektive und adäquate Wärmezufuhr eine positive Beeinflussung der Körperkerntemperatur angestrebt. Für beide Maßnahmen stehen verschiedene Methoden zur Verfügung, die mit unterschiedlichem Nutzen belegt sind.

\subsubsection{Erfassung der Körperkerntemperatur}

Die Genauigkeit und Eignung verschiedener Messorte zur objektiven Erfassung der Körperkerntemperatur wurde in verschiedenen Studien erfasst und bewertet. Das ideale Verfahren sollte dabei standardisiert und einfach anwendbar sein, über eine hohe Genauigkeit verfügen und kein Verletzungsrisiko für den Patienten aufweisen.

Grundsätzlich kann die Temperaturerfassung in der Arteria pulmonalis, Nasopharynx, Ösophagus, Tympanon, Rektum, Harnblase oder Mundraum erfolgen (Insler und Sessler 2006). Alle Verfahren unterscheiden sich hinsichtlich der Messgenauigkeit und Invasivität.

Die Messung in der Pulmonalarterie gilt als exakt und wird als wissenschaftlicher Goldstandard angegeben (De Witte und Sessler 2002). Jedoch ist dieses invasive Verfahren nur möglich, wenn die Indikation eines Pulmonaliskatheters zur hämodynamischen Überwachung gegeben ist. Die Tympanonkontaktmessung konnte sich aufgrund aufwendiger exakter Sondenplatzierung und dem hohen Verletzungsrisiko für das Trommelfell nicht durchsetzen (Torossian 2008). Die Infrarottemperaturerfassung im Gehörgang ist beim wachen Patienten aufgrund der gering invasiven Handhabung möglich, fordert aber die korrekte Handhabung für ausreichen genaue Ergebnisse. Zum Erreichen optimaler Messergebnisse muss eine längere Verweildauer des Gerätes im Ohr vermieden werden. Ebenfalls zeigen sich Ungenauigkeiten durch zu kurze Intervalle zwischen den einzelnen Messungen. Insgesamt langen die gemessenen Temperaturen der Infrarotgeräte im CAL-Modus bis zu $0,4^{\circ} \mathrm{C}$ signifikant niedriger gegenüber der Trommelfellkontaktmessung (Fritz et al. 1996). Von dieser Messmethode sollte somit intraoperativ durch zu hohe Ungenauigkeit abgesehen werden (Torossian 2008).

Die Messung der Körperkerntemperatur mittels einer Ösophagussonde gilt als valide Erfassungsmethode. Jedoch ist zu beachten, dass Temperaturabweichungen von bis zu 
$1,2^{\circ} \mathrm{C}$ im Ösophagusverlauf bestehen und diese Form der Messung nicht beim wachen Patienten angewendet werden kann. Die exakte Platzierung erfolgt entweder mithilfe eines Ösophagusstethoskop an die Stelle der lautesten Herzaktion im Bereich des linken Herzohres (Kaufmann 1987) oder die erforderliche Tiefe muss geschätzt werden (Mekjavic und Rempel1990)

Abstand $(\mathrm{cm})=\frac{\text { Körpergröße }(\mathrm{cm})}{4}-4 \mathrm{~cm}$

Formel 1: Formel zur Berechnung des Abstandes vom Nasenloch bis zum konkreten Messort eines Ösophagusthermometers nach Mekjavic und Rempel 1990

Damit entspricht bei einer Körpergröße von $160 \mathrm{~cm}$ bis $180 \mathrm{~cm}$ die ungefähre Eindringtiefe $36 \mathrm{~cm}$ bis $41 \mathrm{~cm}$ (Formel 1).

Die von Anästhesisten am häufigsten eingesetzte Methode ist die Messung im Nasopharynx. Dieser Bereich ist bis auf wenige Ausnahmen gut zugänglich, jedoch sollte auf vollständigen Kontakt zwischen Sonde und Schleimhaut geachtet werden um falsch niedrige Werte durch kalte Umgebungsluft ausschließen zu können (Cork et al. 1983).

Die Harnblasentemperaturmessung ist dann möglich, wenn die Indikation eines Blasenkatheters gegeben ist. Durch geringe Diurese mit einer Urinproduktion unter $250 \mathrm{ml} / \mathrm{h}$ (z. B Unterbaucheingriffe) kann es zur Beeinträchtigung der Messgenauigkeit kommen (Bräuer et al. 2000a).

Die orale Messung in den hinteren sublingualen Taschen ist die klinisch am besten dokumentierte und verlässlichste Methode. Durch die Einfachheit der Messtechnik, der Reproduzierbarkeit der Resultate sowie der guten Näherung an die Körperkerntemperatur ist dies die bevorzugte Temperaturerfassung in der prä- sowie postoperativen Phase (Hooper und Andrews 2006).

\subsubsection{Möglichkeiten der Wärmeprotektion}

Ein adäquates Wärmemanagement stellt meist eine sinnvolle Kombination aus mehreren geeigneten und wissenschaftlich belegten Verfahren dar. Dabei lassen sich verschiedene Klassen von Wärmeprotektionsverfahren voneinander abgrenzen. Interne Protektionsverfahren entfalten dabei ihre Wirkung im Körperinneren (z.B Medikamente die zu einer Steigerung der Körperkerntemperatur führen). Die Wirkung externer Protektionsverfahren kommt außerhalb des Körpers zustande und umfasst z.B die Anwendung von konvektiven, konduktiven, radiativen Wärmesystemen oder Isolationsmaterialien. Aktive Wärme- 
protektionsverfahren führen dem Körper über konvektive Luftwärmer Wärme aktiv zu, passive Wärmeprotektionsverfahren verhindern den Wärmeverlust durch beispielsweise Isolation.

Zusätzlich lässt sich unterscheiden, ob die Maßnahme präoperativ, intraoperativ oder postoperativ ihre Anwendung im Wärmemanagement findet. Auf Grundlage dieser Klassifikation erfolgt nun die genauere Betrachtung der möglichen Verfahren.

\subsubsection{Wärmeprotektionsverfahren}

\subsubsection{Präoperative Maßnahmen}

\subsection{Vorwärmung}

Ziel dieser präoperativen Maßnahmen ist es, durch die Erhöhung der Wärmemenge in der Körperperipherie den Temperaturgradienten zwischen dem Körperkern und der äußeren Körperschale zu reduzieren. Wie in Kapitel 4.3.2 erläutert, resultiert der Initiale starke Abfall der Körperkerntemperatur aus der Wärmeumverteilung. Um den treibenden Temperaturgradienten zwischen beiden Kompartimenten zu verringern und dadurch die Wärmeumverteilung nach Narkoseeinleitung gering zu halten, liegt es nah, die Körperperipherie zu erwärmen.

Durch eine 90- minütige Vorwärmung mit einer elektrischen Wärmedecke blieben nach einer dreistündigen Operation (TEP) die vorgewärmten Patienten normotherm und zeigten kein Kältezittern in der Aufwachphase (Just et al. 1993). Die nicht vorgewärmten Patienten reagierten postoperativ mit hypothermiebedingtem Kältezittern.

Die optimale Dauer der Vorwärmung mittels konvektiver Luftwärmung wird weiterhin noch kontrovers diskutiert.

In der Literatur finden sich Angaben von 30 bis 60 min (Sessler et al. 1995) bis auf 15 min (Horn et al. 2002). Durch präoperative aktive Erwärmung mithilfe eines Warmluftgebläses (BairHugger ${ }^{\mathrm{TM}}$ ) für 30min war es möglich, den Kernwärmeverlust, der in der ersten Stunde nach Narkoseeinleitung zu 81 \% durch Umverteilung verursacht wird, stark herabzusetzen (Sessler et al. 1995). Eine aktuelle Studie zeigt einen signifikanten Unterschied in der Entwicklung einer perioperativen Hypothermie sowie postoperativem Zittern zwischen einer konvektiven, präoperativen Vorwärmung und einer reinen passiven Isolation des Patienten. Jedoch zeigt sich innerhalb der Studiengruppe mit einer konvektiven präoperativen Wärmemaßnahme keine Effizienzsteigerung durch eine längere Vorwärmzeit. Selbst eine kurze Vorwärmdauer von 10 Minuten mit einem konvektiven Wärmesystem ist eine effiziente Maßnahme, um hypotherme Temperaturverläufe zu 
vermeiden. Es zeigt sich kein signifikanter Unterschied gegenüber einer 20- oder 30minütigen Vorwärmdauer (Horn et al. 2012).

Die Vorwärmung kann mit konduktiven Verfahren, konvektiven Luftgebläsen oder Infrarotstrahlern erfolgen und unmittelbar bei Ankunft des Patienten in der Wartezone begonnen werden (Sessler 2001). Jedoch ist hier der erhöhte organisatorische Aufwand der Vorwärmung zu nennen. Eine konsequente Durchführung ist nur dann möglich, wenn ein verlässlicher Operationsplan sowie die Kooperation und Zusammenarbeit von verschiedenen Abteilungen (Operationsmanagement, operative Abteilung, Krankentransport, Anästhesie, Pflegepersonal) gewährleistet ist (Bräuer et al. 2010).

Dem gegenüber steht eine extrem niedrige Hypothermierate von nur $14 \%$ bei vorgewärmten Patienten mit einer signifikanten Erhöhung der Körperkerntemperatur von $0,3 \pm 0,4^{\circ} \mathrm{C}$ durch präoperative Wärmezufuhr (Bräuer et al. 2010).

\subsection{Steigerung des Energieumsatzes}

Die präoperative Gabe von Aminosäuren gehört zu den internen Wärmeprotektionsverfahren und kann durch die Steigerung des basalen Energieumsatzes einer Hypothermie entgegenwirken. Es kommt über eine Stoffwechselsteigerung zur Erhöhung der Körperkerntemperatur. Zusätzlich wird die intraoperative Auskühlung durch die Erhöhung der Thermoregulationsschwelle verhindert. Nach der präoperativen Gabe einer Aminosäurelösung (240 kJ h${ }^{-1}, 66 \mathrm{~W}$ ) zeigte sich gegenüber einer Kontrollgruppe, die kristalloide Lösung infundiert bekam, ein signifikant geringerer zentraler Temperaturverlust (Selldén et al. 1996). Dieser Effekt ist sowohl bei Allgemein- wie auch bei Spinalanästhesien zu beobachten (Kasai 2003b).

\subsubsection{Intraoperative Maßnahmen}

\subsection{Erhöhung der Raumtemperatur}

Diese Maßnahme gehört zu den externen, passiven Protektionsverfahren. Eine Erhöhung der Operationssaaltemperatur pro $1^{\circ} \mathrm{C}$ reduziert den Wärmeverlust des unbekleideten Patienten über die Haut um ca. 10\%. Dieses Verfahren findet in der Kinderchirurgie weite Anwendung und wird als deutlich effektiv bewertet. Um jedoch einen ausgeglichenen Wärmehaushalt bei einem erwachsenen Patienten zu erzielen, müsste die Saaltemperatur über $26^{\circ} \mathrm{C}$ betragen. Diese hohen Temperaturen liegen aber weit über dem Toleranzbereich, der für Operateure als praktikabel gilt (Mora et al. 2001). 


\subsection{Wärmezufuhr durch konvektive Luftwärmer}

Die Vermeidung der Hypothermie durch Einsatz von konvektiven Luftwärmern ist ein externes, aktives Verfahren. Eine Vielzahl von Studien beweist die hohe Effektivität und flexible Einsetzbarkeit durch unterschiedliche Deckenmodelle. Die Luft wird durch ein Gebläse erwärmt und über einen Schlauch in die Patientendecke zur Hautoberfläche, wo die Wärmeabgabe größtenteils lokalisiert ist, transportiert.

Die auf ca. $39^{\circ} \mathrm{C}$ erwärmte Luft verteilt sich meist gleichmäßig in den Luftkammern und verlässt die Decke über die Unterseite zum Patientenkörper. Dabei ist die Effizienz dieses Verfahrens von der Oberflächengröße, dem möglichst hohen Wärmeaustauschkoeffizienten und dem Temperaturgradienten zwischen Körperoberfläche und Decke abhängig (vgl. Kapitel 2.5.2). Die Größe der gewärmten Fläche spielt dabei die entscheidende einflussnehmende Variable.

Kelley et al. zeigten, dass eine BairHugger ${ }^{\mathrm{TM}}$ Unterkörperdecke, gegenüber Isolationsmaterialien mit einem Infusionswärmer kombiniert, signifikant bessere Ergebnisse erzielt. In einer nachfolgenden Studie wurden drei unterschiedliche Wärmeprotektionsverfahren einer Kontrollgruppe ohne Wärmemaßnahmen gegenübergestellt (Hynson et al. 1993). Dabei zeigten sich nach drei stündiger Narkose deutliche Unterschiede in der erfassten Körperkerntemperatur (Kelley et al. 1990).

Die Patientengruppe, die mit einem konvektiven Luftgebläse intraoperativ gewärmt wurde, zeigte den geringsten Temperaturverlust $\left(-2.0^{\circ} \mathrm{C} \pm 0.5^{\circ} \mathrm{C}\right)$. Bei wasserzirkulierenden Matten konnte ein mittlerer Temperaturverlust $\left(-1,2^{\circ} \mathrm{C} \pm 0.4^{\circ} \mathrm{C}\right)$ nachgewiesen werden. Atemgasklimatisierung $\left(-2.0^{\circ} \mathrm{C} \pm 0.5^{\circ} \mathrm{C}\right)$ sowie die Kontrollgruppe $\left(-2.0^{\circ} \mathrm{C} \pm 0.7^{\circ} \mathrm{C}\right)$ verzeichnen die höchsten intraoperativen Temperaturverluste.

Patienten, die sich sehr langen plastischen Operationen unterzogen (> $400 \mathrm{Min}$.) und mit Baumwolltüchern $\left(-3,3^{\circ} \mathrm{C} \pm 0,6^{\circ} \mathrm{C}\right)$ isoliert oder mit Infusionswärmern $\left(-2,1^{\circ} \mathrm{C} \pm 1,3^{\circ} \mathrm{C}\right)$ versorgt wurden, kühlten deutlich stärker aus als Patienten, die mit konvektiven Maßnahmen gewärmten wurden $\left(-0,7^{\circ} \mathrm{C} \pm 0,7^{\circ} \mathrm{C}\right)$ (Leben et al. 1995). Insgesamt lässt sich die totale Wärmebilanz durch den Einsatz von konvektiven Luftwärmern um 40-64W ändern (Bräuer et al. 2002).

Wie in Kapitel 1.1 erwähnt, ist jedoch der alleinige intraoperative Einsatz von aktiver Wärmezufuhr nicht ausreichend. Trotz Intervention nach der Narkoseeinleitung in Form von eingeleiteten konduktiven Wärmemaßnahmen wird ein deutlicher Anteil hypothermer Patienten beschrieben. Nur die Kombination aus der präoperativen Vorwärmung mit einer direkt anschließenden intraoperativen Wärmetherapie senkt die Inzidenz von perioperativer Hypothermie signifikant. Durch die Anwendung präoperativer 
Wärmemaßnahmen konnte die Körperkerntemperatur der Patienten um $0,3^{\circ} \mathrm{C} \pm 0,4^{\circ} \mathrm{C}$ gesteigert werden.

Insgesamt wurde durch die kombinierte Anwendung aus präoperativer Vorwärmung und intraoperativer Wärmeapplikation bei $86 \%$ der Patienten eine intraoperative Hypothermie verhindert (Bräuer et al. 2010).

Trotz der durch sämtliche Studien belegten hohen Effektivität müssen die vergleichsweise hohen Kosten dieses Verfahrens genannt werden. Pro Einsatz dieses Einmalmaterials belaufen sich diese auf ca. 23 US\$ ( $\mathrm{Ng}$ et al. 2003). Konduktive Wärmeverfahren mit wieder verwendbaren Materialien könnten die Kosten senken und den konsequenten Einsatz ermöglichen.

\subsection{Wärmeprotektion durch Isolation}

Die Isolation gehört zu den externen, passiven Wärmeverfahren. Dabei können die radiativen sowie konvektiven Wärmeverluste je nach Isolationsfähigkeit des Materials sowie Größe der zu isolierenden Fläche um bis zu 30\% reduziert werden (Sessler et al. 1991). Isolation durch Baumwoll- Op-Tücher kann Wärmeverluste um $35 \% \pm 11 \%$ reduzieren (Sessler und Schroeder 1993) doch der verbleibende Wärmeverlust von $198 \mathrm{~kJ} / \mathrm{h}$ (55 W) mündet trotzdem in eine Hypothermie. Auch die Steigerung der Anzahl der OP-Tuchlagen (eine Lage gegen drei Lagen) erhöht die Effektivität nur geringfügig um $18 \% \pm 6 \%$.

Da ein großer Teil des perioperativen Wärmeverlustes über Radiation geschieht, liegt der Einsatz von reflektierenden Isolationsmaterialen nahe.

Eine reflektierende Wärmedecke zeigte keinen Vorteil gegenüber dem Einsatz von einer doppellagigen Baumwolldecke ( $\mathrm{Ng}$ et al. 2003). Beide Studiengruppen zeigten jedoch postoperativ im Aufwachraum eine signifikant geringere Körperkerntemperatur verglichen mit einer konvektiv gewärmten Gruppe.

\begin{tabular}{|l|l|}
\hline Isolationsmaterial & $\begin{array}{l}\text { Temperatur } \\
\text { Einleitung vs. Aufwachraum }\end{array}$ \\
\hline Doppellagige Baumwolldecke & $36.54^{\circ} \mathrm{C} \pm 0.047^{\circ} \mathrm{C}$ vs. $36.02^{\circ} \mathrm{C} \pm 0.06^{\circ} \mathrm{C}$ \\
\hline Reflektierende Isolationsdecke & $36.53^{\circ} \mathrm{C} \pm 0.051^{\circ} \mathrm{C}$ vs. $35.93^{\circ} \mathrm{C} \pm 0.063^{\circ} \mathrm{C}$ \\
\hline Konvektiver Luftwärmer & $36.5^{\circ} \mathrm{C} \pm 0.052^{\circ} \mathrm{C}$ vs. $36.49^{\circ} \mathrm{C} \pm 0.062^{\circ} \mathrm{C}$ \\
\hline
\end{tabular}

Tabelle 1: Effizienzbeurteilung zweier verschiedener Isolationsmaterialien und eines konvektiven Wärmesystems durch Vergleich der Körperkerntemperatur prä- und postoperativ (nach Ng et al. 2003) 
Der Einsatz von konvektiven Luftwärmegebläsen kann auch in dieser Studie als effektivste Maßnahme gewertet werden, um eine intraoperative Hypothermie zu vermeiden.

\subsection{Wärmeprotektion durch Heizmatten}

Beim Einsatz von Heizmatten handelt es sich um ein konduktives, externes und aktives Verfahren. Im Gebrauch befinden sich wasserbetriebene (Bräuer et al. 2004) sowie elektrische (Matsuzaki et al. 2003) Modelle. Bei einer identischen Größe der zu wärmenden Hautfläche am Patienten zeigt konduktive Wärmung prinzipiell eine höhere Effektivität gegenüber konvektiver Wärmung. Der Wärmeaustauchkoeffizient liegt bei der konduktiven Wärmung gegenüber der konvektiven Wärmung zwischen 30 und $300 \%$ höher (Bräuer et al. 2009). Hinsichtlich der Wirkungsorte gibt es Heizmatten, die unter den Rücken oder auf den gesamten Körper gelegt werden. Hier zeigen sich deutliche Unterschiede in der Effektivität. Der Wärmefluss erfolgt entlang dem Temperaturgefälle von der Oberfläche der Heizmatte zur Haut und in Richtung Körperkern. Trotz des hocheffektiven Wärmeaustausches über Konduktion zeigt sich die Änderung der Wärmebilanz als nicht ausreichend.

Eine unter Rücken und Gesäß platzierte Warmwassermatratze $\left(37-40{ }^{\circ} \mathrm{C}\right)$ wurde als kaum wirksam beschrieben (Tollofsrud al. 1984). Ursächlich hierfür ist der zu geringe Temperaturgradient zwischen der Heizmatte und der Auflagefläche. Durch das Eigengewicht des Patienten kommt es zu einer Kompression des aufliegenden Gewebes, der innere Wärmefluss wird weiter eingeschränkt (English et al. 1990). Der effektive Nutzen einer konduktiven Wärmung ist demnach nur gegeben, wenn diese an der nicht aufliegenden Körperoberfläche angewendet wird (Negishi et al. 2003).

Der Einsatz von konduktiven Wärmesystemen, die auf den gesamten Körper gelegt werden, zeigt eine deutlich höhere Effektivität. Auch hier korreliert der erzielte Wärmetransfer mit der Größe der Kontaktoberfläche (Perez-Protto et al. 2010) oder durch eine Optimierung des Kontaktes zwischen Wärmeaustauscher und Hautoberfläche am Patienten (English und Hemmerling 2008).

So wie bei allen aktiven Wärmeverfahren besteht auch durch die konduktive Wärmung prinzipiell das Risiko für Verbrennungen der Hautoberfläche (Acikel et al. 2002). Insbesondere sind Haurareale betroffen, in denen die Durchblutung kompressionsbedingt eingeschränkt wird (Weyland und Bräuer 2014). 


\subsection{Wärmeprotektion durch Infusionswärmer}

Die Infusionserwärmung ist ein internes, aktives Verfahren in der Vermeidung von Hypothermie. Der gezielte Einsatz von leistungsfähigen Infusionswärmern bei der Zufuhr von großen, ungewärmten Flüssigkeitsmengen (>500-1000 $\mathrm{ml} \mathrm{h}^{-1}$ ) wie Blutprodukte oder Infusionslösungen können einen Abfall der mittleren Körperkerntemperatur minimieren (Sessler 2001). Die Applikation von kalten Infusionen $\left(16^{\circ} \mathrm{C}-20^{\circ} \mathrm{C}\right)$ mit einer hohen Flussrate von sechs bis acht Litern kann die Körperkerntemperatur um bis zu $2^{\circ} \mathrm{C}$ vermindern (Sladen 1991). Die Gabe von einem Liter kristalloider Infusionslösung mit Raumtemperatur kann die Körperkerntemperatur eines Patienten um ca. $0,25^{\circ} \mathrm{C}$ senken (Sessler 1994). Auf den Markt existieren verschiedene Infusionserwärmungsmodelle mit unterschiedlichem Aufbau und Wirkprinzipien. Beim Gegenstromwärmeverfahren (z.B. Hotline $^{\mathrm{TM}}$ ) kommt es zu einem Heizwasserstrom entgegen dem Lauf der Infusionslösung. Hierdurch entsteht unabhängig von der Flussrate keine erneute Auskühlung im Infusionssystem zum Patienten. Die Flüssigkeiten werden konstant auf Temperaturen zwischen $37-42^{\circ} \mathrm{C}$ erwärmt. Ein anderes Verfahren ist die Kontakterwärmung (z.B. Astotherm $^{\mathrm{TM}}$ ). Ein Teil des Infusionsschlauches wird dabei um eine Heizspule gewickelt und die vorbeifließende Lösung wird auf $39-42^{\circ} \mathrm{C}$ erwärmt. Nachteilig ist dabei der erneute Wärmeverlust auf der Strecke zum Patienten. Der Wärmeverlust zwischen Wärmeeinheit und Patienten ist bei einer Konstellation aus niedriger Flussrate der Infusion, einer geringen Umgebungstemperatur sowie Einsatz eines langen Infusionsschlauches am höchsten (Schmidt et al. 1996).

Der Einsatz von Infusionswärmern zeigt sich beschränkt auf die Vermeidung von Wärmeverlusten. Es wird keine relevante Wärmezufuhr zum Patienten erreichen, die eine Hypothermie vermeiden würde. Bei Flüssigkeitsumsätzen unter $500 \mathrm{ml} / \mathrm{h}$ zeigen sich dadurch sämtliche Systeme als ineffizient (Sessler 2001).

\subsection{Wärmeprotektion durch Ösophaguswärmer}

Ein aktives, konduktives und semiinvasives Wärmeprotektionsverfahren stellt der Ösophaguswärmer dar. Dabei ist eine exakte Platzierung an einer zentralen, gut vaskularisierten Stelle notwendig, um den Patienten durch zirkulierendes erhitztes Wasser $\left(37^{\circ} \mathrm{C}-42^{\circ} \mathrm{C}\right) \mathrm{zu}$ wärmen. Ein signifikanter Effekt konnte jedoch bei Patienten, die sich einer TEP unterzogen und mit einem Ösophaguswärmer versorgt wurden, gegenüber den Kontrollpatienten mit herkömmlichen Wärmeprotektionsmaßnahmen nicht nachgewiesen werden (Kulkarni et al. 1993). Der Wärmefluß ist durch den geringen Temperaturgradienten zwischen der Schleimhaut und der zusätzlich kleinen Kontaktfläche limitiert. 


\subsection{Wärmeprotektion durch Atemgaserwärmer}

Die Atemgasklimatisierung gehört zu den externen Wärmeprotektionsmaßnahmen. Dabei kann die Atemgaserwärmung durch einen aktiven Atemgasbefeuchter oder passiv in Form von einem „Heat and Moisture Exchanger" erfolgen.

Der Wärmeverlust bei normaler Atmung beträgt 33,5 kJ*h-1 (9,3 W). Durch die Atmung trockener Luft mit einem Wassergehalt $<1 \%$ kann sich der Verlust auf $43.1 \mathrm{~kJ}^{-1} \mathrm{~h}^{-1}(12 \mathrm{~W})$ steigern (Rathgeber et al. 1996).

Wärme- und Feuchtigkeitsaustauscher (HME-Filter) bei Beatmung können den Wärmeverlust auf $5 \mathrm{~kJ}^{2} \mathrm{~h}^{-1}(1,4 \mathrm{~W})$ reduzieren (Rathgeber et al. 1996). Dadurch ist es möglich, den pulmonalbedingten Abstrom von Wärme durch die Verdunstung von Feuchtigkeit zu reduzieren, eine relevante Wärmezufuhr ist jedoch nicht möglich. Die Atemgaskonditionierung erlangt keine klinische Relevanz in der intraoperativen Hypothermieprävention.

\subsubsection{Postoperative Maßnahmen}

\subsection{Medikamentöse Therapie}

In der medikamentösen Therapie von postoperativem Muskelzittern, das zu einem erhöhten Sauerstoffverbrauch führt, zeigen sich Clonidin (0,075-0,15 mg i.v.) und Pethidin (25-50mg i.v) als besonders wirksam. Aufgrund der hohen Inzidenz an kardialen Zwischenfällen in der postoperativen Phase sollte besonders bei hypothermen Patienten mit koronarem Risiko ein erhöhter Sauerstoffbedarf durch Muskelzittern unterdrückt werden.

Clonidin und Pethidin entfalten ihre Wirksamkeit in der Verschiebung der Thermoregulationsschwelle für Vasokonstriktion und Muskelzittern nach unten (De Witte und Sessler 2002). Der pharmakologischen Therapie sind jedoch Grenzen gesetzt. Der Opiateinsatz (Pethidin) wird durch die induzierte Atemdepression limitiert. Clonidin bewirkt in entsprechender Dosierung eine Hypotonie.

\subsection{Aktive Wiedererwärmung}

Zur Verminderung und Prophylaxe von hypothermiebedingtem Muskelzittern und Belastung vom Herz-Kreislaufsystem finden postoperative Wärmetherapien ihre Anwendung. Trotz der Möglichkeit der postoperativen Wiedererwärmung sollte das Hauptaugenmerk stets auf der prä- und intraoperativen Wärmeprotektion liegen.

Durch den Einsatz konvektiver Luftwärmer (Lennon et al. 1990) oder Infrarotstrahler (Weyland et al. 1994) konnte die Inzidenz von Kältezittern signifikant gesenkt werden. Im Vergleich zwischen konvektiver Luftwärmung, Infrarotstrahler und konventioneller Isolation mittels Baumwolldecke zeigten sich keine signifikanten Unterschiede in der 
Schnelligkeit der Wiedererwärmung zwischen beiden Therapiegruppen und der Kontrollgruppe (Weyland et al. 1994). Deutliche Abweichungen ergaben sich für die Medianwerte des maximalen, während der Untersuchungsperiode gemessenen Sauerstoffverbrauchs. Dabei zeigten die Kontrollpatienten einen signifikant höheren Sauerstoffspitzenverbrauch von $5,9 \mathrm{ml} / \mathrm{kg} / \mathrm{min}$ gegenüber den radiativ $\left(4,39 \mathrm{ml}^{*} \mathrm{~kg}^{-1} * \mathrm{~min}^{-1}\right)$ und konvektiv $\left(4,3 \mathrm{ml} * \mathrm{~kg}^{-1} * \mathrm{~min}^{-1}\right)$ versorgten Therapiegruppen.

\subsubsection{Risiken perioperativer Wärmeprotektion und Wärmezufuhr}

Zu den drei relevanten Risiken in der Anwendung von aktiven Wärmeprotektionstherapien zählen thermische Verbrennungen, das Risiko von erhöhten Keimzahlen im OP- Gebiet mit der Folge von vermehrten Wundinfektionen sowie die Luftblasenbildung bei Infusionswärmern.

\subsubsection{Thermische Verbrennungen}

Jede aktive Wärmezufuhr birgt das Risiko für Verbrennungen. Insgesamt lassen sich jedoch solche Zwischenfälle aufgrund strenger Normen (IEC 106-2-35, ASTM F 2196-02) als selten bewerten. Crino und Nagel berichteten von zwei Patienten, die intraoperativ durch die Anwendung von Warmwassermatratzen Verbrennungen zweiten- sowie dritten Grades erlitten. Beide Patienten waren älter als 60 Jahre, litten an diabetischer Mikrobzw. Makroangiopathie und die Operationsdauer betrug länger als 6h. Die Verbrennungen ließen sich an Körperstellen nachweisen, wo das Gewebe durch das Körpergewicht zwischen Auflagefläche und Knochen komprimiert war (Crino und Nagel 1968).

Eine 67-jährige Patientin zeigte nach einer 6,5 h Lebertransplantation Verbrennungen zweiten Grades durch den intraoperativen Gebrauch einer warmwasserbetriebenen ThermoWrap ${ }^{\mathrm{TM}}$ Decke. In Assoziation mit der Vorerkrankung zeigten sich bei der Patientin bekannte Risikofaktoren, die das Auftreten thermaler Verbrennungen begünstigen. Hierzu zählen ein schlechter Ernährungszustand, geringe Muskelmasse, ein geringes Serumalbumin, hohes Alter sowie lange Operationsdauer (Gali et al. 2003).

Auch Verbrennungen durch konvektive Luftwärmer werden in Fallberichten geschildert (Truell et al. 2000). Ursächlich hierfür werden vier Faktoren beschrieben:

1.) Direkter Kontakt der Gebläsedüse mit der Haut

2.) Einsatz des konvektiven Luftgebläses ohne Decke

3.) Einsatz des konvektiven Luftgebläses mit einer nicht- kompatiblen Decke (anderer Hersteller)

4.) Hohe Wärmezufuhr an nicht- oder schlecht durchbluteten Hautarealen 


\subsubsection{Risiko erhöhter Keimzahlen}

Im Zusammenhang mit dem Einsatz von konvektiven Luftwärmern wird häufig das Thema der erhöhten Keimbelastung mit Verschleppung ins Operationsgebiet durch den Luftstrom diskutiert. Dieser Theorie liegt zu Grunde, dass Gebläse die zu erwärmende Luft aus Bodennähe entnehmen.

Das Prinzip des laminaren Reinluftstromes kann nicht mehr realisiert werden. Mittels der Decke sollen so vermehrt Keime in das Operationsgebiet gelangen. In einer Studie mit

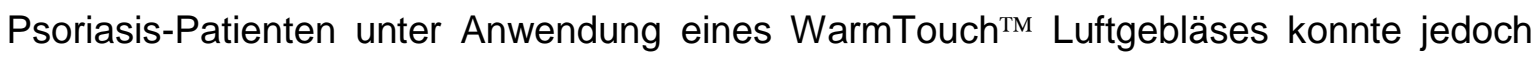
keine erhöhte Keimbelastung nachgewiesen werden (Sharp et al. 2002).

Auch der Einsatz des konvektiven Wärmesystems Bair Hugger ${ }^{\mathrm{TM}}$ bei 16 Patienten, die sich einem großen abdominalchirurgischen Eingriff unterzogen, zeigte nachweislich keine erhöhtes Risiko der Verschleppung von Keimen der natürlichen Hautflora. Ebenfalls wurde keine erhöhte postoperative Infektrate durch den Einsatz von konvektiven Luftwärmegebläsen beobachtet (Huang et al. 2003). Basis dieser Ergebnisse ist jedoch die korrekte Handhabung auf Grundlage der Herstellerinformation. Die Mehrfachverwendung von Wärmedecken und wiederholte Kontamination mit dem Wundgebiet zeigt eine deutlich erhöhte Keimdichte mit Koagulase- negativen Staphylokokken und gesteigerten postoperativen Wundinfektionsraten (Sigg et al. 1999).

\subsubsection{Luftblasenbildung bei Infusionswärmern}

Beim intraoperativen Gebrauch von Infusionswärmern kann es abhängig von der Flussgeschwindigkeit zu einer Gasfreisetzung von 1-3 $\mathrm{ml}$ Gas pro Liter kommen (Woon und Talke 1999). Bei der Applikation der erwärmten Infusionslösung besteht insbesondere bei Patienten mit einem offenen Foramen ovale ein erhöhtes arterielles Embolierisiko. 


\section{Material und Methoden}

\subsection{Ethikkomission}

Untersucht wurden 90 Patienten im Rahmen einer prospektiven, multizentrischen, randomisiert kontrollierten Studie an drei verschiedenen Zentren in drei europäischen Ländern. Beteiligt Studienorte waren das Universitätsklinikum Göttingen, Klinik für Anästhesiologie, die Abteilung Anästhesie des Universitätsklinikum Gent, Belgien sowie die Abteilung Anästhesie der Policlinica Gipuzkoa, San Sebastian, Spanien.

Die vorliegenden Untersuchungen wurden am 14.09.2011 durch die Ethikkomission der Universität Göttingen unter der Antragsnummer 11/4/11 genehmigt. Weitere Zustimmungen erfolgten durch die regionalen Ethikkommissionen. Registriert wurde die Studie unter ClinicalTrials.gov NCT01502163.

\subsection{Patienten}

Am Universitätsklinikum Göttingen wurden 36 Patienten in die Studie eingeschlossen. Im Vorfeld wurden die möglichen Studienpatienten am Tag ihres Prämedikationsgespräches nach Einsicht in den vorläufigen Operationsplan der jeweiligen Abteilung identifiziert. Einund Ausschlusskriterien wurden überprüft. Die Einwilligung erfolgte nach mündlicher und schriftlicher Aufklärung.

Anschließend erfolgte die computergestützte Randomisierung über eine Studienhomepage mit randomisierter Zuordnung der Patienten zu einer der drei möglichen Studiengruppen A (Vergleichsgruppe), B (passive Vorwärmung/lsolation) oder C (aktive Vorwärmung).

\subsubsection{Einschlusskriterien}

Eingeschlossen wurden Patienten beiderlei Geschlechts zwischen 18 und 70 Jahre, einem Body Mass Index (BMI) zwischen 20 und $30 \mathrm{~kg} \mathrm{~m}^{-2}$ sowie ASA-Klasse I-III. Alle Patienten unterzogen sich einem elektiven, operativen Eingriff in Vollnarkose mit einer angesetzten Operationsdauer von 30-180 Min.

\subsubsection{Ausschlusskriterien}

Ausgeschlossen wurden Patienten mit einer präoperativ gemessenen Körperkerntemperatur von mehr als $38^{\circ} \mathrm{C}$ oder weniger als $35^{\circ} \mathrm{C}$, anamnestischen Schilddrüsenerkrankungen oder bekannter Schwangerschaft. Ebenfalls stellte ein rückenmarksnahes Anästhesieverfahren ein Ausschlusskriterium dar. 


\subsection{Narkoseverfahren}

Als Prämedikation erhielten die Patienten am Morgen der Operation 7,5 mg Midazolam per os. Die Narkoseeinleitung erfolgte mit Propofol, Sufentanil oder Remifentanil. Für die endotracheale Intubation erfolgte die Relaxierung durch Rocuronium, Mivacurium oder Cisatracurium. Die Narkoseaufrechterhaltung erfolgte balanciert mit Sevofluran oder total intravenös mit Sufentanil, Remifentanil sowie Propofol.

\subsection{Intraoperative Wärmung}

Patienten jeder Studiengruppe wurden intraoperativ aktiv durch ein konvektives Wärmesystem mit einer Ober- oder Unterkörperdecke (Thermoflect ${ }^{\mathrm{TM}}$ / Mistral Air тм, TSCI Amersfoort, Netherlands) je nach Operationszugang durchgehend gewärmt.

\subsection{Infusionswärmung}

Alle intraoperativ verabreichten Flüssigkeiten wurden über einen Infusionswärmer auf $37^{\circ} \mathrm{C}$ erwärmt.

\subsection{Verwendete Verfahren zur Wärmekonservierung}

Für die konvektive Wärmezufuhr wurde das Gebläse Mistral Air ${ }^{\mathrm{TM}}$ Plus (Firma TSCI, Amersfoort, Niederlande) verwendet.

Das Gerät mit den Maßen $276 \mathrm{~mm}$ x $385 \mathrm{~mm}$ x $239 \mathrm{~mm}$ wiegt $6 \mathrm{~kg}$ und ist auf einem Rollständer fixiert. Das Gerät verfügt über vier Temperaturstufen $\left(32^{\circ} \mathrm{C}, 38^{\circ} \mathrm{C}, 43^{\circ} \mathrm{C}\right.$ oder Umgebungstemperatur) sowie einen eingebauten Luftfilter (HEPA, 0,3 $\mu \mathrm{m}, 99,99 \%$ ). Die erwärmte Luft wird über einen 1,8 Meter langen Schlauch zum Patienten geleitet.

Für die passive Vorwärmung/Isolation sowie aktive Vorwärmung durch konvektive Wärmezufuhr diente der Mistral-Air Premium Warming Suit ${ }^{\mathrm{TM}}$ der Firma TSCI, Amersfoort, NL. Diese neue Form von Wärmedecke ist der Funktion des Krankenhausleibchens nachempfunden und wird in vier verschiedenen Größen hergestellt. Zwei Armeinstiege ermöglichen eine hohe Passgenauigkeit im Oberkörperbereich, der Wärmeanzug kann am Rücken geschlossen werden. Durch ein Druckknopfsystem auf Nabelhöhe kann je nach benötigtem Operationszugang der Wärmeanzug getrennt werden. Die Wärmedecken verfügen über eine Reflexions-Außenschicht, die die Wärmekapazität erhöhen und die Körperwärme des Patienten reflektieren soll. Zwei Gebläse-Anschlüsse im Ober- sowie Unterkörperbereich ermöglichen das Einleiten von erwärmter Luft in die Decke. 


\subsection{Untersuchungsgruppen}

\subsubsection{Vergleichsgruppe (Gruppe A)}

Patienten dieser Gruppe wurden nach dem Standardverfahren versorgt. Sie erhielten auf der Station Antithrombosestrümpfe, ein Baumwollleibchen und wurden mit einer Baumwollsteppdecke bedeckt. Nach Narkoseeinleitung wurde je nach chirurgischem Zugang das Operationsgebiet mit chirurgischen Papiertüchern bedeckt. Alle Patienten wurden intraoperativ durchgehend mit einer Ober- oder Unterkörperdecke (Thermoflect ${ }^{\mathrm{TM}}$ $\mathrm{TSCl}$, Amersfoort, NL) und konvektiver Wärmezufuhr durch ein Luftgebläse (Mistral Air ${ }^{\mathrm{TM}}$, $\mathrm{TSCl}$, Amersfoort, NL) auf höchster Temperaturstufe $\left(43^{\circ} \mathrm{C}\right)$ gewärmt. Alle intraoperativ verabreichten Infusionen wurden durch einen Infusionswärmer auf $37^{\circ} \mathrm{C}$ erwärmt.

\subsubsection{Passive Vorwärmung/ Isolationsgruppe (Gruppe B)}

Studiengruppe B wurde 30-60 Min. vor Transfer in die Wartezone einer passiven Vorwärmung/lsolation -beginnend auf Station- mithilfe des neuen Wärmeanzuges (MistralAir Premium Warming Suit TM TSCl, Amersfoort, NL) unterzogen. Antithrombose-Strümpfe wurden belassen. Nach Narkoseeinleitung erfolgte die Trennung von Ober- und Unterkörperteil je nach Operationszugang, und es fand eine fortgeführte durchgehende intraoperative konvektive Wärmung (Mistral Air ${ }^{\mathrm{T} M}$ ) statt. Das Gerät wurde auf Maximalleistung bei einer Temperatur von $43^{\circ} \mathrm{C}$ gestellt. Alle intraoperativ verabreichten Infusionen wurden durch einen Infusionswärmer auf $37^{\circ} \mathrm{C}$ erwärmt.

\subsubsection{Aktive Vorwärmung (Gruppe C)}

Studiengruppe $C$ wurde 30-60 Min. vor Transfer in die Wartezone einer aktiven Vorwärmung -beginnend auf Station- mithilfe des neuen Wärmeanzuges (Mistral-Air Premium Warming Suit ${ }^{\mathrm{TM}} \mathrm{TSCl}$, Amersfoort, NL) mit zusätzlichem Anschluss eines Warmluftgebläses (Mistral Air ${ }^{\mathrm{TM}}$ ) unterzogen. Unter Berücksichtigung der individuellen Wärmetoleranz des Patienten wurde, wenn möglich, die höchste Temperatureinstellung $\left(43^{\circ} \mathrm{C}\right)$ gewählt. Nach Narkoseeinleitung erfolgte auch hier die Trennung von Ober- und Unterkörperteil je nach Operationszugang, und es fand eine fortgeführte durchgehende intraoperative konvektive Wärmung auf höchster Temperatureinstellung statt. Alle intraoperativ verabreichten Infusionen wurden durch einen Infusionswärmer auf $37^{\circ} \mathrm{C}$ erwärmt. 


\subsection{Messtechnik und Zeitintervalle}

\subsubsection{Prä-und postoperative Temperaturmessung}

Die präoperative Temperaturmessung erfolgte standardmäßig sublingual zu drei festgelegten Zeitpunkten mit einem elektronischen Thermometer (Geratherm rapid, Geratherm Medical AG, Geschweda, Germany).

Definierte Messpunkte waren auf der Station (alle Studiengruppen), vor der Vorwärmung (Studiengruppe B und C) sowie vor der Einleitung (alle Studiengruppen). Nach Ankunft im Aufwachraum wurden die postoperativen Temperaturen im 10-minütigen Intervall erneut sublingual mit einem elektronischen Thermometer erfasst. Die richtige Platzierung der Messsonde im Mundboden sowie ein durchgehender Mundschluss wurden bei jeder Messung sichergestellt.

\subsubsection{Temperaturmessung intraoperativ}

Die intraoperative Temperaturmessung erfolgte durch die Platzierung einer Temperatursonde (Temprecise \#4-1512-A, Arizant International Corp. Eden Prairie, MN, USA) im distalen Ösophagus zwischen 30 und $35 \mathrm{~cm}$ ab Zahnreihe. Die erste Temperaturerfassung erfolgte 5 Min. nach Einleitung, im weiteren Operationsverlauf im 15-minütigen Messintervall bis zur Narkoseausleitung.

\subsubsection{Temperaturmessung Raumtemperatur}

Die Temperatur im Operationssaal wurde durchgehend gemessen und lag zwischen 19$22^{\circ} \mathrm{C}$.

\subsubsection{Erfassung des subjektiven Wärmeempfindens und Aldrete Skala}

Das subjektive Wärmeempfinden wurde mit Hilfe einer visuellen Analogskala mit den Zahlenwerten von 1 (stärkstes Unbehagen) bis 10 (maximales Wohlbefinden) vom Patienten bewertet. Definierte Erfassungspunkte waren vor der Vorwärmung, vor der Einleitung sowie nach Ankunft im Aufwachraum. Weiterhin wurde im Aufwachraum im 10minütigen Zeitintervall das Auftreten von postoperativem Kältezittern sowie der Punktewert des Patienten in einer modifizierten Aldrete-Bewertungsskala (Aldrete und Kroulik 1970) bestimmt. Als Bewertungskriterien wurden die Aktivität, die Atmung, der Kreislauf (systolischer Blutdruck), das Bewusstsein sowie die Hautfarbe herangezogen. Pro Kriterium wurde ein Punktewert zwischen 0 (Minimum) und 2 (Maximum) bestimmt. Die Höchstpunktzahl liegt bei 10 zu erreichenden Punkten (Aldrete et al. 1970). 


\subsubsection{Erfassung der Dauer einzelner Maßnahmen}

Protokolliert wurde die Dauer der Vorwärmung, der zeitliche Abstand zwischen Vorwärmung und Einleitung des Patienten sowie die Gesamtdauer der Narkose und Operation.

\subsection{Statistische Auswertung}

Zur Kalkulation der angestrebten Rekrutierungszahl erfolgte auf historischen Daten basiert eine Power Analyse. Als klinisch relevanter Unterschied in der zentralen Körpertemperatur zum OP-Ende wurden $0,5{ }^{\circ} \mathrm{C}$ definiert. Hiernach wurde eine Studienpopulation von 23 Patienten in jeder Gruppe kalkuliert $(\alpha=0,016 ; \beta=0,2)$. Um potentielle Ausschlüsse von Patienten durch Protokollverletzungen zu kompensieren wurde das Rekrutierungsziel auf 30 Patienten pro Gruppe erhöht.

Der Vergleich nominaler Daten erfolgte mittels Fisher's exact-Test. Ein Test auf Normalverteilung parametrischer Daten erfolgte vorher mittels Kolmogorov-Smirnov-Test. Normalverteilte Daten wurden mittels Students t-Test verglichen, nicht normalverteilte Daten wurden mittels Mann-Whitney-U-Test analysiert.

Zeitabhängige Veränderungen der Körperkerntemperatur wurde mittels einer Analyse der Varianzen für Messwiederholungen (ANOVA) und dem Post-hoc-Scheffé's-Test ausgewertet. Die Darstellung der Ergebnisse erfolgt als Mittelwert \pm Standardabweichung oder Median und Interquartile. Als Signifikanzgrenze wurde ein p von 0,05 definiert.

Alle statistischen Berechnungen erfolgten mit STATISTICA für Windows 10.0 (StatSoft Inc., Tulsa, OK, USA). 


\section{Ergebnisse}

\subsection{Patienten}

Insgesamt wurden an drei verschiedenen Zentren 90 Patienten für die Studie rekrutiert. Aufgrund von Protokollverletzungen wurden insgesamt 22 Patienten aus der Analyse ausgeschlossen. 15 Patienten mussten vor der Auswertung aufgrund eines zu hohen BMI (>30) ausgeschlossen werden. In 6 Fällen betrug die Operationsdauer $<30$ Min. Eine Operation wurde abgesagt. Ein Patient erfüllte nicht das vorgegebene Kriterium Alter $<75$ Jahre.

Einschluss in die Studie fanden die Daten von 68 randomisierten Patienten, die den drei Untersuchungsgruppen A (Vergleichsgruppe), B (Isolation) und C (aktive Vorwärmung) zugeteilt waren (Abb. 5).

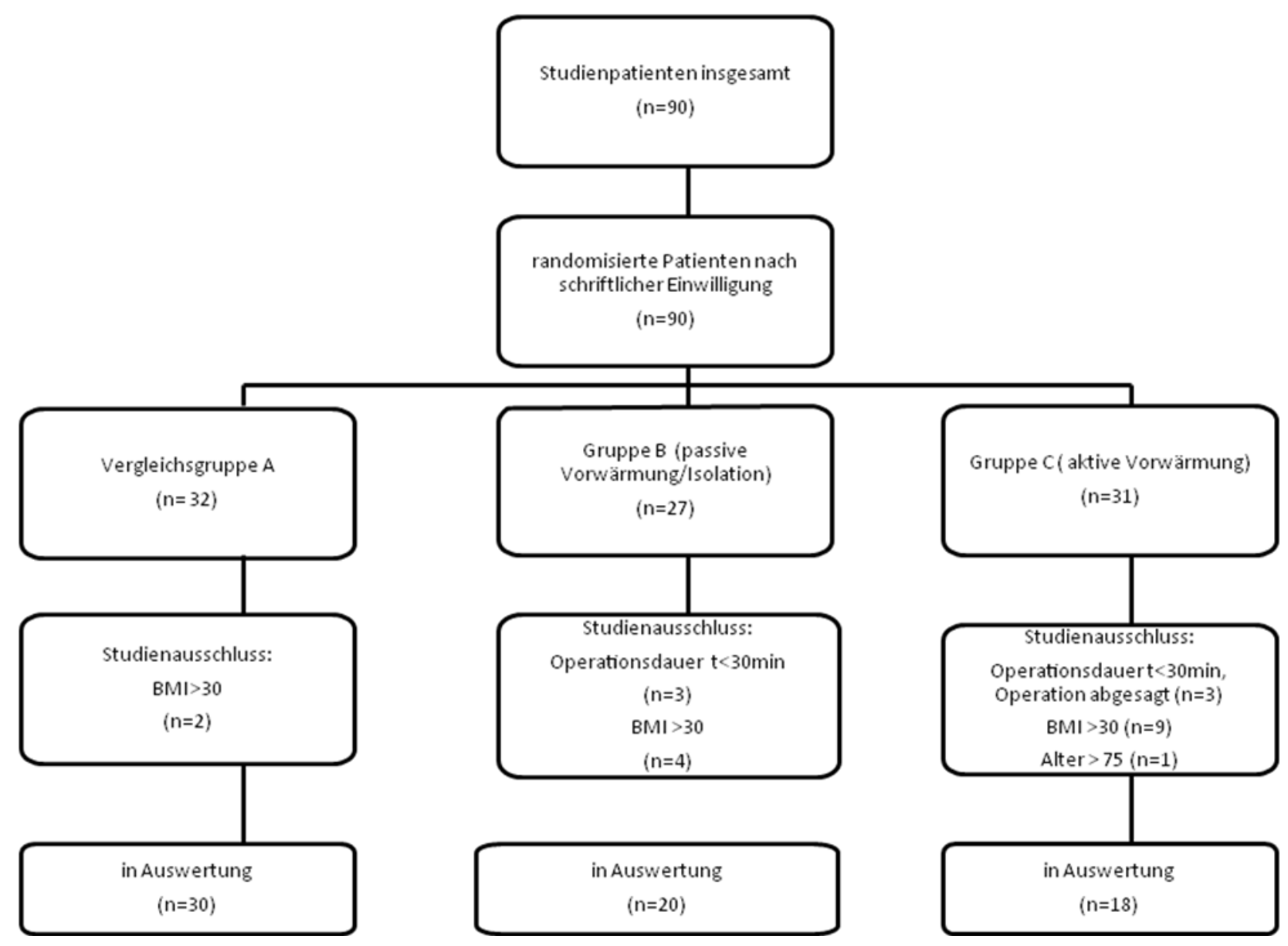

Abbildung 5: Flussdiagramm der Studie 
Nach Randomisierung bestand kein signifikanter Unterschied in Bezug auf das Alter, die Größe, das Gewicht, den BMI sowie die ASA-Klassifikation zwischen den drei Untersuchungsgruppen. Bei der Geschlechtsverteilung zeigt sich in den verschiedenen Studiengruppen nach Randomisierung ein Ungleichgewicht zwischen männlichen und weiblichen Probanden (Tab. 2).

\subsection{Operationsgebiete}

Die Verteilung der operativen Eingriffsgebiete zeigte sich nach Randomisierung der Patienten in den verschiedenen Untersuchungsgruppen als ausgeglichen. In allen drei Studiengruppen waren Eingriffe im Abominalbereich am häufigsten, gefolgt von Operationen im Bereich der unteren und oberen Extremitäten (Tab.2).

\subsection{Perioperative Variablen}

Die präoperativ auf Station ermittelte, mittlere Körperkerntemperatur zeigte in allen Studiengruppen vergleichbare Ausgangswerte. Ebenfalls zeigten sich keine signifikanten Unterschiede in der Auswertung des subjektiven präoperativen Wärmeempfindens auf Station

Die mittlere Temperatur im Operationssaal betrug in Studiengruppe $A 20,5^{\circ} \mathrm{C} \pm 1,3{ }^{\circ} \mathrm{C}$, in Studiengruppe $B 20,5^{\circ} \mathrm{C} \pm 1,1^{\circ} \mathrm{C}$, Studiengruppe $\mathrm{C} 20,6^{\circ} \mathrm{C} \pm 0,9^{\circ} \mathrm{C}$.

Die Dauer der präoperativen Isolation (Gruppe B) bzw. aktiven Vorwärmung (Gruppe C) lag in Studiengruppe B bei $35 \pm 14$, in Studiengruppe C $44 \pm 13$ Min. Die Gesamtzeit der Anästhesie betrug im Mittel zwischen 81 und 99 Min. Die Operationsdauer lag durchschnittlich zwischen 60 und 69 Min. und zeigte keinen signifikanten Unterschied innerhalb der drei Studiengruppen (Tab. 2). 
Gruppe A

(Vergleichsgruppe)

$(n=30)$

$52 \pm 15$

$22 / 8$

$172 \pm 9$

$75 \pm 11$

$25 \pm 2$

$15 / 11 / 4$
Gruppe B

(passive Vorwärmung)

$(n=20)$

$45 \pm 17$

$18 / 2$

$179 \pm 7$

$80 \pm 9$

$25 \pm 2$

$15 / 3 / 2$

Gruppe C

(aktive Vorwärmung)

$(n=18)$

$43 \pm 16$

$13 / 5$

(männlich/weiblich)

BMI $\left(\mathrm{kg} / \mathrm{m}^{2}\right)$

ASA- Klasse I/II/III

Operationsgebiet $n(\%)$

Bauch

$17[56,7]$

11 [55]

9 [50]

untere Extremität

$8[26,7]$

7 [35]

$5[27,8]$

obere Extremität

$2[6,7]$

1 [5]

$2[11,1]$

Brust

3 [10]

1 [5]

$1[5,6]$

Kopf und Hals

0 [0]

$36,2 \pm 0,5$

$36,1 \pm 0,4$

$36,1 \pm 0,5$

Station $\left({ }^{\circ} \mathrm{C}\right)$

subjektives

$6,9 \pm 1,7$

$6,3 \pm 2,3$

$6,3 \pm 2,1$

Wärmeempfinden

Station (1-10)

Saaltemperatur im OP $\left({ }^{\circ} \mathrm{C}\right)$

$20,5 \pm 1,3$

$20,5 \pm 1,1$

$20,6 \pm 0,9$

Zeitdauer der Vorwärmung

(Min.)

Zeitdauer zwischen Beginn

Vorwärmung /Einleitung

(Min.)

Zeitdauer der Anästhesie

(Min.)

Zeitdauer Operation (Min.)

$$
35 \pm 14
$$$$
44 \pm 13
$$

$$
13 \pm 5
$$

$20 \pm 12$

$81 \pm 34$

$97 \pm 38$

$99 \pm 36$

Tabelle 2: Zusammenstellung anthropometrischer Daten und perioperativer Variablen, Angaben in Mittelwerten \pm Standardabweichung oder Patientenzahlen 


\subsection{Auswertung}

\subsubsection{Verlauf der präoperativen Körperkerntemperaturen vor Narkoseeinleitung}

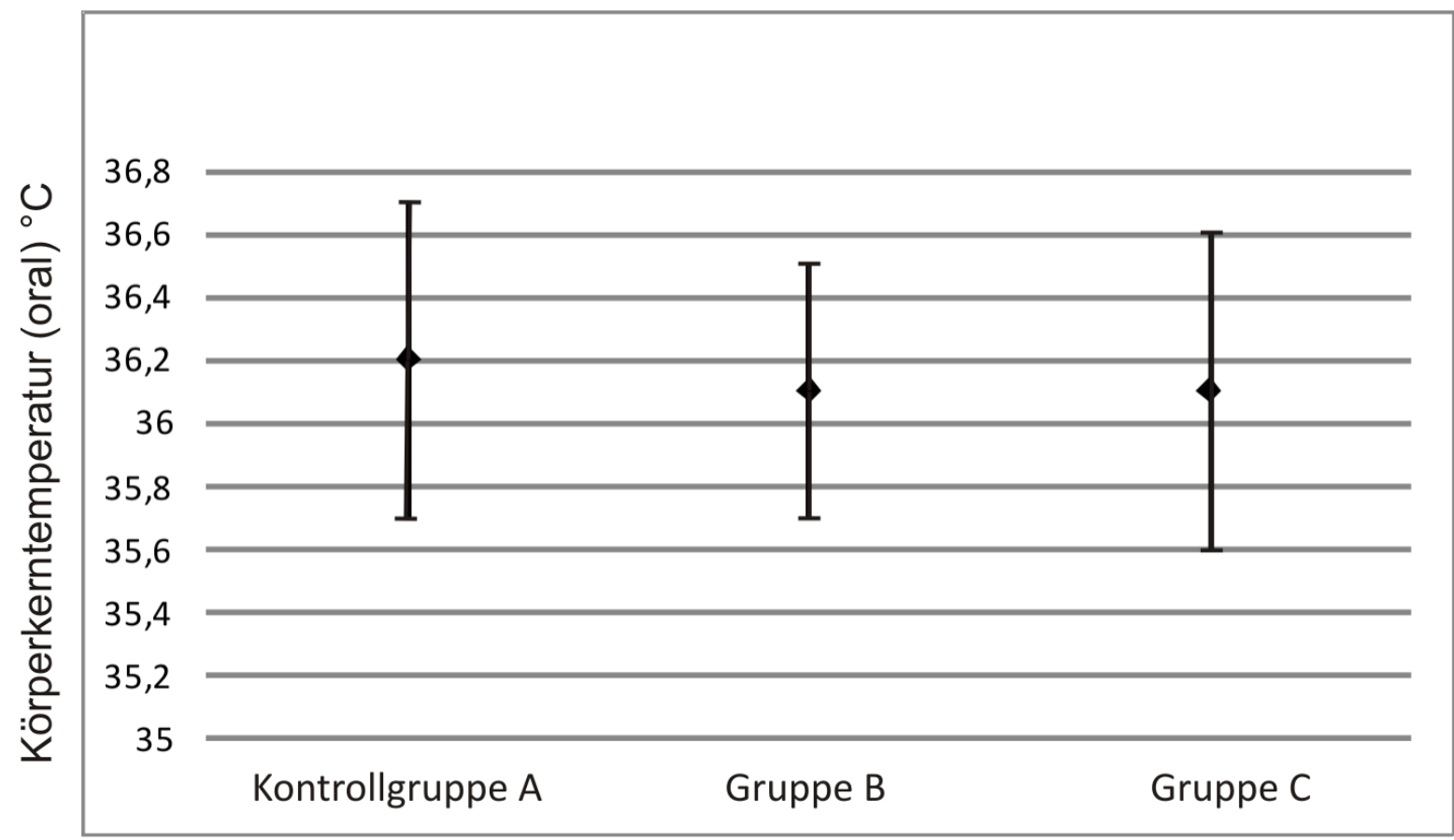

Abbildung 6: Körperkerntemperatur (oral) der verschiedenen Studiengruppe auf Station, Angabe in Mittelwerten \pm Standardabweichung

In Abbildung 6 ist die auf der Station vor der Vorwärmung gemessene, mittlere Körperkerntemperatur innerhalb der jeweiligen Studiengruppe aufgetragen. Es zeigen sich keine signifikanten Unterschiede in den Ausgangstemperaturen auf Station. Die Körperkerntemperatur der Vergleichsgruppe $A$ lag mit $36,2^{\circ} \mathrm{C} \pm 0,5^{\circ} \mathrm{C}$ geringfügig höher als bei Studiengruppe $B\left(36,1^{\circ} \mathrm{C} \pm 0,4^{\circ} \mathrm{C}\right)$ und Studiengruppe $\mathrm{C}\left(36,1^{\circ} \mathrm{C} \pm 0,5^{\circ} \mathrm{C}\right)$. 


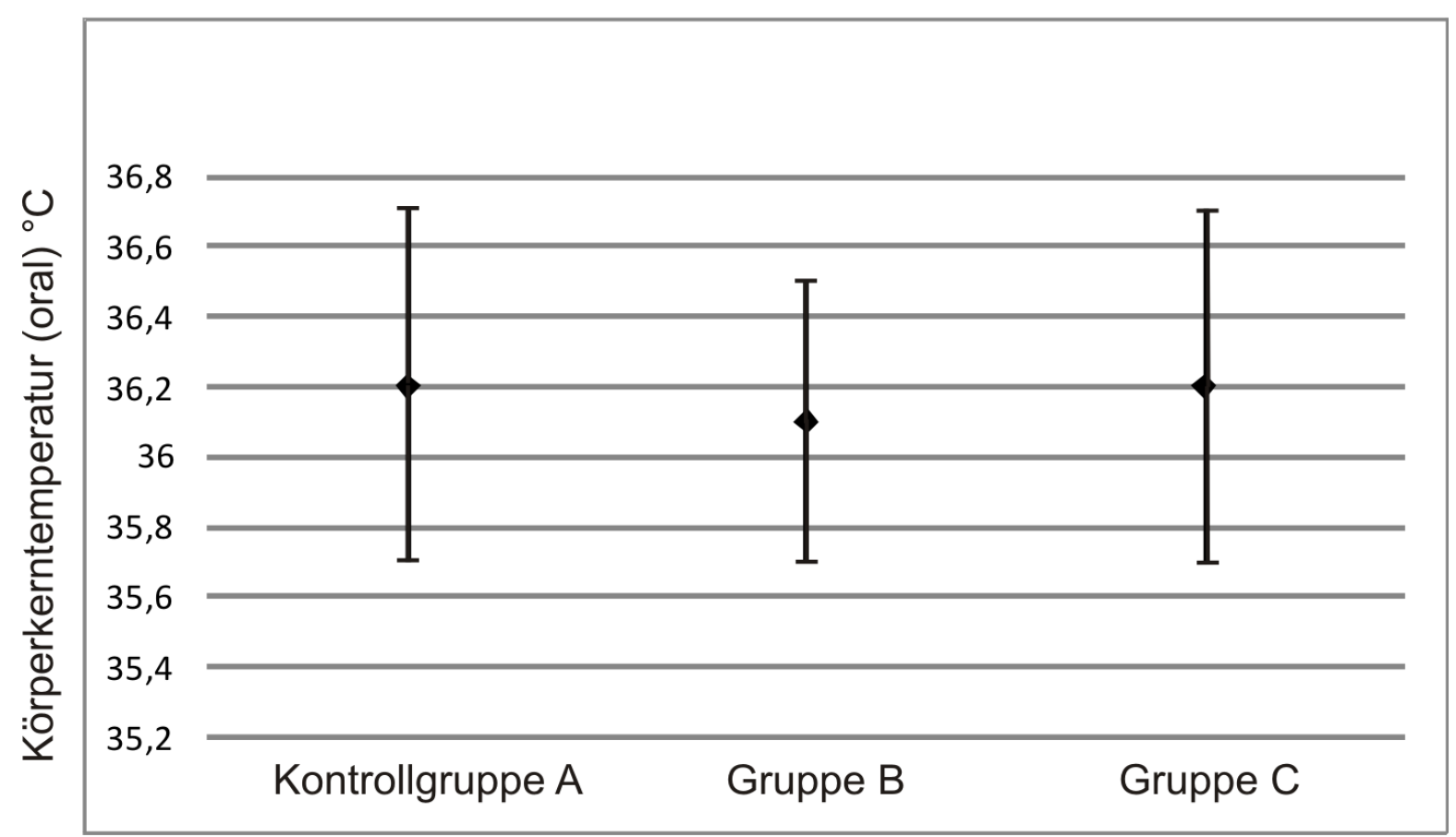

Abbildung 7: Körperkerntemperatur (oral) der verschiedenen Studiengruppe vor Beginn der passiven /aktiven Vorwärmung, Angabe in Mittelwerten \pm Standardabweichung

Vor Beginn der passiven- bzw. aktiven Vorwärmung in Studiengruppe B und C zeigten sich erneut keine signifikanten Unterschiede in der oral gemessenen Körperkerntemperatur (Abb. 7). Weiterhin lag die mittlere Körperkerntemperatur der Vergleichsgruppe $A\left(36,2^{\circ} \mathrm{C} \pm 0,5^{\circ} \mathrm{C}\right)$ etwas über der konstanten mittleren Körperkerntemperatur von Studiengruppen $\mathrm{B}\left(36,1^{\circ} \mathrm{C} \pm 0,4^{\circ} \mathrm{C}\right)$.

Die mittlere Körperkerntemperatur wurde in Studiengruppe $\mathrm{C}$ vor der aktiven Vorwärmung bei $36,2^{\circ} \mathrm{C} \pm 0,5^{\circ} \mathrm{C}$ ermittelt. 


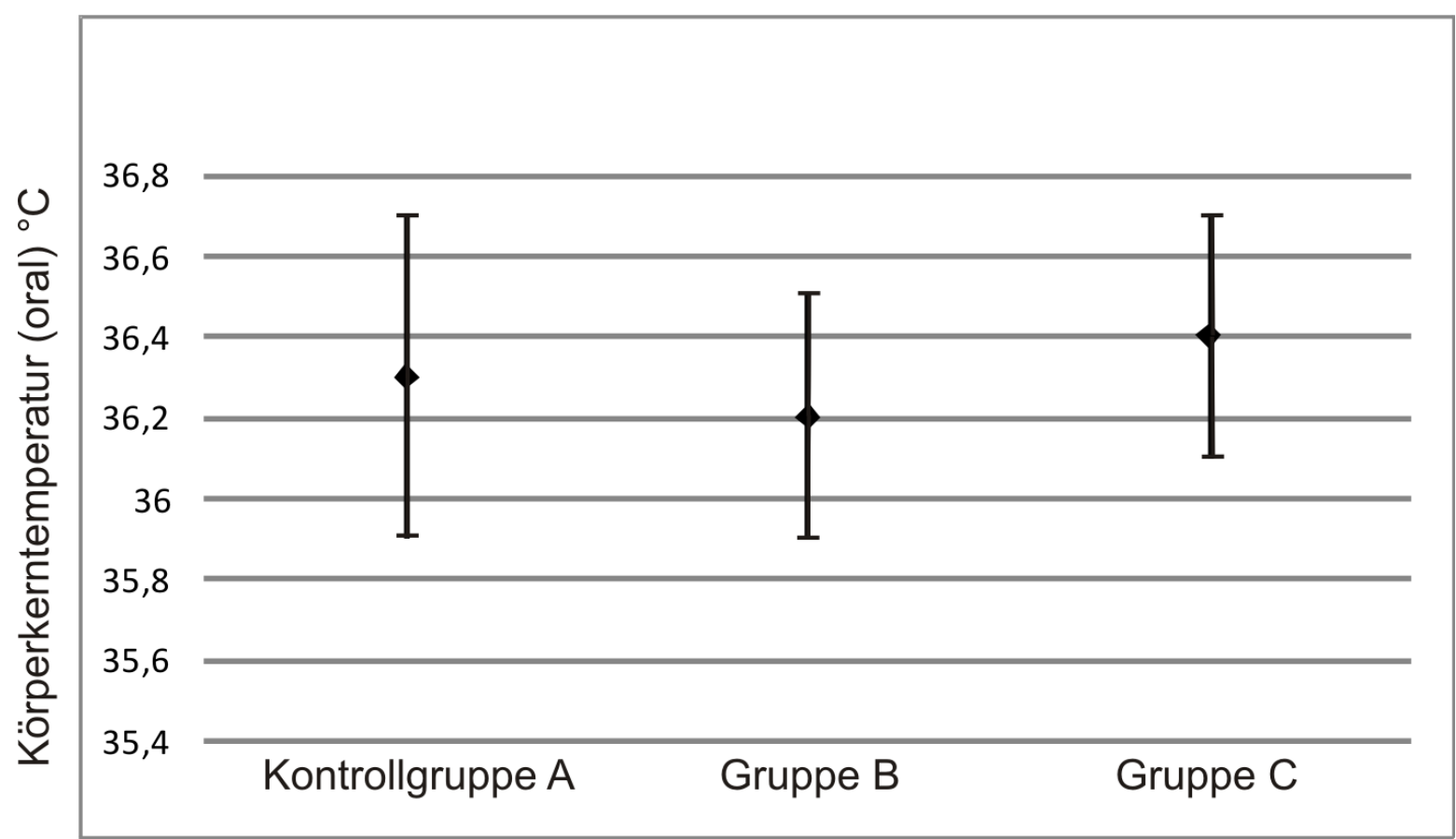

Abbildung 8: Körperkerntemperatur (oral) nach passiver/ aktiver Vorwärmung in Gruppe B und C, Angabe in Mittelwerten \pm Standardabweichung

Abbildung 8 zeigt die mittlere Körperkerntemperatur nach der Anwendung des Mistral-Air Premium Warming Suit ${ }^{\mathrm{TM}}$ in Studiengruppe B und C. Die Vorwärmdauer betrug in der passiven Studiengruppe B durch Isolation $35 \pm 14$ Min. Eine aktive Wärmezufuhr in Form des Warming Suit mit Anschluss eines konvektiven Wärmeluftgebläses in Studiengruppe C kam mit durchschnittlich $44 \pm 13$ Min. zur Anwendung. Die mittlere orale Körperkerntemperatur in Studiengruppe A ohne Intervention zeigt mit $36,3^{\circ} \mathrm{C} \pm 0,4{ }^{\circ} \mathrm{C}$ eine Steigerung gegenüber dem Ausgangswert um $0,1^{\circ} \mathrm{C}$.

In Studiengruppen B lag die mit Ende der passiven Vorwärmung ermittelte Körperkerntemperatur im Mittel um $0,1^{\circ} \mathrm{C}$ höher als die zuvor gemessene mittlere Ausgangstemperatur vor der Intervention $\left(36,1^{\circ} \mathrm{C} \pm 0,4^{\circ} \mathrm{C} \Leftrightarrow 36,2^{\circ} \mathrm{C} \pm 0,3^{\circ} \mathrm{C}\right)$.

In der vorgewärmten Studiengruppe $C$ zeigte sich eine mittlere Steigerung der Körperkerntemperatur nach der konvektiven Wärmeluftzufuhr von $0,2^{\circ} \mathrm{C}\left(36,2^{\circ} \mathrm{C} \pm 0,5^{\circ} \mathrm{C} \Leftrightarrow\right.$ $36,4^{\circ} \mathrm{C} \pm 0,3^{\circ} \mathrm{C}$ ). Zwischen den Gruppen A, B und $\mathrm{C}$ zeigt sich zu keinem Zeitpunkt ein signifikanter Unterschied ( $p>0,05)$. 


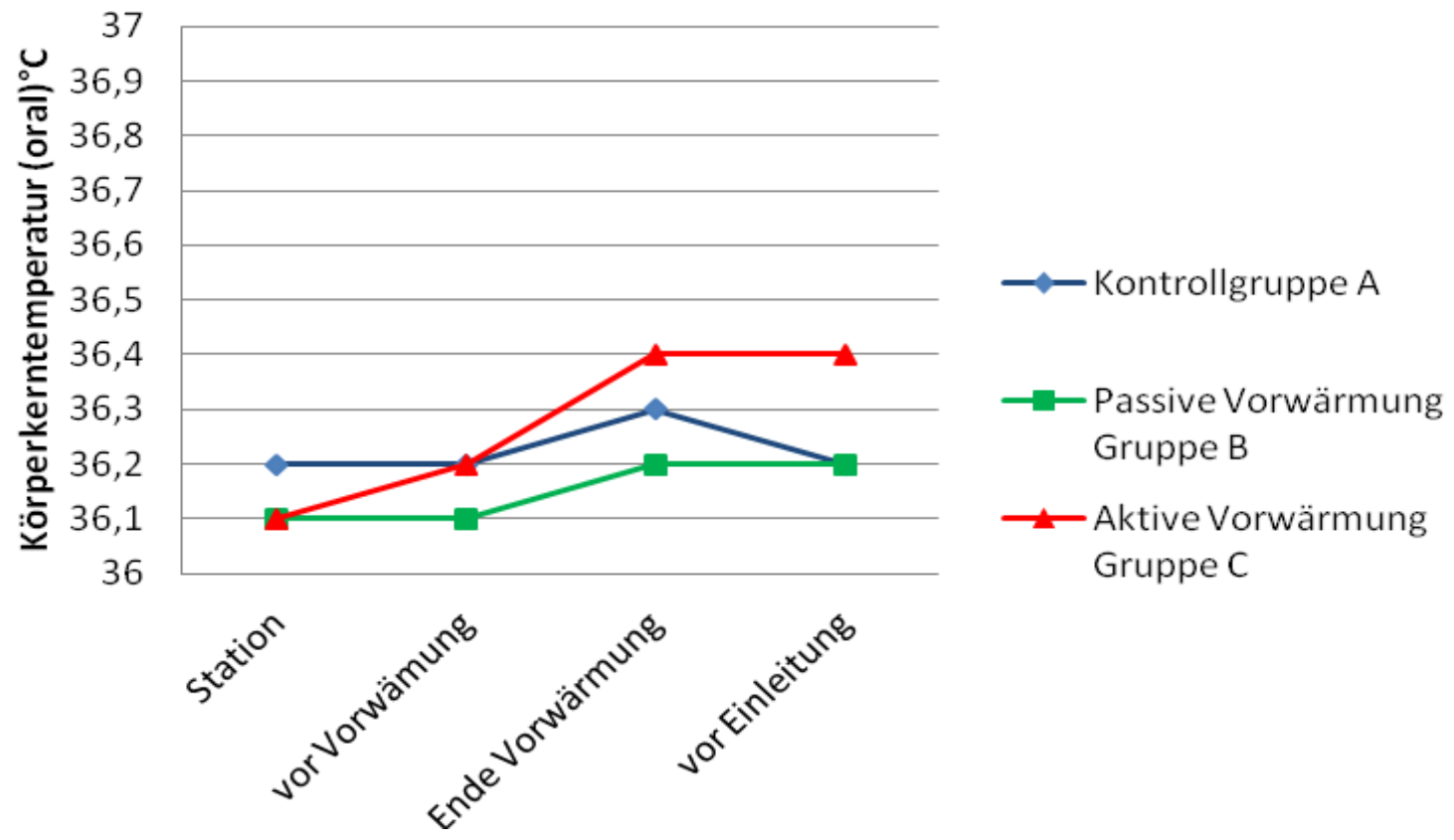

Abbildung 9: Präoperativer Temperaturverlauf aller drei Studiengruppen angegeben in mittleren Körperkerntemperaturen (orale Messung)

Abbildung 9 zeigt eine Zusammenfassung der Verläufe der präoperativ erfassten mittleren Körperkerntemperaturen (oral) in den drei Interventionsgruppen bis kurz vor Narkoseeinleitung. Es ergibt sich zu keinem Zeitpunkt ein signifikanter Unterschied zwischen den Gruppen A, B und C $(p>0,05)$. 


\subsubsection{Subjektives Wärmeempfinden}

Das subjektive Wärmeempfinden wurde an drei definierten Zeitpunkten durch den Patienten mithilfe einer visuellen Analogskala mit den Zahlenwerten von 1-10 beschrieben. Es zeigten sich keine signifikanten Unterschiede zwischen den einzelnen Studiengruppen bei der ersten Bestimmung vor Beginn der vorwärmenden Maßnahme. Weiterhin zeigte sich keine Signifikanz in Bezug auf einen Unterschied im subjektiven Wärmeempfinden bei Ankunft im Einleitungsraum sowie bei Ankunft im Aufwachraum (Tab. 3).

\begin{tabular}{l|ccc}
$\begin{array}{l}\text { Subjektive } \\
\text { Wärmeempfinden } \\
\text { (VAS 1-10) }\end{array}$ & Vergleichsgruppe A & $\begin{array}{c}\text { Studiengruppe B } \\
\text { Passive Vorwärmung }\end{array}$ & $\begin{array}{c}\text { Studiengruppe C } \\
\text { Aktive Vorwärmung }\end{array}$ \\
\hline vor der Vorwärmung & $6,9 \pm 1,7$ & $6,3 \pm 2,3$ & $6,3 \pm 2,1$ \\
vor der Einleitung & $6,1 \pm 1,68$ & $7,16 \pm 1,27$ & $7,5 \pm 1,07$ \\
Ankunft Aufwachraum & $7,03 \pm 1,99$ & $6,93 \pm 1,86$ & $7,93 \pm 1,46$
\end{tabular}

Tabelle 3: subjektives Wärmeempfinden ermittelt zu drei definierten Zeitpunkten mithilfe der VAS (1-10 Punkte). Angabe in Mittelwert \pm Standardabweichung. 


\subsubsection{Verlauf der intraoperativen Körperkerntemperaturen nach Narkoseeinleitung}

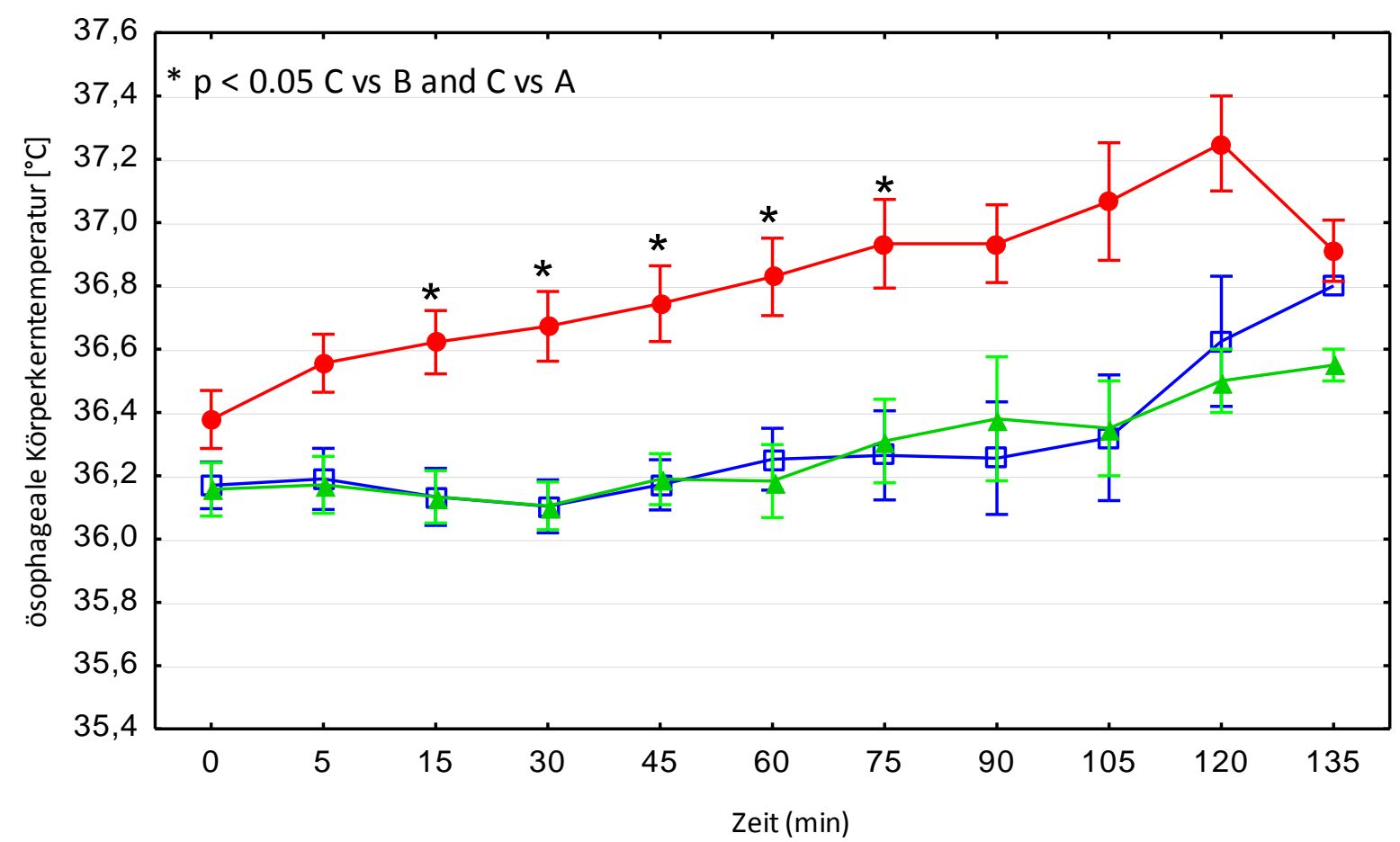

量 Kontrollgruppe A

passive Vorwärmung Gruppe B

aktive Vorwärmung Gruppe C

Abbildung 10: Intraoperativer Verlauf der mittleren Körperkerntemperaturen \pm Standardabweichung nach Narkoseeinleitung zu den definierten Zeitpunkten t0-t135 in der Vergleichsgruppe A ( $\square$ ), Gruppe $B(\Delta)$ und Gruppe $C(\circ),{ }^{*} p<0.05$ C vs. B und $C$ vs. A

Zum Zeitpunkt 15 Min. nach Narkoseeinleitung (t15) zeigten sich erstmals signifikante Unterschiede in den ösophageal gemessenen Körperkerntemperaturen zwischen der aktiv gewärmten Gruppe C und der Vergleichsgruppe A sowie der passiv gewärmten Gruppe B.

Im weiteren Narkoseverlauf konnte der signifikante Unterschied der Körperkerntemperatur in der aktiv vorgewärmten Studiengruppe C gegenüber Gruppe A sowie B weiter bis 75 Min. nach Narkoseeinleitung (t 75) nachgewiesen werden ((t 30, 45, 60, 75 Min. $p<0,05$ ) Abb. 10). 


\subsubsection{Entwicklung der Körperkerntemperatur zum Operationsende}

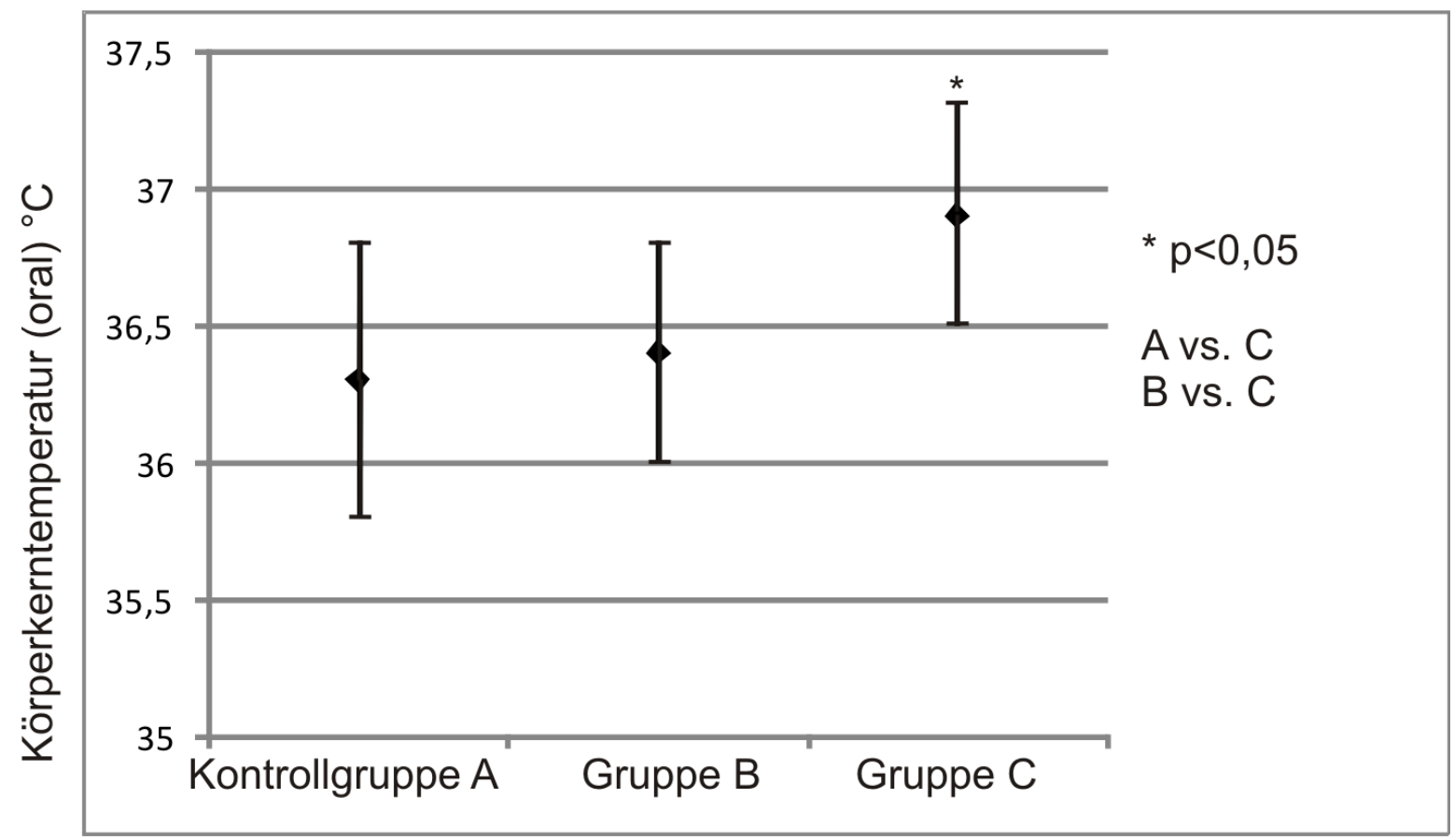

Abbildung 11: Mittlere Körperkerntemperaturen (ösophageal) zum Operationsende, Angabe in Mittelwert \pm Standardabweichung

Zum Ende der Operation zeigten sich signifikante Unterschiede ( $p<0,05$ C vs. B und $C$ vs. A) in der mittleren Körperkerntemperatur (ösophageale Temperaturmessung) von Studiengruppe $C\left(36,9^{\circ} \mathrm{C} \pm 0,4^{\circ} \mathrm{C}\right)$ gegenüber der Vergleichsgruppe $A\left(36,3^{\circ} \mathrm{C} \pm 0,5^{\circ} \mathrm{C}\right)$ und Studiengruppe B $\left(36,4^{\circ} \mathrm{C} \pm 0,4^{\circ} \mathrm{C}\right)$ (Abb.11). Zwischen den Gruppen A und B bestand kein signifikanter Unterschied.

\subsection{Hypothermie-Inzidenz}

Der exakte Fisher-Test zeigte zu Operationsende in Studiengruppe $\mathrm{C}$ eine geringere Hypothermie-Inzidenz gegenüber Vergleichsgruppe $A(p<0,018)$. Von 18 Studienpatienten in der aktiv-vorgewärmten Studiengruppe C zeigte nur ein Patient $(5,6 \%)$ bis zum Zeitpunkt t30 eine Körperkerntemperatur $<36^{\circ} \mathrm{C}$. Zum Zeitpunkt t45 konnten noch 16 Personen in Studiengruppe $\mathrm{C}$ in die Auswertung eingeschlossen werden, davon ein Patient mit einer Körperkerntemperatur $<36^{\circ} \mathrm{C} \quad(6,3 \%)$. An den definierten Messzeitpunkten t60, t75, t90, t105, t120 und t135 konnten in Studiengruppe C keine hypothermen intraoperativen Temperaturverläufe (0\%) beobachtet werden (Abb. 12). Zusammenfassend lässt sich zum Operationsende eine Hypothermierate von 0 bei 18 Studienpatienten in Gruppe $\mathrm{C}$ beschreiben. 
In der gegenübergestellten Vergleichsgruppe A zeigten von 30 Studienpatienten 7 Patienten $(23,3 \%)$ vor der Narkoseeinleitung eine präoperative Hypothermie. Zum Zeitpunkt t5 und t15 konnte bei $9(30 \%)$ von 30 Patienten eine Körperkerntemperatur $<36^{\circ} \mathrm{C}$ nachgewiesen werden. Nach 30 Min. Operationszeit konnten weiterhin 30 Patienten in die Auswertung eingeschlossen werden, davon 12 Personen (40\%) mit intraoperativer Hypothermie. Erst zum Zeitpunkt t120 mit 4 verbliebenen Patienten im Operationsverlauf konnten keine Körperkerntemperaturen $<36^{\circ} \mathrm{C}$ ösophageal gemessen werden (Abb.12). Zusammenfassend lässt sich in Vergleichsgruppe A eine Hypothermierate von 8 bei 30 Studienpatienten zum Operationsende beschreiben.

Bei der Gegenüberstellung von Studiengruppe C und der passiv vorgewärmten Studiengruppe B zeigte sich keine Signifikanz in der Inzidenz, eine intraoperative Hypothermie zu entwickeln $(p<0,11)$.

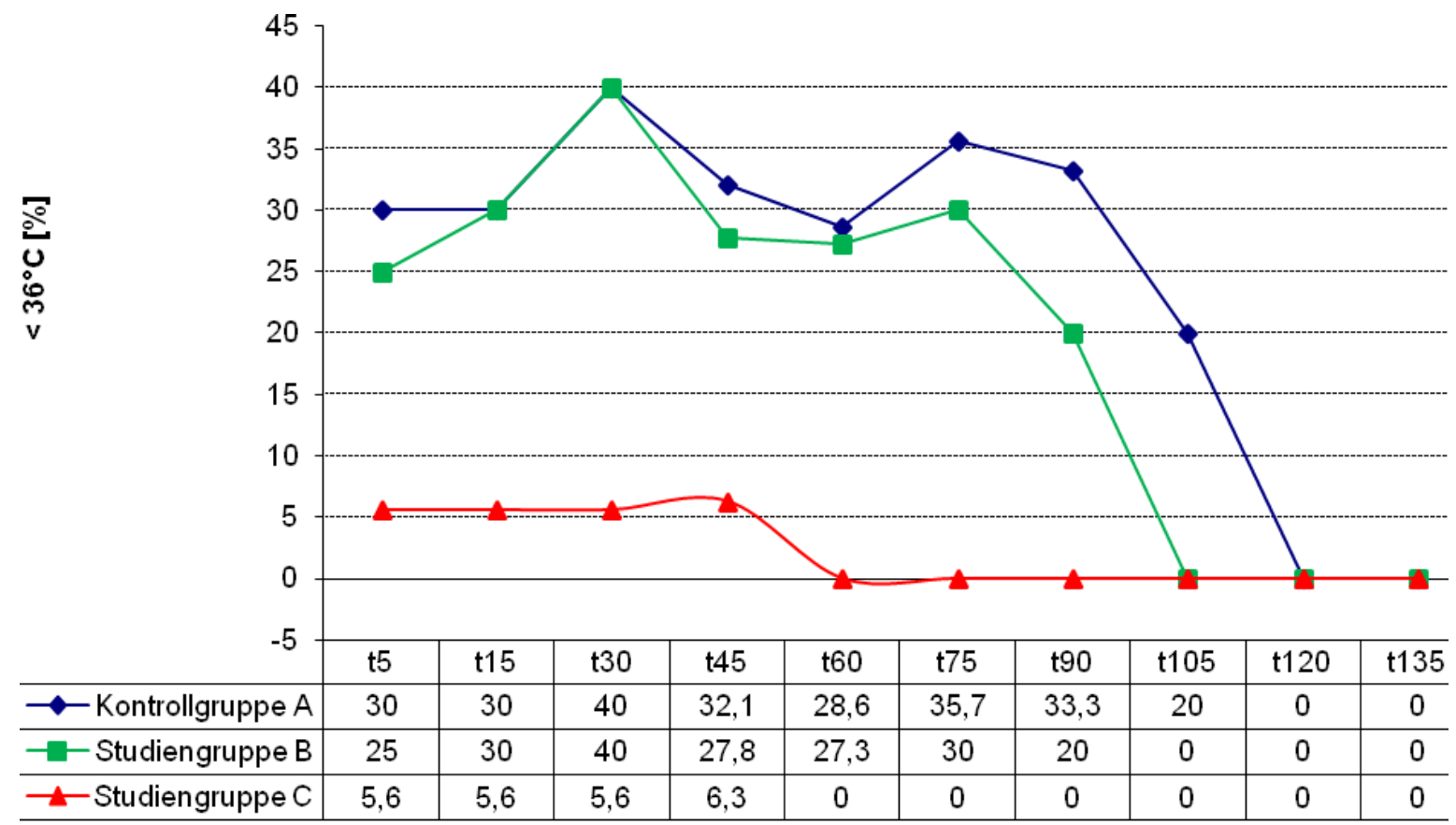

Zeit nach der Narkoseeinleitung (min)

Abbildung 12: Hypothermierate im Narkoseverlauf (Min.) in den verschiedenen Studiengruppen bezogen auf gemessene Körperkerntemperaturen $<36^{\circ} \mathrm{C}$, angegeben in $\%$. 


\subsection{Verlauf der postoperativen Körperkerntemperaturen im Aufwachraum}

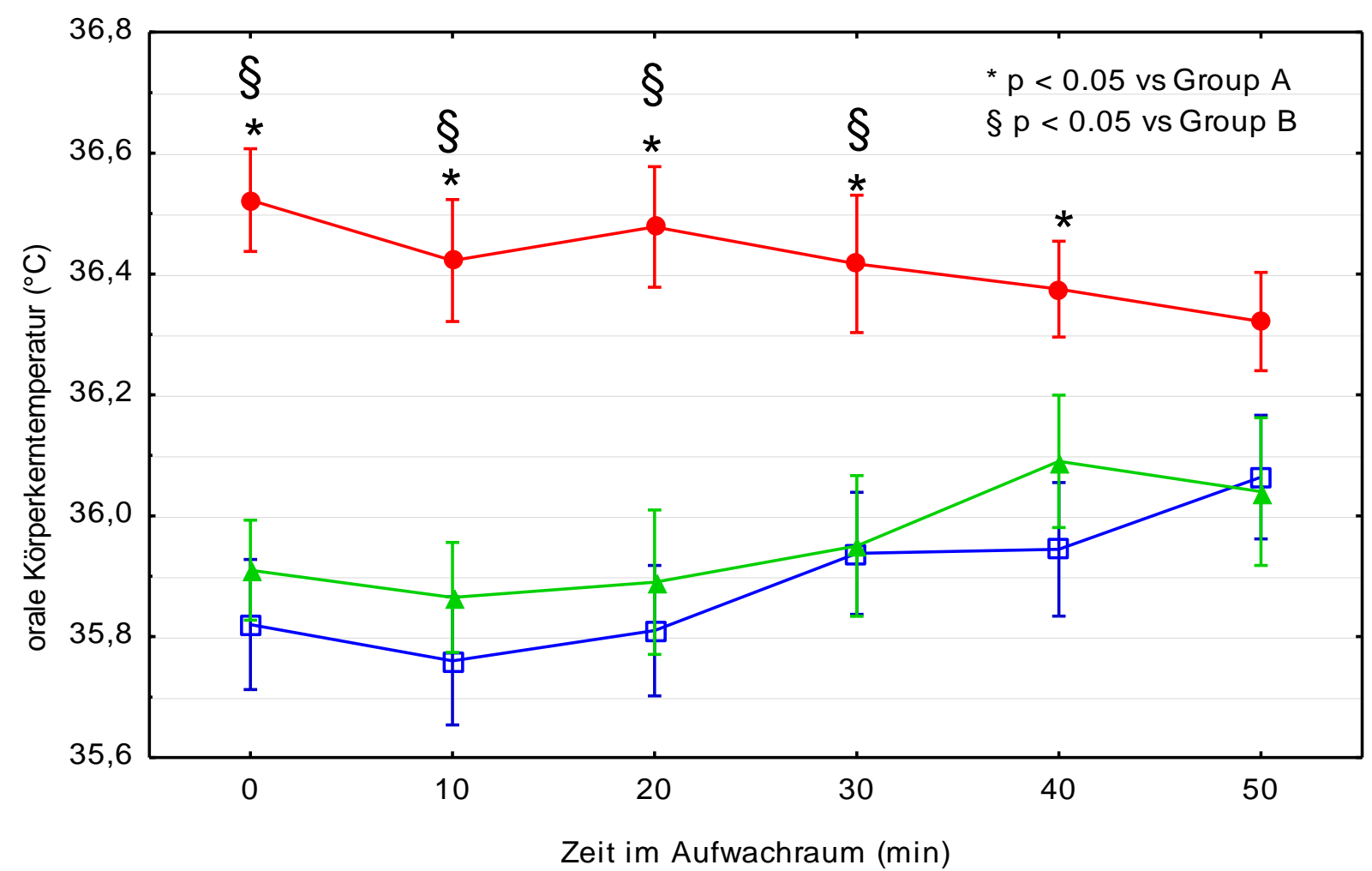

重Kontrollgruppe A

至passive Vorwärmung Gruppe B

Taktive Vorwärmung Gruppe A

Abbildung 13: Verlauf der Körperkerntemperaturen in den Studiengruppen im Aufwachraum, Angabe in Mittelwerten \pm Standardabweichung

Abbildung 13 zeigt die postoperative Entwicklung der mittleren Körperkerntemperaturen nach der Operation im Aufwachraum.

Während der ersten 30 Min. im Aufwachraum zeigten sich signifikant höhere orale mittlere Körperkerntemperaturen in Studiengruppe C gegenüber der Kontrollgrupp A sowie Studiengruppe B $(p<0,05)$. Nach 40 Min. postoperativem Aufenthalt im Aufwachraum zeigten sich weiterhin signifikante Unterschiede in der mittleren Körperkerntemperatur zwischen Studiengruppe $C$ und Vergleichsgruppe $A(p<0,05)$. 


\subsection{Aldrete Skala}

Zur postoperativen Überwachung im Aufwachraum wurde bei jedem Patienten bei Ankunft sowie im Abstand von 10 Min. der Wert auf der Aldrete Skala bestimmt. Es ließ sich zu keinem Zeitpunkt ein signifikanter Unterschied zwischen den Studiengruppen hinsichtlich der Veränderung der Aldrete- Bewertungsskala feststellen.

\begin{tabular}{l|lll}
$\begin{array}{l}\text { Aldrete-Skala } \\
\text { (0-10 Punkte) }\end{array}$ & Vergleichsgruppe A & Studiengruppe B & Studiengruppe C \\
\hline t0 & $6,70 \pm 1,19$ & $7,30 \pm 1,08$ & $7,03 \pm 0,87$ \\
t10 & $7,91 \pm 1,08$ & $8,07 \pm 0,94$ & $8,30 \pm 0,74$ \\
t20 & $8,27 \pm 0,99$ & $8,74 \pm 1,11$ & $8,80 \pm 0,87$ \\
t30 & $8,59 \pm 0,90$ & $9,07 \pm 0,98$ & $9,03 \pm 0,80$ \\
t40 & $8,96 \pm 0,94$ & $9,26 \pm 0,97$ & $9,36 \pm 0,84$ \\
t50 & $9,35 \pm 0,78$ & $9,57 \pm 0,73$ & $9,55 \pm 0,67$ \\
t60 & $9,70 \pm 0,62$ & $9,83 \pm 0,37$ & $9,58 \pm 0,67$
\end{tabular}

Tabelle 4: Punktwerte der Aldrete-Skala zu den Zeitpunkten t0-t60 in den Studiengruppen A,B und C. Angabe in Mittelwerten \pm Standardabweichung.

\subsection{Postoperatives Kältezittern}

Insgesamt ließ sich in Bezug auf die Häufigkeit von postoperativem Kältezittern im Aufwachraum keine eindeutige Signifikanz zwischen den drei Studiengruppen nachweisen. Studiengruppe $C$ zeigte einen Trend zur geringeren Inzidenz gegenüber der passiv vorgewärmten Studiengruppe B und Vergleichsgruppe A.

In der aktiv vorgewärmten Studiengruppe $C$ wurde bei keinem Patienten Kältezittern im Aufwachraum beobachtet (0/18), in Studiengruppe B nach passiver Vorwärmung in 4 von 20 Patientenfällen (C vs. B p>0,06). In der Vergleichsgruppe $A$ kam es in 5 von 30 Fällen zum nachweislichen Kältezittern ( $C$ vs. A p>0,08) 


\subsection{Postoperative Komplikationen}

In keiner Studiengruppe konnten postoperativ nach der Anwendung des Warming Suit mit bzw. ohne Anschluss des konvektiven Warmluftgebläses oder der intraoperativen Anwendung der Ober- und Unterkörperdecke Lagerungsschäden oder thermische Verbrennungen nachgewiesen werden.

\section{Diskussion}

\subsection{Diskussion der Arbeitshypothese}

Die Narkose nimmt dem Patienten die Möglichkeit, seine Körpertemperatur durch willkürliche sowie unwillkürliche Mechanismen zu wahren. Somit liegt die Verantwortung beim Anästhesisten, den Patienten in einem normothermen Temperaturbereich durch die Operation zu führen und bestmöglich eine Körpertemperatur $>36^{\circ} \mathrm{C}$ für den Patienten zu erhalten. Ziel ist es, die Nebenwirkungen der perioperativen Hypothermie wie gestörte Blutgerinnung, veränderte Pharmakokinetik, gestörter Proteinmetabolismus, Wundheilungsstörungen und längere postoperative Verweildauer im Aufwachraum zu reduzieren oder gar zu verhindern.

Somit erscheint es wesentlich, in der klinisch orientierten Forschung nach effektiven, praktikablen und kostengünstigen Verfahren zu suchen, die zur Erhaltung der perioperativen Normothermie beitragen.

Ziel dieser Studie ist es, die Effektivität von zwei neuen Prewarming-Strategien im klinischen Alltag sowie unter operativen Bedingungen zu testen. Ferner wurde untersucht, ob das Verfahren der standardmäßigen, intraoperativen konvektiven Luftwärmung durch eine präoperativ vorausgehende Isolation oder aktive Vorwärmung mit dem Mistral Air TM Wärmeanzug zu steigern ist.

Generell stellt sich der Mechanismus der präoperativen Vorwärmung als gut erforscht und als verstandenes Verfahren in der Hypothermieprophylaxe dar (Andrzejowski et al. 2008, De Witte et al. 2010). Eine adäquate Vorwärmung des Patienten zielt auf eine Erhöhung der Wärmemenge in der Körperperipherie.

Durch die Reduktion des Temperaturgradienten zwischen dem Körperkern und der Körperschale kann die Wärmeumverteilung nach Narkoseeinleitung von zentral nach peripher deutlich verringert werden (Matsukawa et al. 1995b). Gewählt wurde ein abteilungsübergreifendes Patientenkollektiv, da der wesentliche Faktor für die Entstehung der perioperativen Hypothermie in der Narkoseeinleitung selbst gesehen wird. Die unterschiedlichen Eingriffe mit den spezifischen Größen des OP-Feldes waren zwischen den Studiengruppen vergleichbar verteilt. Die Raumtemperatur im Operationssaal lag 
konstant bei allen Studiengruppen im Bereich zwischen $20^{\circ} \mathrm{C}$ und $21^{\circ} \mathrm{C}$. Morris (1971a) beschrieb bei diesen Temperaturen eine hohe Hypothermieinzidenz. Um den Einfluss von ungleichen Mengen kalter Infusionslösungen auszuschließen, wurde ein Infusionswärmer (HotLine ${ }^{\mathrm{TM}} \mathrm{HL}$-90) für alle verabreichten Flüssigkeiten verwendet. Unter der eingestellten Flussgeschwindigkeit kann eine Infusionstemperatur von $>33^{\circ} \mathrm{C}$ angenommen werden (Schmidt et al. 1996).

Die Temperaturerfassung vor Narkoseeinleitung erfolgte zu drei definierten Zeitpunkten am wachen Patienten in der hinteren sublingualen Tasche. Durch die Einfachheit der Messtechnik, die gute Reproduzierbarkeit sowie geringe Invasivität stellt dies die bevorzugte Temperaturerfassung in der prä- sowie postoperativen Phase dar (Hooper und Andres 2006).

Intraoperativ erfolgte die Messung der Körperkerntemperatur am narkotisierten Patienten mit Hilfe einer Ösophagussonde. Dieses Verfahren gilt als Goldstandard der zentralen Körpertemperaturerfassung (Imrie und Hall 1990, Bräuer et al. 1997). Die Berechnung der erforderlichen Eindringtiefe der Sonde für eine valide Messung erfolgte dabei über die Formel nach Mekjavic und Rempel (Formel 1) und lag zwischen 30-35 cm ab Zahnreihe im distalen Ösophagus (Mekjavic und Rempel 1990). Verfälschte Messergebnisse durch Beeinflussung der Sonde durch Ventilation, kalten Speichel bei oraler Lage oder Magensaft konnten vermieden werden. Es erfolgte keine Messung der oberflächlichen Hauttemperatur zur Abschätzung der Gesamtkörperwärmemenge.

Hinsichtlich des komplexen zeitlichen Ablaufplanes im Operationsbereich war es nicht möglich, eine standardisierte Vorwärmdauer für alle Studiengruppen einzuhalten. Hieraus resultieren die abweichenden Zeitangaben in den Studiengruppen $B$ und $C$ bezüglich der präoperativen Dauer der Vorwärmung (Tabelle 2). Horn et al. zeigten jedoch, dass schon eine kurze Vorwärmdauer von nur 10 bis 20 Min. am Patienten zu einem signifikanten Effekt bezüglich der postoperativen Hypothermierate gegenüber der nicht- vorgewärmten Kontrollgruppe führt (Horn et al. 2012). Alle Patienten in unsere Studie wurden länger als 10 Min. einer vorwärmenden Maßnahme unterzogen. Auch dieser größere Zeitrahmen wird als effektiv bewertet (Horn et al. 2012).

\subsection{Diskussion der wärmeprotektiven Verfahren in den Studiengruppen}

Die Vergleichsgruppe A ohne die Anwendung von präoperativen vorwärmenden Maßnahmen diente der Gegenüberstellung der vorgewärmten Studiengruppe B (passiv) und Studiengruppe C (aktiv). Durch Studiengruppe B sollte geprüft werden, ob die reine präoperative Isolation durch die reflektierende Oberfläche des Mistral-Air Warming Suit ${ }^{\mathrm{TM}}$ zu signifikanten Veränderungen der intraoperativen Körperkerntemperatur führt. In 
Studiengruppe C wurde der Mistral-Air Warming Suit ${ }^{\mathrm{TM}}$ mit dem konvektiven Mistral-Air Luftwärmer als Kombinationssystem zur Hypothermieprophylaxe untersucht. In der Gegenüberstellung des Wärmeanzuges in Kombination mit einem konvektiven Luftwärmer, der reinen Isolationsleistung des Wärmeanzuges und der Vergleichsgruppe soll geprüft werden, welches System am effizientesten einer perioperativen Hypothermie entgegenwirken kann.

Nur in der aktiv vorgewärmten Studiengruppe C zeigten sich signifikant höhere Körperkerntemperaturen nach der Narkoseeinleitung vom Zeitpunkt t 15 bis zum Zeitpunkt t 75 im Operationsverlauf. Auch zum Operationsende sowie nach Ankunft im Aufwachraum t 0 bis t 30 war eine signifikant höhere Körperkerntemperatur bei Patienten der Studiengruppe $C$ nachweisbar. Hingegen zeigten sich keine signifikanten Unterschiede zwischen der Vergleichsgruppe A und der der passiven Isolationsgruppe B. Zwar liegt es durch den hohen perioperativen Wärmeverlust durch Radiation nahe, diesen Mechanismus des Wärmeverlustes durch reflektierende Folien zu vermindern. Jedoch zeigten Bourke et al., dass ein hoher Prozentsatz (> 60\%) der Körperoberfläche über einen Zeitraum von mindestens 2 h bedeckt werden muss, um effektiv wirken zu können (Bourke et al. 1984).

Diese lange Vorbereitungszeit kann im klinischen Ablaufplan nicht integriert werden und stellt dadurch schon einen limitierenden Faktor dar.

Auch die vorliegenden Messungen dieser Studie zeigen, dass nur durch eine aktive, präoperative Wärmezufuhr eine weitere Reduktion der intraoperativen Hypothermierate möglich ist. Die Isolation durch die metallisierte Oberfläche des Wärmeanzuges zeigte sich als gleichwertig im Vergleich mit der Isolation durch die standardisierte Baumwollsteppdecke und im Bezug auf die Temperaturentwicklung der aktiven Vorwärmung als unterlegen. $\mathrm{Ng}$ et al. konnten in einer Studie ebenfalls keinen Vorteil einer reflektierenden Wärmedecke gegenüber einer doppellagigen Baumwolldecke nachweisen ( $\mathrm{Ng}$ et al. 2003). Auch die kombinierte Anwendung eines reflektierenden Isolationsmaterials (Thermadrape, O.R. Concepts Inc., Roanoke, USA) mit einem Infusionswärmer (Hotline HL-90) zeigt keinen signifikanten Unterschied in der postoperativen Hypothermierate gegenüber der Versorgung mit einer doppellagigen Baumwolldecke plus Infusionswärmer (Bräuer et al. 2000b).

Betrachtet man die Entwicklung der Körperkerntemperaturen direkt nach Narkoseeinleitung in der Vergleichsgruppe sowie in der passiv- vorgewärmten Studiengruppe B, so zeigt sich kein prägnanter Abfall der zentralen Körpertemperatur. Matsukawa et al. (1995b) beobachteten an Probanden, die sich einer Allgemeinnarkose unterzogen, einen initial sehr hohen zentralen Temperaturverlust $\left(1,6^{\circ} \mathrm{C} \mathrm{h}^{-1}\right)$ der im weiteren Verlauf ein Plateau 
erreicht. Durch den Einsatz von Gewebethermometern, Wärmeflussmessern, indirekter Kalorimetrie und Hauttemperatursonden konnte gezeigt werden, dass dieser Wärmeverlust zu $81 \%$ auf einer Wärmeumverteilung beruht. Einen ähnlichen, abfallenden Verlauf der zentralen Körperkerntemperatur 15 Min. nach Narkoseeinleitung beschrieben auch Bock et al. in einer Studie (Bock et al. 1998).

In der hier vorliegenden Patientenuntersuchung zeigte sich ein nur gering ausgeprägter zentraler Temperaturverlust von rund $0,1^{\circ} \mathrm{C}$ in beiden passiv isolierten Studiengruppen. Der initiale Temperaturverlust nach Narkoseeinleitung war schon zum Zeitpunkt t 30 bei beiden Gruppen mit einem Minimalwert erreicht. Ähnlich moderate Verläufe ohne einen signifikanten Temperaturabfall nach Narkoseeinleitung konnten jedoch in vergleichbaren Studienmodellen ebenfalls beobachtet werden (Ruetzler et al. 2011, Perl et al. 2012).

Man kann davon ausgehen, dass in der vorliegenden Studie der Einfluss der Wärmeumverteilung auf den zentralen Temperaturverlust der Patienten nach Narkoseeinleitung als weniger hoch anzusehen ist. Probanden in der Studie von Matsukawa et al. waren 2,5 h vor der Narkoseeinleitung einer kälteren Umgebungstemperatur ausgesetzt. Folglich lag die Hauttemperatur dieser Patienten deutlich niedriger (Matsukawa et al. 1995a). Der stärker ausgebildete Temperaturgradient zwischen Körperkern und Körperperipherie erhöht die Wärmeumverteilung mit einem merklichen Einfluss auf den zentralen Temperaturverlust (Sessler et al. 1995). Weiterhin lässt diese Beobachtung auf eine gute, jedoch nicht suffiziente präoperative periphere Isolation der Patienten dieser Studie schließen. Durch eine hohe Raumtemperatur im Wartebereich sowie doppellagige Baumwolldecken lässt sich die perioperative Hypothermie nicht verhindern. Doch zeigt der nur gering ausgeprägte Temperaturverlust in der ersten Phase nach Narkoseeinleitung im Vergleich mit den Daten von Matsukawa et al. (1995a), dass durch effektive präoperative Isolationsmaßnahmen Einfluss auf den Temperaturverlauf durch Wärmeumverteilung genommen werden kann.

In der aktiv vorgewärmten Studiengruppe C lässt sich ein stetiger Anstieg der zentralen Körperkerntemperatur ab dem Zeitpunkt der Einleitung verzeichnen. Im Gegensatz dazu zeigt sich ein Abfall der zentralen Körperkerntemperatur in beiden Isolationsgruppen bis zum Zeitpunkt t30 nach Einleitung. Dies lässt den Schluss zu, dass durch die konvektive Erwärmung peripherer Kompartimente durch den Warming Suit mit angeschlossenem Warmluftgebläse vor Narkoseeinleitung der Effekt der Wärmeumverteilung in der ersten Phase von zentral nach peripher sehr gering gehalten werden kann. Es scheint, dass der starke initiale Abfall der Körperkerntemperatur, wie von Sessler et al. beschrieben, durch einen verkleinerten Temperaturgradienten zwischen Körperkern und Peripherie durch effizientes Vorwärmen umgangen werden kann (Sessler et al. 1995). Der Patient erreicht 
trotz vasodilatatorisch wirksamen Narkosemedikamenten schneller ein Gleichgewicht zwischen Wärmeabgabe und Wärmeproduktion (steady-state). Der Abfall der zentralen Körperkerntemperatur kommt zum erliegen. Die thermoregulatorische Vasokonstriktion setzt vergleichsweise früher ein, die Körperkerntemperatur kann konstant gehalten werden oder steigt unter der aktiven Wärmung sogar an.

Im Umkehrschluss zeigt sich, dass der Wärmeverlust von Patienten in der Vergleichsgruppe sowie in der passiven Isolationsgruppe B über die Körperoberfläche, die OPWunde und das nicht abgedeckte OP-Feld über der körpereigenen Wärmeproduktion lag. Bis 30 Min. nach Narkoseeinleitung ist anzunehmen, dass sich die Patienten beider Studiengruppen nicht im steady-state von Wärmeproduktion und Wärmeabgabe befanden.

Kritisch zu betrachten ist die Tatsache, dass in Studien bezüglich der intraoperativen Hypothermieinzidenz meist der mediane Wert der Körperkerntemperatur zur Diskussion um die Effektivität einer Wärmemethode herangezogen wird. Zwar wird eine mittlere Körperkerntemperatur von $>36^{\circ} \mathrm{C}$ nach Operationsende als erstrebenswert angesehen, jedoch muss bedacht werden, dass sich bei dieser Betrachtung auch $50 \%$ der Patienten eine niedrigere Körperkerntemperatur aufweisen können und den Risiken der periopertiven Hypothermie weiterhin ausgesetzt sind. Zusätzlich muss die zum Teil relevante Anzahl von Patienten bedacht werden, die schon mit einer präoperativen Körperkerntemperatur von $<36^{\circ} \mathrm{C}$ den Operationssaal erreichen und somit definitionsgemäß schon präoperativ eine hypotherme Körperkerntemperatur aufweisen (Mitchell und Kennedy 2001).

In einer vorausgehenden Studie von Fanelli et al. konnte kein signifikanter Unterschied zwischen der reinen intraoperativen Anwendung einer aufgelegten Heizdecke gegenüber einem konvektiven Luftwärmegebläse zur Vermeidung der intraoperativen Hypothermie nachgewiesen werden (Fanelli et al. 2009). Auch die vorliegende Studie kommt zu dem Ergebnis, dass eine ausschließlich intraoperativ angewendete, konvektive Wärmemaßnahme mit zusätzlicher Infusionswärmung nicht ausreichend ist, um dem intraoperativen Hypothermieverlauf entgegenzuwirken. Zwar zeigt die standardmäßige Anwendung von Warmluftgebläsen nach Narkoseeinleitung ein vorhandenes Problembewusstsein bei den beteiligten Disziplinen hinsichtlich der Risiken und Folgen der Hypothermie. Jedoch kann der maßgebliche Faktor für die erlangte Hypothermie, die Wärmeumverteilung, nur durch ein optimiertes, präoperatives Wärmemanagement beeinflusst werden (Vanni et al. 2003).

\subsection{Diskussion der Studienlimitationen}

Als deutliche Schwachstelle im Studiendesign zeigte sich im Nachhinein, dass nach Rekrutierungsschluss von 90 gemessenen Patienten 22 Patienten aufgrund Protokollverlet- 
zungen ausgeschlossen werden mussten. Am häufigsten kam es dabei zu einer Missachtung der gesetzten Obergrenze von BMI oder Alter. Hilfreich wäre dabei ein Rechentool in der Randomisierungssoftware, welches aus der obligaten Eingabe von Größe und Gewicht den BMI ermittelt. Dadurch hätte diese potentielle Fehlerquelle ausgeschlossen werden können. In 6 Fällen wurde die Operationsdauer von mindestens 30 Min. durch nicht vorauszusehende Ereignisse unterschritten.

Wie bereits erwähnt war es nicht möglich, eine standardisierte Vorwärmdauer in den Studiengruppe B und C einzuhalten. Durch ständig Wiederkehrende, kurzfristige Änderungen in der Reihenfolge der Operationen war es kaum möglich, mehr als einen Patienten pro Tag in die Studie einzuschließen. Oft ergaben sich große zeitliche Leerläufe, in denen die Patienten sehr lange Wartezeiten im Operationsbereich zu überbrücken hatten. Die durchschnittliche Vorwärmzeit wurde maßgeblich durch diese Faktoren bestimmt und zeigt dadurch eine weite Streuung innerhalb der Studiengruppen. Jedoch zeigt sich hier ein organisatorischer Ansatz, um eine störungsfreie Integration der präoperativen Vorwärmung in die üblichen Ablaufprozesse zu integrieren. Die anfallende Zeit für die Patienten in der Wartezone kann hier für eine sinnvolle medizinische Maßnahme genutzt werden. Ebenfalls könnte die präoperative Vorwärmung als eine standardmäßige Maßnahme in die Narkosevorbereitung integriert werden (Bräuer et al. 2010).

Eine weitere Limitation zeigt sich im deutlich gemischten Patientenkollektiv. Zwar ist die Vergleichbarkeit von homogenen Studiengruppen valider, jedoch verdeutlicht die heterogene Patientenauswahl dieser Studie den klinischen Alltag in der Anästhesie. Durch die unterschiedlichen präventiven Maßnahmen vor der Narkoseeinleitung wird zunächst unabhängig von der nachfolgenden chirurgischen Maßnahme Einfluss auf die Wärmeumverteilung genommen.

In der Auswertung wurde die Änderung der Gesamtkörperwärmemenge (GKW) nicht erfasst. Die Grundlage für die Berechnung der GKW bildet die mittlere Körpertemperatur nach Burton (Burton 1935). Es wird ein fixes Verhältnis von zentraler Körpertemperatur und Hauttemperatur von 0,66 / 0,34 angenommen. Eine spätere Bestimmung nach Stolwijk und Hardy zeigt ein Verhältnis von 0,9 / 0,1 (Stolwijk und Hardy 1966). Durch eine suffiziente Vorwärmung der Körperperipherie wird die GKW gesteigert, die Körperkerntemperatur wird jedoch nicht verändert. Durch die Erhöhung der Wärmemenge in der Körperperipherie wird der Temperaturgradienten zwischen dem Körperkern und der äußeren Körperschale reduziert Wie in Kapitel 4.3.2 erläutert, resultiert der initiale starke Abfall der Körperkerntemperatur aus der Wärmeumverteilung. Grundlage der Auswertung war hier die Erfassung sowie Veränderung der Körperkerntemperatur. Die Auswirkung auf die 
GKM durch den Mistral-Air Premium Warming Suit ${ }^{\mathrm{TM}}$ und eine mögliche Berechnung des Wärmeflusses fand nicht statt.

\subsection{Schlussfolgerung}

Die alleinige Anwendung von einem Infusionswärmer, einer Abdeckung mit OP-Tüchern sowie konvektiver Wärmezufuhr durch ein Luftgebläse auf höchster Temperaturstufe nach Narkoseeinleitung zur Verminderung perioperativer Wärmeverluste kann in dem gewählten Modell eine Hypothermie nicht verhindern. Der größte zentrale Wärmeverlust kann schon während der Narkoseeinleitung beobachtet werden und ist Folge der Wärmeumverteilung (Matsukawa et al. 1995b, Kurz et al. 1995b). Zusätzlich spielen Faktoren wie eine gesteigerte Wärmeabgabe durch Reduktion der Isolation nach Narkoseeinleitung sowie der Wärmeverlust durch das Abwaschen mit kalten, wässrigen Desinfektionslösungen (Sessler et al. 1993) eine Rolle. Im weiteren Verlauf übersteigen die Wärmeverluste die körpereigene Wärmeproduktion, es stellt sich eine hypotherme Körperkerntemperatur ein.

Auch der Einsatz des Mistral-Air Premium Warming Suit ${ }^{\mathrm{TM}}$ als reines Isolationsmaterial zeigte sich als kein effektives System in der Hypothermieprävention. Die Anwendung von ähnlichen metallbeschichteten Abdeckungen (ThermaDrape ${ }^{\mathrm{TM}}$ ) in vorausgegangenen Studien zeigte keine signifikante höhere Isolation zu herkömmlichen OP-Baumwolltüchern (Simmons et al. 1992, Bräuer et al. 2000b). Hinsichtlich der Effizienz, der entstehenden Kosten für die Verwendung von diesem Einmalmaterial sowie die Umweltbelastung durch Entsorgung kann es nicht empfohlen werden, den Mistral-Air Premium Warming Suit ${ }^{\mathrm{TM}}$ zur Isolation in der präoperativen Vorwärmung anzuwenden.

Das konvektive Wärmverfahren mit dem Mistral-Air Premium Warming Suit ${ }^{\mathrm{TM}}$ mit Warmluftgebläse zeigte sich im beschriebenen Modell als signifikant wirksameres Verfahren zur Hypothermieprävention in der Gegenüberstellung mit der Vergleichsgruppe A sowie Studiengruppe B. Die körpereigene Wärmeproduktion und der Wärmegewinn durch den konvektiven Luftwärmer übersteigen den Wärmeverlust. Es resultiert eine positive Wärmebilanz, die zu steigenden zentralen Temperaturen führt. $\mathrm{Zu}$ Operationsende sowie in den ersten $30 \mathrm{Min}$. im Aufwachraum zeigten sich weiterhin signifikant höhere Körperkerntemperaturen gegenüber den beiden Vergleichsgruppen.

\section{Zusammenfassung}

Durch Verminderung der Stoffwechselaktivität unter der Narkose und der Gabe von Medikamenten mit einer ausgeprägten vasodilatatorischen Wirkung ist die körpereigene 
Wärmeproduktion häufig geringer als der entstehende Wärmeverlust. Durch zusätzliche Faktoren wie Wärmeumverteilung, fehlende Isolation im Operationsgebiet, freiliegende seröse Häute sowie große Mengen von kalten Infusionslösungen kommt es häufig zu einem schnellen intraoperativen zentralen Temperaturverlust. Dies ist Ausdruck dafür, dass das thermische Gleichgewicht (steady-state) als Grundlage für die Erhaltung der Körperkerntemperatur gestört ist. Zusätzlich verliert der Patient unter Narkose die Möglichkeit zur autonomen Thermoregulation, es resultiert ein erhöhtes Risiko für eine perioperative Hypothermie. Eine veränderten Pharmakokinetik, kardiozirkulatorische Komplikationen, Störungen des Immunsystems und des Proteinstoffwechsels, ein erhöhtes Blutungs- und Transfusionsrisiko sowie vermehrte Wundinfektionen und Wundheilungsstörungen können als direkte Folgen beobachtet werden.

Ziel der hier vorliegenden Studie war es, den Mistral-Air Premium Warming Suit ${ }^{\text {TM }}$ als konvektives Wärmesystem sowie als Isolationsmaterial in der klinischen Anwendung am Patienten zu testen. Weiterhin wurde untersucht, ob die standardmäßige Isolation mit einer Baumwollsteppdecke durch den Einsatz des metallisierten Isolationsmaterials zu steigern ist.

Nach Zustimmung der regionalen Ethikkommissionen in Deutschland, Spanien und Belgien wurden 90 Patienten in die Studie eingeschlossen, die sich einer geplanten Operation in Vollnarkose zwischen 30 und 180 Minuten unterziehen mussten.

Am Universitätsklinikum Göttingen wurden 36 Patienten für die Studie rekrutiert. Einschlusskriterien waren ASA I-III, BMI zwischen 20 und $30 \mathrm{~kg} \mathrm{~m}^{2}$, Alter zwischen 18 und 70 Jahre sowie ITN. Es erfolgte eine computergestützte Randomisierung mit Zuordnung in eine der drei möglichen Studiengruppen. Nach Narkoseeinleitung mit Propofol, Sufentanil oder Remifentanil, Rocuronium, Mivacurium oder Cisatracurium wurde die Narkose mit Sevofluran oder total intravenös aufrechterhalten. Als Körperkerntemperatur wurde die ösophageale Temperatur bestimmt. Alle Gruppen wurden intraoperativ mit einem Infusionswärmer versorgt und durchgehend konvektiv mit einer Ober- oder Unterkörperdecke gewärmt. Daneben erfolgte die Abdeckung rund um das Operationsgebiet mit sterilen Tüchern. Studiengruppe B erhielt zusätzlich eine präoperative Isolation mit Hilfe des Mistral-Air Premium Warming Suit ${ }^{\mathrm{TM}}$. Studiengruppe $\mathrm{C}$ wurde einer konvektiven präoperativen Vorwärmung mit dem Mistral-Air Premium Warming Suit ${ }^{\mathrm{TM}}$ und angeschlossenem Warmluftgebläse unterzogen. Als klinisch relevanter Unterschied in der zentralen Körpertemperatur zum OP-Ende wurden $0,5{ }^{\circ} \mathrm{C}$ definiert. Hiernach wurde eine Studienpopulation von 23 Patienten in jeder Gruppe kalkuliert $(\alpha=0,016 ; \beta=0,2)$. 
Um potentielle Ausschlüsse von Patienten durch Protokollverletzungen zu kompensieren, wurde das Rekrutierungsziel auf 30 Patienten pro Gruppe erhöht.

Zeitabhängige Veränderungen der Körperkerntemperatur wurde mittels einer Analyse der Varianzen für Messwiederholungen (ANOVA) und dem Post-hoc Scheffé's-Test ausgewertet. Die Darstellung der Ergebnisse erfolgt als Mittelwert \pm Standardabweichung oder Median und Interquartile. Als Signifikanzgrenze wurde ein $p$ von 0,05 definiert.

Der Verlauf der im Ösophagus gemessenen intraoperativen Körperkerntemperatur in der konvektiv vorgewärmten Studiengruppe C unterschied sich signifikant von den beiden gegenübergestellten Studiengruppen.

15 Min. nach Einleitung bis zum Zeitpunkt 75 Min. nach Einleitung sowie zum Operationsende konnten signifikant höhere Körperkerntemperaturen bei konvektiver Luftwärmung vor Narkoseeinleitung -verglichen mit beiden Isolationsgruppen- nachgewiesen werden. Auch während der ersten 30 Min. im Aufwachraum zeigten sich signifikant höhere orale mittlere Körperkerntemperaturen in Studiengruppe $C$ gegenüber der Kontrollgrupp A sowie Studiengruppe B. Nach 40 Min. postoperativem Aufenthalt im Aufwachraum zeigten sich weiterhin signifikante Unterschiede in der mittleren Körperkerntemperatur zwischen Studiengruppe $\mathrm{C}$ und Vergleichsgruppe A.

Die Hypothermieinzidenz zum Operationsende zeigte sich in Studiengruppe $C(0 / 18) \mathrm{im}$ Vergleich zur Vergleichsgruppe A (8/30) signifikant niedriger.

Es konnte sich zu keinem Zeitpunkt ein signifikanter Unterschied in der Inzidenz von Vergleichsgruppe A gegenüber der passiv isolierten Studiengruppe nachgewiesen werden. Die präoperative Isolation des Patienten mit einem reflektierenden Material ist somit der passiven Isolation mit einer standardmäßigen Baumwollsteppdecke nicht überlegen. Die reine intraoperative Anwendung eines konvektiven Wärmesystems zur Vermeidung einer Hypothermie ist nicht suffizient und dem aktuellen Forschungsstand nicht mehr angemessen. Nur die kombinierte Anwendung einer konvektiven Vorwärmung aus einem Luftwärmer sowie einem reflektierenden Wärmeanzug zeigt sich als eine signifikante Methode, intraoperativ Temperaturverläufe $<36^{\circ} \mathrm{C} z u$ vermeiden. Somit ist der Mistral-Air Premium Warming Suit ${ }^{\mathrm{TM}}$ in der Anwendung als konvektives Vorwärmsystem ein effektives Verfahren zur Hypothermieprophylaxe im klinischen Gebrauch. 


\section{Tabellen- und Abbildungsverzeichniss}

\subsection{Tabellen}

Tabelle 1: Effizienzbeurteilung zweier verschiedener Isolationsmaterialien und eines konvektiven Wärmesystems

Tabelle 2: Zusammenstellung anthropometrischer Daten und perioperativer Variablen

Tabelle 3: subjektives Wärmeempfinden ermittelt zu drei definierten Zeitpunkten mithilfe der VAS.

Tabelle 4: Punktwerte der Aldrete-Skala zu den Zeitpunkten t0-t60 in den Studiengruppen

$A, B$ und $C$.

\subsection{Abbildungen}

Abbildung 1: Regelkreis der Thermoregulation (Modell modifiziert nach Simon (1997),

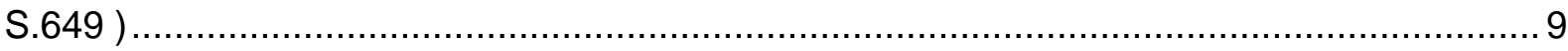

Abbildung 2: Die Thermoregulationsschwellen modifiziert nach Sladen (1991).................. 10

Abbildung 3: Verteilung der Wärmeabgabemechanismen beim stehenden bekleideten Menschen in Ruhe

Abbildung 4: Schwellenwerte der Thermoregulation Normal / Anästhesie (Modell

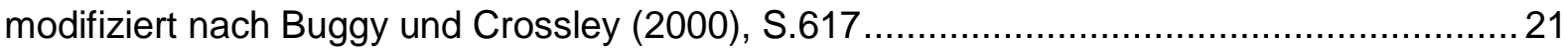

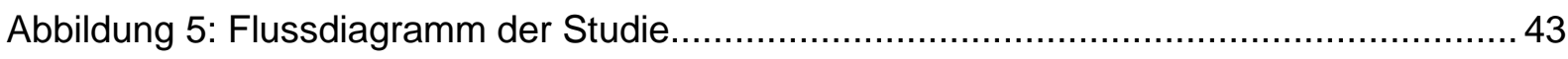

Abbildung 6: Körperkerntemperatur (oral) der verschiedenen Studiengruppe auf Station .... 46

Abbildung 7: Körperkerntemperatur (oral) der verschiedenen Studiengruppe vor Beginn

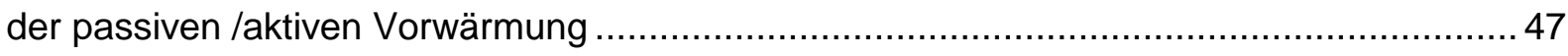

Abbildung 8: Körperkerntemperatur (oral) nach passiver/ aktiver Vorwärmung ................... 48

Abbildung 9: Präoperativer Temperaturverlauf aller drei Studiengruppen .......................... 49

Abbildung 11: Mittlere Körperkerntemperturen (ösophageal) zum Operationsende .............52

Abbildung 12: Hypothermierate im Narkoseverlauf in den verschiedenen Studiengruppen.. 53

Abbildung 13: Verlauf der Körperkerntemperaturen in den Studiengruppen im

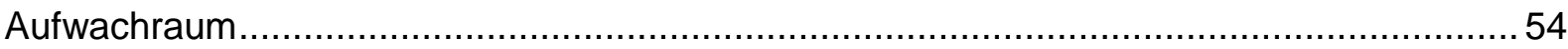




\section{Literatur}

Abelha FJ, Castro MA, Neves AM, Landeiro NM, Santos CC (2005): Hypothermia in a surgical intensive care unit. BMC Anesthesiol $\underline{5}, 7$

Acikel C, Kale B, Celikoz B (2002): Major thermal burn due to intraoperative heating blanket malfunction. Burns 28(3), 283-284

Aldrete JA, Kroulik D (1970): A postanesthetic recovery score. Anesth Analg 49(6), 924-934

Andrzejowski J, Hoyle J, Eapen G, Turnbull D (2008): Effect of prewarming on post-induction core temperature and the incidence of inadvertent perioperative hypothermia in patients undergoing general anaesthesia. Br J Anaesth 101(5), 627-631

Arkilic CF, Akca O, Taguchi A, Sessler DI, Kurz A (2000): Temperature monitoring and management during neuraxial anesthesia: an observational study. Anesth Analg 91(3), 662-666

Arnett EL, Watts DT (1960): Catecholamine excretion in men exposed to cold. J Appl Physiol 15(3),499-500

Bay J, Nunn JF, Prys-Roberts C (1968): Factors influencing arterial PO2 during recovery from anaesthesia. Br J Anaesth 40, 398-407

Beilin B, Shavit Y, Razumovsky J, Wolloch Y, Zeidel A, Bessler H (1998): Effects of mild perioperative hypothermia on cellular immune responses. Anesthesiology $\underline{89(5)}, 1133-1140$

Bigelow WG, Lindsay WK, Harrison RC, Gordon RA, Greenwood WF (1950): Oxygen transport and utilisation in dogs at low body temperatures. Am J Physiol 160, 125-137

Bock M, Bach A, Böhrer H, Martin E, Motsch J (1998): Effects of preinduction and intraoperative warming during major laparotomy. Br J Anaesth $\underline{80(2)}$, 159-63

Boulant JA: Hypothalamic control of thermoregulation:Neurophysiological basis. In: Behavioral studies of the hypothalamus; Band 3. Hrsg.v. Morgan PJ, Panksepp J. Marcel Dekker, New York $1980,1-82$

Boulant JA: Hypothalamic neurons regulating body temperature. In: APS handbook of physiology: enviromental physiology. Hrsg.v. Fregly MJ, Blatteis CM. Oxford Press, New York 1996, 105-126

Bourke DL, Wurm H, Rosenberg M, Russell J (1984): Intraoperative heat conservation using a reflective blanket. Anesthesiology $\underline{60(2)} .151-154$

Bräuer A, Weyland W, Fritz U, Schuhmann MU, Schmidt JH, Braun U (1997): Bestimmung der Körperkerntemperatur.Ein Vergleich von Ösophagus-, Blasen- und Rektaltemperatur während der postoperativen Wiedererwärmung Anaesthesist $\underline{46}, 683-688$

Bräuer A, Martin JD, Schuhmann MU, Braun U, Weyland W (2000a): Genauigkeit der Blasentemperaturmessung bei intraabdominellen Eingriffen. Anaesthesiol Intensivmed Notfallmed Schmerzther $\underline{35}$, 435-439

Bräuer A, Perl T, Wittkopp E, Braun U, Weyland W (2000b): Stellenwert eines reflektierenden Isolationsmaterials (Thermadrape) zur Verhinderung intraoperativer Hypothermie. Anaesthesiol Intensivmed Notfallmed Schmerzther $\underline{35}, 756-762$ 
Bräuer A, English MJ, Steinmetz N, Lorenz N, Perl T, Braun U, Weyland W (2002): Comparison of forced-air warming systems with upper body blankets using a copper manikin of the human body. Acta Anaesthesiol Scand 46(8), 965-972

Bräuer A, Pacholik L, Perl T, Mielck F, Weyland W, Braun U (2004): Wärmetransfer bei konduktiver Wärmung durch Wassermatten. Anasthesiol Intensivmed Notfallmed Schmerzther 39(8), 471-476

Bräuer A, Bovenschulte H, Perl T, Zink W, English MJ, Quintel M (2009): What determines the efficacy of forced-air warming systems? A manikin evaluation with upper body blankets.

Anesth Analg 108(1), 192-198

Bräuer A, Waeschle RM, Heise D, Perl T, Hinz J, Quintel M, Bauer M (2010): Präoperative Vorwärmung in der klinischen Routine. Der Anaesthesist 59(9), 842-850

Brück K: Wärmehaushalt und Temperaturregelung. In: Physiologie des Menschen. Hrsg. v. Schmidt RF, Thews G. 24. korr. Aufl; Springer-Verlag, Berlin u.a 1990, 660-682

Burton AC (1935): The average temperatures of the tissues of the body. JN $\underline{9}, 261-280$

Caterina MJ, Schumacher MA, Tominaha M, Rosen TA, Levine JD, Julius D (1997): The capsaicin receptor: a heat-activated ion channel in the pain pathway. Nature $\underline{389(6653)}$, 816-824

Cheng C, Matsukawa T, Sessler DI, Makoto O, Kurz A, Merrifield B, Lin H, Olofsson P (1995): Increasing mean skin temperature linearly reduces the core- temperature thresholds for vasoconstriction and shivering in humans. Anesthesiology $\underline{82}, 1160-1168$

Ciofolo MJ, Clergue F, Devilliers C,Ben Ammar M, Viars P (1989): Changes in ventilation, oxygen uptake, and carbon dioxide output during recovery from isoflurane anesthesia. Anesthesiology $\underline{70(5), 737-741}$

Cooper TE, Trezek GJ (1971): Correlation of thermal properties of some human tissue with water content. Aerospace Med $\underline{42}$, 24- 27

Cork RC, Vaughan RW, Humphrey LS (1983): Precision and accuracy of intraoperative temperature monitoring. Anesth Analg $\underline{62}, 211-214$

Crino MH, Nagel EL (1968): Thermal burns by warming blankets in the operating room. Anesthesiology $\underline{29}, 149-152$

Dae MW, Gao DW, Sessler DI, Chair K, Stillson CA (2002): Effect of endovascular cooling on myocardial temperature, infarct size, and cardiac output in human-sized pigs. Am J Physiol Heart Circ Physiol 282, 1584-1591

Delaunay L, Bonnet F, Liu N, Beydon L, Catoire P, Sessler DI (1993): Clonidine comparably decreases the thermoregulatory thresholds for vasoconstriction and shivering in humans. Anesthesiology $\underline{79}$, 470- 474

De Witte JL, Sessler DI (2002): Perioperative Shivering. Anesthesiology $\underline{96}, 467-484$

De Witte JL, Demeyer C, Vandemaele E (2010): Resistive-heating or forced-air warming for the prevention of redistribution hypothermia. Anesth Analg $\underline{110}, 829-833$

English MJ (2001): Physical principles of heat transfer. Curr Anaesth Crit Care 12, 66-71

English MJ, Hemmerling TM (2008): Heat transfer coefficient: Medivance Arctic Sun Temperature Management System vs. water immersion. Eur J Anaesthesiol 25(7), 531-537 
English MJ, Farmer C, Scott WA (1990): Heat loss in exposed volunteers. J Trauma Acute Care Surg 30(4). $422-425$

Fanelli A, Danelli G, Ghisi D, Ortu A, Moschini E, Fanelli G (2009): The efficacy of a resistive heating under-patient blanket versus a forced-air warming system: A randomized controlled trial. Anesth Analg 108(1), 199-201

Faraday N, Rosenfeld BA (1998): In vitro hypothermia enhances platelet GPIlb- Illa activation and P-selectin expression. Anesthesiology $\underline{88}$, 1579-1585

Frank SM, Beattie C, Christopherson R, Norris EJ, Perler BA, Williams GM, Gottlieb SO (1993): Unintentional hypothermia is associated with postoperative myocardial ischemia. Anaesthesiology $\underline{78}, 468-476$

Frank SM, Shir Y, Raja SN, Fleisher LA, Beattie C (1994): Core hypothermia and skin-surface temperature gradients. Epidural versus general anesthesia and the effects of age. Anesthesiology $\underline{80(3)}, 502-508$

Frank SM, Fleisher LA, Breslow MJ, Higgins MS, Olson KF, Kelly S, Beattie C (1997): Perioperative maintenance of normothermia reduces the incidence of morbid cardiac events.

A randomized clinical trial. JAMA 277(14), 1127-1134

Fritz U, Rohrberg M, Lange C, Weyland W, Bräuer A (1996): Infrarot-Temperaturmessung im Gehörgang mit dem DIATEK 9000 Instatemp und dem DIATEK 9000 Thermoguide Einflußgrößen und Vergleich mit anderen Methoden der Temperaturmessung des Körperkerns. Anaesthesist 45(11), 1059-1066

Fritz H, Holzmayr M, Walter B, Moeritz KU, Lupp A, Bauer R (2005): The effect of mild hypothermia on plasma fentanyl concentration and biotransformation in juvenile pigs.

Anesth Analg 100(4), 996-1002

Gali B, Findlay JY, Plevak DJ (2003): Skin injury with the use of a water warming device. Anesthesiology $\underline{98,1509-1510}$

Gekle M, Singer D, Jessen C: Temperaturregulation und Wärmehaushalt. In: Physiologie, 5.Auflage. Hrsg.v. Klinke R, Pape HC, Silbernagl S. Thieme, Stuttgart 2005, 493-508

Grundmann U, Berg K, Stamminger U, Juckenhöfel S, Wilhelm W (1997): Vergleichende Untersuchung von Pethidin und Clonidin zur Prophylaxe des postoperativen Kältezitterns. Anasthesiol Intensivmed Notfallmed Schmerzthe 32(1), 36-42

Gunga HC: Wärmehaushalt und Temperaturregulation; in: Physiologie, 5.Auflage; hrsg. v. Speckmann EJ, Hescheler J, Köhling R; Elsevier, München 2008, 615-641

Harms V: Physik für Mediziner und Pharmazeuten. 7. Auflage; Harms Verlag, Lindhöft 2000

Heier T, Caldwell JE, Sessler DI, Miller RD (1991): Mild intraoperative hypothermia increases duration of action and spontaneous recovery of vecuronium blockade during nitrous oxideisoflurane anesthesia in humans. Anesthesiology $\underline{74(5)}, 815-819$

Hirose M, Hara Y, Matsukati M (1995): Premedication with famotidine augments core hypothermia during general anesthesia. Anesthesiology $\underline{83}, 1179-1183$

Hooper VD, Andrews JO (2006): Accuracy of noninvasive core temperature measurement in acutely ill adults: the state of the science. Biol Res Nurs $\underline{8(1)}, 24-34$

Horn EP, Torossian A (2010): Perioperative Hypothermie - Prophylaxe, Therapie und Physiologie. Anästhesiol Intensivmed Notfallmed Schmerzther 54(3), 160-167 
Horn EP, Sessler DI, StandI T, Schroeder F, Bartz HJ, Beyer JC, Schulte am Esch J (1998): Non-thermoregulatory shivering in patients recovering from isoflurane or desflurane anesthesia. Anesthesiology 89(4), 878-886

Horn EP, Schroeder F, Gottschalk A, Sessler DI, Hiltmeyer N, StandI T, Am Schulte Esch J (2002): Active warming during cesarean delivery. Anesth Analg 94(2), 409-14

Horn EP, Bein B, Böhm R, Steinfath M, Sahili N, Höcker J (2012): The effect of short time periods of pre-operative warming in the prevention of peri-operative hypothermia. Anaesthesia $\underline{67(6)}, 612-617$

Huang JKC, Shah EF, Vinodukumar N, Hegarty MA, Greatorex RA (2003): The Bair Hugger patient warming system in prolonged vascular surgery: an infection risk? Crit Care $\underline{7(3)}$, 13-16

Hung OR, Dyck JB, Varvel J, Shafer SL, Stanski DR (1996): Comparative absorption kinetics of intramuscular midazolam and diazepam. Can J Anesth $\underline{43}, 450-455$

Hynson JM, Sessler DI, Moayeri A, McGuire J (1993): Absence of nonshivering thermogenesis in anesthesized adult humans. Anesthesiology $\underline{79}, 695-703$

Imrie MM, Hall GM (1990): Body temperature and anaesthesia. Br J Anaesth $\underline{64}$, 346-354

Insler SR, Sessler DI (2006): Perioperative thermoregulation and temperature monitoring. Anesthesiol Clin 24(4), 823-837

Jones HD, McLaren CAB (1965): Postoperative shivering and hypoxemia after halothane, nitrous oxide and oxygen anaesthesia. Br J Anaesth $\underline{37}, 35-41$

Joris J, Banache M, Bonnet F, Sessler DI, Lamy M (1993): Clonidine and ketanserin both are effective treatment for postanesthetic shivering. Anesthesiology 79(3), 532-9

Just B, Trévien V, Delva E, Lienhart A (1993): Prevention of intraoperative hypothermia by preoperative skin surface warming. Anesthesiology $\underline{79}, 214-218$

Kasai T, Hirose M, Matsukawa T, Takamata A, Yaegashi K, Tanaka Y (2003a): Preoperative blood pressure and catecholamines related to hypothermia during general anesthesia.

Acta Anesthesiol Scand $\underline{47(2)}$, 208-212

Kasai T, Nakajima Y, Matsukawa T, Ueno H, Sunaguchi M, Mizobe T (2003b): Effect of preoperative amino acid infusion on thermoregulatory response during spinal anaesthesia.

$\mathrm{Br} \mathrm{J}$ Anaesth $\underline{90}, 58-61$

Kaufman RD (1987): Relationship between esophageal temperature gradient and heart and lung sounds heard by esophageal stethoscope. Anesth Analg $\underline{66}, 1046-1048$

Kelley SD, Prager MC, Sessler DI, Roberts JP, Ascher NL (1990): Forced-air warming minimizes hypothermia during orthotopic liver transplantation. Anesthesiology $\underline{73}$, A433

Kenney WL, Munce TA (2003): Aging and human temperature regulation. J Appl Physiol $\underline{95}$, 2598-2603

Kitamura A, Hoshino T, Kon T, (2000): Patients with diabetic neuropathy are at risk of a greater intraoperative reduction in core temperature. Anesthesiology $\underline{92(5)}, 1311-8$

Kudoh A, Takase H, Takazawa T (2003): Chronic treatment with antidepressants decreases intraoperative core hypothermia. Anesth Analg $\underline{97}$, 275-279 
Kulkarni P, Matson A, Bright J, Pearson J, Carli F (1993): Clinical evaluation of the oesophageal heat exchanger in the prevention of perioperative hypothermia. $\mathrm{Br} \mathrm{J}$ Anaesth $\underline{70}, 216-$ 218

Kurz A, Sessler DI, Annadata R, Dechert M, Christensen R, Bjorksten AR (1995a): Midazolam minimally impairs thermoregulatory control. Anesth Analg $\underline{81,393-398}$

Kurz A, Sessler DI, Narzt E, Lenhardt R, Lackner F (1995b): Morphometric influences on intraoperative core temperature changes. Anesth Analg $\underline{80}, 562-567$

Kurz A, Sessler DI, Lenhardt R (1996): Perioperative normothermia to reduce the incidence of surgical-wound infection and shorten hospitalization. Study of wound infection and temperature group. N Engl J Med $\underline{334(19)}, 1209-1215$

Leben J, Tryba JM, Steinau HU (1995): Hypothermieprävention bei freiem Gewebstransfer, Effektivität und klinische Konsequenz. ZAK Wien

Lee KA (1988): Circadian temperature rhythmus in relation to menstrual cycle phase. J Biol Rhythms $\underline{3}, 255-263$

Lenhardt R, Marker E, Goll V, Tschernich H, Kurz A, Sessler DI, Narzt E, Lackner F (1997):

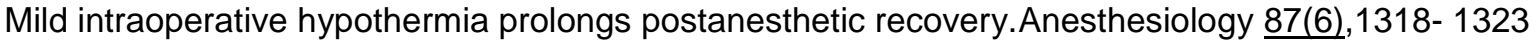

Lennon RL, Hosking MP, Conover MA, Perkings WJ (1990): Evaluation of a forced-air warming system for warming hypothermic postoperative patients. Anesth Analg $\underline{70}, 424-427$

Leslie K, Sessler DI (2003): Perioperative hypothermia in the high-risk surgical patient. Best Pract Res Clin Anaesthesiol 17(4), 485-498

Leslie K, Sessler DI, Bjorksten AR, Moayeri A (1995): Mild hypothermia alters propofol pharmacokinetics and increases the duration of action of atracurium.

Anesth Analg 80(5), 1007-1014

Liu M, Hu X, Liu J (2001): The effect of hypothermia on Isoflurane MAC in children. Anesthesiology $94,429-432$

Lopez M, Sessler DI, Walter K, Emerick T, Ozaki M (1994): Rate and gender dependance of the sweating, vasoconstriction and shivering thresholds in humans. Anesthesiology $\underline{80}, 780-788$

Matsukawa T, Kurz A, Sessler DI, Bjorksten AR, Merrifield B, Cheng C (1995a): Propofol lineary reduces the vasoconstriction and shivering thresholds. Anesthesiology 82, 1169-1180

Matsukawa T, Sessler DI, Sessler AM, Schroeder M, Ozaki M, Kurz A, Cheng C (1995b): Heat flow and distribution during induction of general anesthesia. Anesthesiology $\underline{\text { 82(3) }}$, 662-673

Matsukawa T, Hanagata K, Ozaki M, Iwashita H, Koshimizu M,Kumazawa T (1997): I.m. midazolam as premedication produces a concentration-dependent decrease in core temperature in male volunteers. Br J Anaesth $\underline{78}, 396-399$

Matsukawa T, Ozaki M, Nishiyama T, Imamura M, Iwamoto R, lijima T, Kumazawa T (2001): Atropine Prevents Midazolam induced Core Hypothermia in elderly patients. $\mathrm{J}$ clin anesth $\underline{13}, 504-$ 508

Matsuzaki Y, Matsukawa T, Ohki K, Yamamoto Y, Nakamura M, Oshibuchi T (2003): Warming by resistive heating maintains perioperative normothermia as well as forced air heating. $\mathrm{Br} \mathrm{J}$ Anaesth 90(5), 689-691

McKemy D, Neuhausser W, Julius D (2002): Identification of a cold receptor reveals a general role for TRP channels in thermosensation. Nature $\underline{416}, 52-58$ 
Mekjavic IB, Rempel ME (1990): Determination of esophageal probe insertion length based on standing and sitting hight. J Appl Physiol $\underline{69}$, 376-379

Melling AC, Ali B, Scott EM, Leaper DJ (2001): Effects of preoperative warming on the incidence of wound infection after clean surgery: a randomised controlled trial. Lancet $\underline{358(9285)}, 876-880$

Mitchell AM, Kennedy RR (2001): Preoperative core temperatures in elective surgical patients show an unexpected skewed distribution. Can J Anaesth $\underline{48,850-853}$

Mora R, English MJM, Athienitis AK (2001): Assessment of thermal comfort during surgical operations. ASHRAE Transactions $\underline{108}, 52-62$

Morley-Forster PK (1986): Unintentional hypothermia in the operating room. Can Anaesth Soc $J$ $\underline{33(4)}, 515-528$

Morris RH (1971a): Influence of ambient temperature on patient temperature during intraabdominal surgery. Ann Surg 173(2), 230-233

Morris RH (1971b): Operating room temperature and the anesthetized, paralyzed patient. Arch Surgery $102(2), 95-97$

Morris RH, Wilkey BR (1970): The effects of ambient temperature on patient temperature during surgery not involving body cavities. Anaesthesiology $\underline{32}, 102-107$

National Collaborating Centre for Nursing and Supportive Care: The management of inadvertent perioperative hypothermia in adults. In: Clinical practice guideline. Hrsg.v. National Institute for Health and Clinical Excellence (NICE), April 2008, 29

Negishi C, Hasegawa K, Mukai S, Nakagawa F, Ozaki M, Sessler DI (2003): Resistive-heating and forced-air warming are comparably effective. Anesth Analg 96(6), 1683-1687

Negovsky VA (1988): Postresuscitation disease. Crit Care Med 16(10), 942-946

Ng SF, Oo CS, Loh KH, Lim PY, Chan YH, Ong BC (2003): A comparative study of three warming interventions to determine the most effective in maintaining perioperative normothermia. Anesth Analg 96(1), 171-176

Peier AM, Moqrich A, Hergarden AC, Reeve AJ, Andersson DA, Story GM, Earley TJ, Dragoni I, McIntyre P, Bevan S, Patapoutian A (2002): A TRP channel that senses cold stimuli and menthol. Cell $\underline{108}, 705-715$

Perez-Protto S, Sessler DI, Reynolds LF, Bakri M, Mascha E, Cywinski J, Parker B, Argalious M (2010): Circulating-water garment or the combination of a circulating-water mattress and forcedair cover to maintain core temperature during major upper-abdominal surgery. Br J Anaesth 105(4), 466-470

Perl T, Rhenius A, Eich CB, Quintel M, Heise D, Bräuer A (2012): Conductive warming and insulation reduces perioperative hypothermia. Cent Eur J Med 7(3), 284-289

Pickering G (1958): Regulation of body temperature in health and disease. Lancet 271(7011), 5964

Poulos DA (1981): Central processing of cutaneous temperature information. Fed Proc $\underline{40}$, 28252829

Rathgeber J, Weyland W, Bettka T, Züchner K, Kettler D (1996): Reduktion intraoperativer Wärmeverluste und Behandlung hypothermer Patienten durch atemgasklimatisierende 
Maßnahmen Wärme- und Feuchtigkeitsaustauscher vs. aktive Befeuchter im beatmeten Lungenmodell. Anaesthesist $\underline{45}, 807-813$

Rohrer MJ, Natale AM (1992): Effect of hypothermia on the coagulation cascade. Crit Care Med 20(10), 1402-1405

Rosomoff HL, Clasen RA, Hartstock R, Bebin J (1965): Brain reaction to experimental injury after hypothermia. Arch Neurol 13(4), 337-345

Ruetzler K, Kovaci B, Güloglu E, Kabon B, Fleischmann E, Kurz A, Mascha E, Dietz D, Remzi F, Sessler DI (2011): Forced-air and a novel patient-warming system (vitalHEAT vH2) comparably maintain normothermia during open abdominal surgery. Anesth Analg 112(3), 608-614

Satinoff E (1978): Neural organization and evolution of thermal regulation in mammals. Science $\underline{201(4350)}, 16-22$

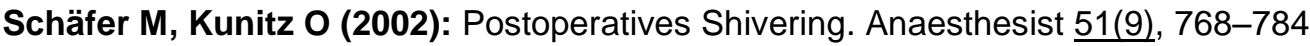

Schirmer U (2007): Hypothermie in der Herzchirurgie. Anaesthesist 56(9), 930-935

Schmidt JH, Weyland W, Fritz U, Bräuer A, Rathgeber J, Braun U (1996): Experimentelle Untersuchung zur Effektivität verschiedener Infusions- und Blutwärmeverfahre. Anaesthesist $\underline{45}, 1067-1074$

Scott EM, Buckland R (2006): A systematic review of intraoperative warming to prevent postoperative complications. AORN Journal 83(5), 1090-1104, 1107-1113

Selldén E, Bränström R, Brundin T (1996): Preoperative infusion of amino acids prevents postoperative hypothermia. Br J Anaesth $\underline{76}, 227-234$

Sessler DI: Temperature monitoring. In: Anesthesia, 3.Auflage. Hrsg.v. Miller RD, Eriksson LI, Fleisher L, Young WL. Churchill Livingstone, New York 1990, 1227-1242

Sessler DI (1991): Central thermoregulatory inhibition by general anesthesia. Anesthesiology $\underline{75}$, 557-559

Sessler DI (1993): Perianesthetic thermoregulation and heat balance in humans.FASEB $\underline{7}, 638-$ 6447

Sessler DI (1994): Consequences and treatment of perioperative hypothermia. Anesth Clin North 12, 425-456

Sessler DI (1997): Mild perioperative hypothermia. N Engl J Med 336(24), 1730-1737

Sessler DI (2000): Perioperative heat balance. Anaesthesiology 92, 578-596

Sessler DI (2001): Complications and treatment of mild hypothermia. Anaesthesiology 95(2), 531543

Sessler DI, Ponte J (1990): Shivering during epidural anesthesia. Anaesthesiology $\underline{72(5)}$, 816-821

Sessler DI, Schroeder M (1993): Heat loss in humans covered with cotton hospital blankets. Anesth Analg $\underline{77}, 73-77$

Sessler DI, Olofsson Cl, Rubinstein EH, Beebe JJ (1988): The thermoregulatory threshold in humans during halothane anesthesia. Anesthesiology $\underline{68}, 836-842$

Sessler DI, McGuire J, Sessler AM (1991): Perioperative thermal insulation. Anesthesiology $\underline{74}$, 875-879 
Sessler DI, Schroeder M, Merrifield B, Matsukawa T, Cheng C (1995): Optimal duration and temperature of prewarming. Anesthesiology $\underline{82}, 674-681$

Sharp RJ, Chesworth T, Fern ED (2002): Do warming blankets increase bacterial counts in the operating field in a laminar-flow theatre? The Journal of Bone and Joint Surgery 84(4), 486-488

Sigg DC, Houlton AJ, laizzo PA (1999): The potential for increased risk of infection due to the reuse of convective air-warming/cooling coverlets. Acta Anaesthesiol Scand 43(2), 173-176

Simmons M, Phillips P, Doctor U, Liehr P (1992): The effect of two intraoperative heatconserving methods on orthopedic patients receiving regional and general anesthesia. J Post Anesth Nurs $\underline{7(3)}, 170-175$

Simon E: Wärmehaushalt und Temperaturregelung. In: Physiologie des Menschen. Hrsg. v. Schmidt RF, Thews G, Lang F. 27. korr. Aufl; Springer-Verlag, Berlin u.a 1997, 649-671

Singer AJ, Clark RA (1999): Cutaneous wound healing. N Engl J Med 341, 738-746

Sladen RN (1991): Thermal regulation in anesthesia and surgery. ASA $\underline{19}, 164-186$

Spöhr F, Böttiger BW (2002): Fremdblut sparende Maßnahmen. Der Anaesthesist $\underline{51}, 221-233$

Steinfath M, Wappler F, Scholz J (2002): Maligne Hyperthermie. Der Anaesthesist 51ㄴ(4), 328348

Stolwijk JAJ, Hardy JD (1966): Partitional calorimetric studies of responses of man to thermal transients. J Appl Physiol 21, 967-977

The Commission for Thermal Physiology of the International Union of Physiological Sciences (2001): Glossary of terms for thermal physiology,3rd edn. Jpn J Physiol 51, 245-280

Tollofsrud SG, Gundersen Y, Andersen R (1984): Peroperative hypothermie. Acta Anaesthesiol Scand 28: 511-515

Tominaga M, Caterina MJ, Malmberg AB, Rosen TA, Gilbert H, Skinner K, Raumann BE, Basbaum Al, Julius D (1998): The cloned capsaicin receptor integrates multiple pain-producing stimuli. Neuron $\underline{21}, 531-543$

Torossian A (2008): Thermal management during anaesthesia and thermoregulation standards for the prevention of inadvertent perioperative hypothermia. Best Prac Res Clin Anaesthesiol 22(4), $659-668$

Toyota K, Sakura S, Saito Y, Ozasa H, Uchida H (2004): The effect of pre-operative administration of midazolam on the development of intra-operative hypothermia. Anaesthesia $\underline{59}$, 116-121

Truell K, Bakerman P, Teodori M, Maze A (2000): Third-degree burns due to intraoperative use of a Bair Hugger warming device. Ann Thorac Surg 69(6), 1933-1934

Urwyler A, Hartung E (1994): Die maligne Hyperthermie. Anaesthesist 43(8), 557-569

Valeri CR, Khabbaz K, Khuri SF, Marquardt C, Ragno G, Feingold H, Gray AD, Axford T (1992): Effect of skin temperature on platelet function in patients undergoing extracorporeal bypass. J Thorac Cardiovasc Surg 104(1), 108-116

Vanni S, Braz J, Modolo N, Amorim R, Rodrigues G (2003): Preoperative combined with intraoperative skin-surface warming avoids hypothermia caused by general anesthesia and surgery. J Clin Anesth 15(2). 119-125 
Vassilieff N, Rodencher N, Sessler DI, Conseiler C, Lienhart A (1994): Nifedipine and intraoperative core body temperature in humans. Anesthesiology $\underline{80}, 123-128$

Vaughan MS, Vaughan RW, Cork RC (1981): Postoperative hypothermia in adults: relationship of age, anesthesia, and shivering to rewarming. Anesth Analg $\underline{60,746-751}$

Weiskopf RB (1995): Cardiovascular effects of desflurane in experimental animals and volunteers. Anaesthesia $\underline{50}, 14-27$

Weyland W, Bräuer A: C.2.2 Konduktive Verfahren. In: 001-018- S3-Leitlinie: Vermeidung von perioperativer Hypothermie. Hrsg. v. Torossian A, Bein B, Bräuer A, Greif R, Höcker J, Horn EP, Ittner KP, Kimberger O, Klar E, Müller-Wolff T, Schmittenbecher P, Welk I, Weyland W, Wulf H; AWMF 2014, 34-36

Weyland W, Fritz U, Fabian S, Jaeger H, Crozier T, Kietzmann D, Braun U (1994): Postoperative Wärmetherapie im Aufwachraum. Der Anaesthesist 43(10), 648-657

Wilkerson JE, Raven PB, Bolduan NW , Horvath SM (1974): Adaptations in mans adrenal funktion in response to acute cold stress. J Appl Physiol $\underline{36}$, 183-189

Winkler M, Akca O, Birkenberg B, Hetz H, Scheck T, Arkiliç CF, Kabon B, Marker E, Grübl A, Czepan R, Greher M, Goll V, Gottsauner-Wolf F, Kurz A (2000): Aggressive warming reduces blood loss during hip arthroplasty. Anesth Analg 91(4), 978-984

Woon S, Talke P (1999): Amount of air infused to patient increases as fluid flow rates decrease when using the Hotline HL-90 fluid warmer. J Clin Monit 15, 149-152

Xiong J, Kurz A, Sessler DI, Plattner O, Christensen R, Dechert M, Ikeda T (1996): Isoflurane produces marked and non-linear decreases in the vasoconstriction and shivering threshold. Anesthesiology $\underline{85}, 240-245$ 


\section{Danksagung}

Ich möchte mich herzlich bei meinem Doktorvater und Betreuer Herrn PD Dr. Thorsten Perl für seine Unterstützung bei der Entstehung dieser Arbeit bedanken. Stets stand er mir mit Rat und Tat und einem offenen Ohr zu Seite.

Mein besonderer Dank gilt zusätzlich all den helfenden Händen im OP und in der Prämedikationsambulanz der Universität Göttingen, die diese Dissertation möglich gemacht haben. 